EmANUELe Lima ViLleLA

\title{
Avaliação da durabilidade dos diferentes modelos de sondas de troca de gastrostomia
}

Dissertação apresentada à Faculdade de Medicina da Universidade de São Paulo para obtenção do título de Mestre em Ciências

Programa de Gastroenterologia Clínica Orientador: Prof. Dr. Paulo Sakai

São Paulo 
Dados Internacionais de Catalogação na Publicação (CIP)

Preparada pela Biblioteca da

Faculdade de Medicina da Universidade de São Paulo

Creprodução autorizada pelo autor

Villela, Emanuele Lima

Avaliação da durabilidade dos diferentes modelos de sondas de troca de gastrostomia / Emanuele Lima Villela. -- São Paulo, 2013.

Dissertação(mestrado)--Faculdade de Medicina da Universidade de São Paulo. Programa de Gastroenterologia Clínica.

Orientador: Paulo Sakai.

Descritores: 1.Gastrostomia 2.Intubação gastrointestinal 3.Assistência de longa duração 4.Falha de equipamento 5.Nutrição enteral 


\section{Dedicatória}

Ao meu querido e falecido avô Doutor José Penha, que certamente é a minha grande referência de que a medicina é mais que uma profissão, é a arte de ajudar ao próximo.

A lembrança de seu caráter e dignidade incomparáveis será presença constante a nortear minha vida. 


\section{Agradecimentos}

Sou grata a Deus, autor de todo o bem, por me ter permitido abraçar esta nobre profissão, e aprender o meu ofício nesta distinta e reconhecida Instituição da Universidade de São Paulo (USP). Alcançar agora o objetivo maior de obter um Mestrado em Medicina é motivo de grande realização para mim.

Agradeço aos dignos professores, médicos assistentes e colegas do Serviço de Endoscopia Gastrointestinal do Hospital das Clínicas da Faculdade de Medicina da USP (FMUSP), por todo desvelo e competência profissional que sempre me demonstraram e pelos inestimáveis ensinamentos que pacienciosamente me passaram durante os anos de convivência.

Reitero minha gratidão ao Professor Doutor Eduardo Guimarães Hourneaux de Moura, chefe do Serviço, pelas excelentes oportunidades concedidas e pelo modelo de capacidade profissional.

Sou e serei sempre muito grata ao Professor Doutor Paulo Sakai, pela orientação abalizada desta tese. $O$ senhor tem me provado o quanto de dignidade um profissional sério pode viver e ensinar aos demais pelo próprio exemplo de sua trajetória de vida.

Às enfermeiras e auxiliares do Serviço, o meu efusivo agradecimento pelo auxílio no atendimento e carinho com os pacientes deste estudo.

Sou profundamente grata à minha amiga pessoal Dra Maíra Ribeiro de Almeida pelo valioso auxílio no atendimento de muitos dos pacientes deste estudo.

Agradeço pela enorme ajuda concedida pelo Professor Doutor Joel Faintuchi através de sua visão científica.

Obrigada ao Professor Doutor Flair José Carrilho e aos demais 
médicos assistentes do setor de gastroenterologia clínica da FMUSP que tiveram grande importância na minha formação e certamente serviram de exemplos e estímulo ao meu interesse na área científica.

Confirmo também minha gratidão a todos os trabalhadores do setor da Pós-Graduação da FMUSP. Vocês foram extremamente gentis sempre que precisei de algum esclarecimento e/ou favor.

Agradeço também, às empresas que comercializam as sondas do presente estudo pela colaboração e confiança em nosso projeto.

Muito obrigada à empresa Faga Medical que se prontificou a nos auxiliar nas análises fisicoquímicas com grande profissionalismo.

Agradeço imensamente aos meus pais José Pinto Villela e Tereza Cristina Lima Villela que procuraram heroicamente conciliar suas atividades ao estímulo para que eu buscasse a realização de meus sonhos. A certeza do amor e confiança de ambos, alicerçou cada passo de minha carreira. Muito obrigada a Pablo José Lima Villela que, mais que meu irmão, se demonstrou a vida inteira um grande amigo.

Serei eternamente grata a toda a minha família que, mesmo à distância, sempre serviu de base para que eu pudesse construir os meu sonhos.

Obrigada também, à minha nova família (família Quilici Belczak) que se juntou à minha no decorrer deste projeto através do meu casamento. $O$ incentivo e o carinho de vocês é um novo combustível na busca das minhas conquistas.

Finalmente, muito obrigada ao meu marido, Professor Doutor Sergio Quilici Belczak, pela constante paciência e tolerância nos momentos em que necessitei permanecer afastada para dar continuidade aos estudos desta tese e por ser servir de exemplo profissional constante em minha vida. 


\section{Sumário}

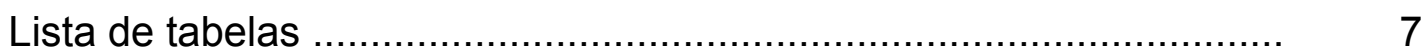

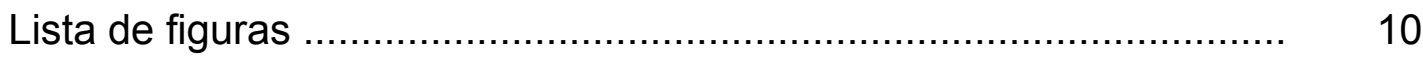

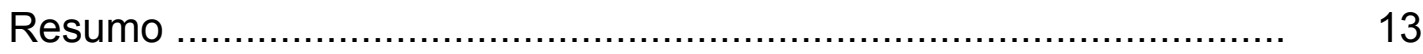

Abstract............................................................................. 15

1. INTRODUÇÃO ................................................................. 17

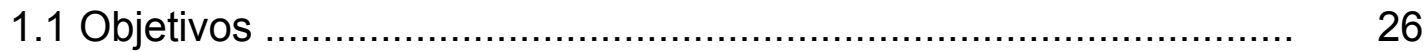

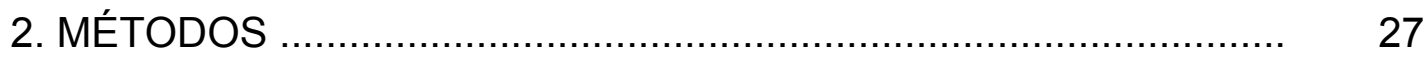

2.1 Dinâmica do estudo ........................................................... 27

2.2 Seleção da amostra ................................................................ 28

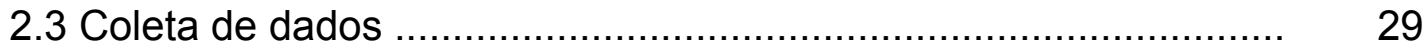

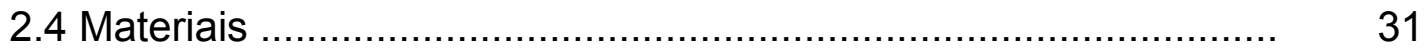

2.5 Grupos de estudo ....................................................... 37

2.6 Análises fisicoquímicas das sondas balonadas ........................ 39

2.7 Análises estatísticas ............................................................ 45

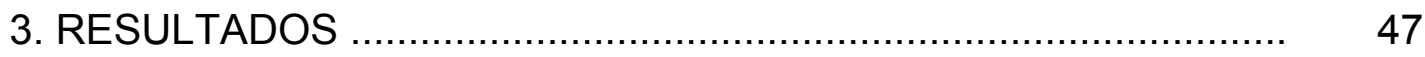

4. DISCUSSÃO ….............................................................. 80

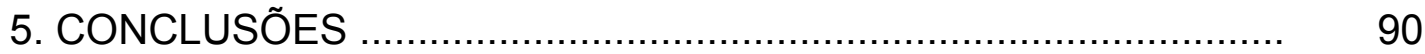

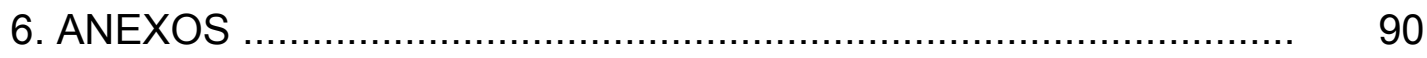

7. REFERÊNCIAS .............................................................. 107 


\section{Lista de tabelas}

Tabela 1 Caracterização dos pacientes que compuseram os cinco grupos para o estudo de durabilidade de diferentes modelos de sondas de troca de gastrostomia

Tabela 2 Distribuição das frequências relativas aos motivos término do acompanhamento dos pacientes do protocolo de estudo de acordo com as diferentes marcas de sondas de troca de gastrostomia

Tabela 3 Ocorrências de deslizamento do anteparo externo da sonda e de resoluções após fixação nos cinco grupos de estudo

Tabela 4 Valores calculados do Qui-quadrado $\left(X^{2}\right)$ e respectivos valores de $p$ na análise comparativa das marcas de sondas no que se refere à distribuição das intercorrências

Tabela 5 Distribuição das frequências absolutas e percentuais de intercorrências observadas nos pacientes em uso das sondas das diferentes marcas

Tabela 6 Apresentação de 26 pacientes que foram incluídos em dois ou mais grupos de estudo e os motivos de sua exclusão dos grupos de que participaram

Tabela 7 Estimativas dos tempos médios (em dias) da durabilidade das sondas de troca de gastrostomia considerando problemas ocorridos em balões, tubos e tampas

Tabela 8 Estimativas da função de durabilidade das sondas de troca de gastrostomia considerando problemas ocorridos em balões, tubos e tampas 
Tabela 9 Resultados da aplicação do modelo de regressão de Cox, tomando-se por referência aleatória os dados registrados para o grupo de pacientes em uso das sondas Bard $^{\circledR}$ (devido à sua menor durabilidade determinada pelo método de Kaplan Meier)

Tabela 10 Resultados da aplicação do modelo de regressão de Cox, tomando-se por referência os dados registrados para o grupo de pacientes em uso das sondas Kangaroo ${ }^{\circledR} \ldots$.

Tabela 11 Resultados da aplicação do modelo de regressão de Cox, tomando-se por referência os dados registrados para o grupo de pacientes em uso das sondas Wilson Cook $^{\circledR}$

Tabela 12 Resultados da aplicação do modelo de regressão de Cox, tomando-se por referência os dados registrados para o grupo de pacientes em uso das sondas Silmag ${ }^{\circledR}$.........

Tabela 13 Resultados da aplicação do modelo de regressão de Cox, tomando-se por referência os dados registrados para o grupo de pacientes em uso das sondas Freka ${ }^{\circledR}$.

Tabela 14 Estimativas dos tempos médios (em dias) da durabilidade das sondas de troca de gastrostomia considerando ruptura dos balões

Tabela 15 Estimativas da função de durabilidade das sondas de troca de gastrostomia considerando ruptura dos balões ...

Tabela 16 Resultados da aplicação do modelo de regressão de Cox, tomando-se por referência aleatória os dados registrados para o grupo de pacientes em uso das sondas Bard $^{\circledR}$ (devido à sua menor durabilidade determinada pelo método de Kaplan Meier)

Tabela 17 Resultados do teste de resistência dos balões em função do padrão nominal da carga volumétrica 
Tabela 18 Resultados das medidas do teste de resistência dos balões em função do diferencial extranominal da carga vo lumétrica

Tabela 19 Resultados das observações do teste de resistência dos balões em função do diferencial extranominal da carga volumétrica

Tabela 20 Resultados do teste de resistência do meio ao qual o material é exposto em soluções que simulam o pH ácido do estômago de indivíduos saudáveis $(\mathrm{pH}>1,0$ e <2,0) e de 


\section{Lista de figuras}

Figura 1 Sonda balonada para troca da marca Silmag ${ }^{\circledR}$ disponível no Serviço de Endoscopia Gastrointestinal do HCFMUSP

Figura 2 Ruptura de balão interno de sonda de troca de gastrostomia

Figura 3 Exemplos de sondas que apresentaram ruptura do balão um dia (A), cinco dias (B), 21 dias (C) e 84 dias (D) após a troca

Figura 4 Representação gráfica da distribuição do número absoluto de pacientes de acordo com a quantidade de procedimentos realizados

Figura 5 Fotos ilustrativas do balão cheio no teste de resistência em função do padrão nominal da carga volumétrica em uma amostra de cada modelo de sondas balonadas avaliadas

Figura 6 Fotos ilustrativas dos passos para o teste de resistência em função do diferencial extranominal da carga volumétrica em uma amostra de um dos modelos (Kangaroo ${ }^{\circledR}$ ) de sondas balonadas avaliadas

Figura 7 Fotos ilustrativas do processo de preparação para o teste de resistência ao meio em que o material é exposto

Figura 8 llustração gráfica das frequências percentuais relativas a intercorrências na sonda de troca de gastrostomia observadas ao longo do acompanhamento de todos os 100 procedimentos incluídos no estudo 
Figura 9 Exemplos de sondas que apresentaram intercorrências no balão - ruptura $(A)$, no tubo - deslizamento do anteparo externo com fixação do mesmo (B) e na tampa -

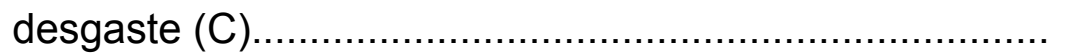

Figura 10 Ilustração gráfica da distribuição das frequências relativas de desgaste do tubo na sonda de troca de gastrostomia de acordo com a marca de sonda (grupo de estudo) em uso pelos pacientes

Figura 11 Ilustração gráfica da distribuição das frequências relativas de desgaste da tampa na sonda de troca de gastrostomia de acordo com a marca de sonda (grupo de estudo) em uso pelos pacientes

Figura 12 Ilustração gráfica da distribuição das frequências relativas de abertura espontânea da tampa na sonda de troca de gastrostomia de acordo com a marca de sonda (grupo de estudo) em uso pelos pacientes

Figura 13 Ilustração gráfica da distribuição das frequências relativas de ruptura do balão na sonda de troca de gastrostomia de acordo com a marca de sonda (grupo de estudo) em uso pelos pacientes

Figura 14 Ilustração gráfica da distribuição das frequências relativas de deslizamento do anteparo externo na sonda de troca de gastrostomia de acordo com a marca de sonda (grupo de estudo) em uso pelos pacientes

Figura 15 Ilustração gráfica da distribuição das frequências relativas de extravasamento periestomal na sonda de troca de gastrostomia de acordo com a marca de sonda (grupo de estudo) em uso pelos pacientes

Figura 16 Ilustração gráfica da distribuição das frequências relativas de obstrução do tubo na sonda de troca de gastrostomia de acordo com a marca de sonda (grupo de estudo) em uso pelos pacientes 
Figura 17 Representação gráfica da distribuição percentual dos pacientes de acordo com a quantidade de intercorrências observadas na sonda de troca de gastrostomia ......

Figura 18 Curvas das estimativas da função de durabilidade das sondas de troca de gastrostomia considerando a interrupção do uso das sondas por ruptura do balão, desgaste do tubo e/ou desgaste da tampa (Método de Kaplan Meier)

Figura 19 Curvas das estimativas da função de durabilidade das sondas de troca de gastrostomia considerando a interrupção do uso das sondas por ruptura do balão, desgaste do tubo e/ou desgaste da tampa (Modelo de regressão de Cox)

Figura 20 Curvas das estimativas da função de durabilidade das sondas de troca de gastrostomia considerando a interrupção do uso das sondas por ruptura do balão (Método de Kaplan Meier)

Figura 21 Curvas das estimativas da função de durabilidade das sondas de troca de gastrostomia considerando a interrupção do uso das sondas por ruptura do balão (Modelo de regressão de Cox)

Figura 22 Médias e desvios-padrão dos perímetros dos balões vazios $(A)$ e cheios $(B)$ e das porcentagens de expansão dos balões (C) das quatro amostras de cada modelo de sondas analisadas.

Figura 23 Médias e desvios-padrão dos perímetros dos balões iniciais $(A)$ e cheios $(B)$, das porcentagens de expansão dos balões (C) e dos volumes insuflados (D) das três amostras de cada modelo de sondas analisadas 


\section{Resumo}

Villela EL. Avaliação da durabilidade dos diferentes modelos de sondas de troca de gastrostomia [dissertação]. São Paulo: Faculdade de Medicina, Universidade de São Paulo; 2013.

Introdução: No acompanhamento diário de pacientes que realizam troca de sonda de gastrostomia endoscópica percutânea (GEP), observa-se a precocidade com que ocorrem essas trocas devido à curta durabilidade da sonda, especialmente decorrente da ruptura do balão interno da sonda. Objetivo: Este estudo prospectivo visou à avaliação da durabilidade de cinco diferentes marcas de sondas de troca de GEP. Método: Cem procedimentos consecutivos de troca de sonda de GEP (realizados em 65 pacientes) foram distribuídos, a cada grupo de 20 procedimentos, em cinco grupos determinados pelas marcas de sondas avaliadas $\left(\right.$ Kangaroo $^{\circledR}$, Wilson Cook $^{\circledR}$, Silmag ${ }^{\circledR}$, Fre$\mathrm{ka}^{\circledR}$ e Bard $^{\circledR}$ ). Conforme o protocolo proposto, após a troca, os pacientes foram seguidos ao longo de seis meses, e, nesse período, foram realizadas três avaliações para verificação de eventuais intercorrências. Para avaliação da durabilidade das sondas, foi considerado o período de permanência dos pacientes no protocolo, determinada pelo término do período de estudo ou pela necessidade de troca da sonda por ruptura do balão ou desgaste do tubo ou da tampa. As curvas de durabilidade das sondas foram determinadas pelo Método de Kaplan Meier e pelo Modelo de Regressão de Cox. Re- 
sultados: Houve variações importantes na durabilidade das sondas quando considerados os três motivos de troca da sonda associados. Essa diferença não foi observada quando se considerou apenas a ruptura do balão, cujas ocorrências se mostraram associadas com pacientes em uso de GEP por distúrbios neurológicos sem diagnóstico. A durabilidade das sondas foi tanto menor, quanto maior o número de trocas anteriores. Conclusões: A marca da sonda de troca de GEP não influenciou a sua durabilidade quando determinada pela ruptura do balão, mas, quando determinada também por desgaste em tubo e tampa, as sondas Wilson Cook $^{\circledR}$ apresentaram durabilidade significativamente maior do que as sondas $\mathrm{Silmag}^{\circledR}$ e $\mathrm{Bard}^{\circledR}$. O número de trocas anteriores se mostrou fator determinante de menor durabilidade das sondas. 


\section{Abstract}

Villela EL. Durability of five different percutaneous endoscopic gastrostomy (PEG) tubes [thesis]. São Paulo: Medicine School, University of São Paulo; 2013.

Introduction: During the follow-up of patients after replacement of percutaneous endoscopic gastrostomy (PEG) tubes, the early need of new replacements seems to be consequence of the short durability of the tubes, especially due to the rupture of their internal balloon. Objectives: In this prospective study, the durability of five different PEG tubes was estimated. Methods: One hundred consecutive procedures (in 65 patients) for replacing PEG tubes were divided into five groups determined by the tubes model: Kangaroo $^{\circledR}$, Wilson Cook $^{\circledR}$, Silmag ${ }^{\circledR}$, Freka $^{\circledR}$ and Bard $^{\circledR}$. According to the protocol developed for the study, patients were followed up along six months, and three evaluations for verifying eventual outcomes were carried out during this period. Estimation of the tubes durability considered the time patients remained in the protocol, which was determined by the termination of the follow up period or by the need for replacing the tubes due to the balloon rupture or to the loss of use of tube or cover. Curves of tubes durability were established by applying the Kaplan-Meier Method and the Cox Regression Model. Results: Important variations of the tubes durability were observed when the three causes for replacement were considered all together. Differences were not observed when considered only the balloon rupture, which was associ- 
ated with patients using PEG in virtue of not specified neurologic disorders. Shorter tubes durability was associated with more previous replacements. Spontaneous opening of the cover and slipping of the external protection were significantly less frequent in the Freka ${ }^{\circledR}$ tubes, although such outcomes did not determined the tubes durability. Conclusion: The model of PEG replacement tubes did not influence their durability regarding the balloon rupture alone. Considering such occurrence associated with problems in tubes or covers, the longest durability was observed in Wilson Cook ${ }^{\circledR}$, followed by Freka, ${ }^{\circledR}$ Kangaroo $^{\circledR}$, Silmag ${ }^{\circledR}$ and Bard $^{\circledR}$ tubes. The number of previous replacements showed to be determining factor for the tubes durability. 


\section{Introdução}

Historicamente, o conceito de gastrostomia é uma comunicação direta do estômago com o exterior criada em intervenção cirúrgica para descompressão gástrica foi proposto por Egeberg em 1837 e, em 1839, Sedillott realizou uma série de gastrostomias em cães. O mesmo Sedillott, em 1846, realizou essa intervenção em três seres humanos que evoluíram para óbito. Trinta anos mais tarde, Verneuil realiza, em 1876, a primeira gastrostomia bem sucedida em humano (apud Bleck et al., 1998).

A primeira referência ao uso da gastrostomia para alimentação enteral foi descrita por Isaacson, em 1948, para o tratamento de paciente com disfagia decorrente da compressão do esôfago por aneurisma cardíaco duplo (Isaacson, 1948). Desde então, diferentes técnicas foram desenvolvidas e aprimoradas para gastrostomia cirúrgica, que passou a ser o método-padrão para acesso enteral em casos selecionados, ao lado da colocação e manutenção de sondas nasoenterais nos pacientes com riscos cirúrgicos.

Em 1980, Gauderer et al. descreveram a gastrostomia endoscópica percutânea (GEP) como método minimamente invasivo, seguro e de fácil execução para os casos de necessidade de alimentação enteral de médio e longo prazo em pacientes com funções intestinais preservadas. Paralelamente à publicação desse estudo, com curto intervalo de poucos meses, Hashiba (1980) relatou a sua técnica de abertura de gastrostomia sob controle e manipulação endoscópica, atestando, igualmente, a praticidade, rapidez e se- 
gurança da GEP. Estudos imediatamente posteriores confirmaram as baixas taxas de morbidade e mortalidade relacionadas com a GEP (Ponsky e Gauderer, 1981; Preshaw, 1981).

As indicações da GEP já estão bem estabelecidas por diferentes consensos e diretrizes organizados e publicados por sociedades pertinentes (August et al., 2002; Eisen et al., 2002a,b; Stroud et al., 2003; Löser et al., 2005). Desse modo, a GEP é considerada uma excelente opção como via de alimentação enteral de longo prazo (período superior a três ou quatro semanas), especialmente para pacientes com alterações de deglutição decorrentes de desordens neurológicas transitórias ou permanentes, de lesões malignas obstrutivas do trato aerodigestivo superior, e de traumatismos faciais, mandibulares ou cranioencefálicos, e que apresentem desnutrição ou risco nutricional, mas com trato gastrointestinal íntegro e funcional (Safadi et al., 1998; Löser et al., 2005; Perona et al., 2010).

Ainda que menos frequentemente, a GEP pode ser indicada também para pacientes que, a despeito de não apresentar disfagia, tenham doenças crônicas (síndrome do intestino curto, doença de Crohn, síndromes de má absorção) ou condições catabólicas agudas ou crônicas (grandes queimaduras, síndrome da imunodeficiência adquirida, fibrose cística, doença cardíaca congênita) que requeiram suporte nutricional complementar (Safadi et al., 1998; Löser et al., 2005).

Diferentes condições e situações não associadas diretamente com suporte nutricional determinaram a expansão do espectro de indicações da GEP, as quais incluem, mais comumente, a descompressão paliativa do tra- 
to gastrointestinal em pacientes com distúrbios motores (atonia gástrica), obstrução benigna (bridas múltiplas ou obstrução gástrica distal em pacientes não operáveis) ou obstrução maligna (carcinomatose peritoneal, tumores obstrutivos ou congelamento pélvico) (Gauderer, 2002).

Menos comuns são as indicações da GEP para administração de medicamentos impalatáveis, recirculação de bile, fixação gástrica em volvo ou hérnias de diafragma, promoção de acesso para dilatação retrógrada ou anterógrada de esôfago ou hipofaringe, colocação de próteses esofágicas e promoção de acesso gástrico para aplicação de terapêuticas intraluminais (Rafferty e Tham, 2010).

Entre as contraindicações absolutas para a realização da GEP se incluem: condições que contraindiquem a realização de qualquer exame endoscópico; presença de obstrução intestinal quando o procedimento visa ao fornecimento de suporte nutricional enteral; presença de obstruções completas do trato aerodigestivo superior que impossibilitem acesso ao estômago; impossibilidade de a parede anterior gástrica ser posicionada de forma correta e segura em relação à parede abdominal; coagulopatias não corrigidas; e expectativa de sobrevida curta (Eisen et al., 2002a,b). A mais importante contraindicação absoluta da GEP é a recusa do paciente à sua realização (Safadi et al., 1998).

Quando indicada e realizada de maneira adequada, a GEP se configura em procedimento eficaz e seguro. Ainda assim, pode ocorrer uma série de complicações de menor ou maior gravidade que podem decorrer do ato en- 
doscópico ou do método, e, nessa última hipótese, ocorrem a complicações da GEP propriamente dita.

Essas complicações específicas da GEP podem ser precoces ou tardias, conforme ocorram, respectivamente, nos primeiros 15 dias ou depois de 15 dias da realização do procedimento (McClave e Chang, 2003). Alguns autores consideram o período de 30 dias para essa classificação. As complicações precoces imediatas são aquelas que ocorrem no momento de realização da GEP, e estão associadas com o exame endoscópico e com o procedimento. As complicações precoces mediatas ocorrem depois da realização do procedimento até o $15^{\circ}$ dia (Lin et al., 2001). As complicações tardias são aquelas que ocorrem depois de o pertuito da GEP estar estabelecido, quando o processo cicatricial determina a fixação dos folhetos visceral e parietal do peritônio no local do estoma (McClave e Chang, 2003).

O perfil dos pacientes submetidos à GEP nem sempre permite acompanhamento de longo prazo, pois a maioria deles apresenta desordens neurológicas importantes que dificultam a mobilização e o transporte para retornos de seguimento (Rodríguez Ortega et al., 2011), tem idade avançada associada com comorbidades severas (Wanden-Berghe et al., 2010), possui expectativa de vida geralmente limitada, além de estar institucionalizada em hospitais de retaguarda geriátricos ou oncológicos. Por essa razão, a perda de seguimento não é incomum e, associada com a heterogeneidade dos estudos quanto a definições, tipo de população estudada e tempo de acompanhamento utilizado, resulta em provável subnotificação das complicações decorrentes da GEP (Shastri et al., 2008; Tokunaga et al., 2008). 
Por fim, a mortalidade associada à GEP é inferior a $2 \%$ (Hicks et al., 1990; Mathus-Vliegen e Koning, 1999; Perona et al., 2010).

Há um grande série de estudos sobre a GEP, incluindo técnicas de realização do procedimento, análises epidemiológicas e seguimentos de curto e longo prazo para avaliação de morbidades e mortalidade. Por outro lado, os primeiros autores que se preocuparam em avaliar as especificações técnicas das sondas disponíveis em mercado para a realização de GEP foram Guedon et al. (1993; 1999). Esses autores consideraram que a maioria dos tubos usados na realização da GEP disponíveis no mercado era feita de silicone ou de poliuretano, e compararam três marcas diferentes de sonda no que tange ao material de que eram feitas. Observaram que as sondas de poliuretano se mostraram mais duráveis e resistentes para o uso de longa duração ou para uso permanente de GEP.

Em estudo realizado por Sartori et al. (2003) foi encontrada durabilidade média de sondas para GEP de 287 dias para aquelas feitas de silicone, e de 573,9 dias para as sondas de poliuretano. Blacka et al. (2004) também compararam sondas para GEP feitas com ambos os materiais em estudo prospectivo, e concluíram que os tubos de silicone se deterioraram mais rapidamente e apresentaram colonização fúngica com maior frequência que os de poliuretano.

Como característica comum, as sondas de gastrostomia apresentam um anteparo interno cujo objetivo básico é prevenir a saída ou remoção acidental da sonda. Alem disso, por meio da sua aposição contra a parede anterior do estômago, o anteparo funciona como um tampão que diminui o risco de 
extravasamento da dieta e de secreções gástricas pelo estoma. A estrutura dos anteparos internos varia em cada modelo. Eles podem ser divididos basicamente em dois tipos: anteparo flexível e balão.

O desenho básico mais comum de anteparo flexível tem a forma de uma abóbada ou tulipa, embora possa se apresentar na forma de um disco plano, uma placa triangular, um cone ou uma gaiola.

Os modelos iniciais apresentavam retentores internos pequenos e rígidos, que necessitavam de remoção endoscópica obrigatória. Porém, nos últimos anos, houve um grande aprimoramento do material e desenho dessas sondas.

Dessa forma, os modelos disponíveis atualmente no mercado, apresentam o anteparo interno macio e colapsável, permitindo sua retirada por simples tração externa, em ambiente ambulatorial sendo excepcionalmente necessária a retirada endoscópica ou cirúrgica das sondas. De acordo com a forma de constrição e material desses anteparos, há diferença na intensidade da força necessária para sua remoção. (Mello, 2012).

No caso do anteparo interno balonado, além da remoção ser facilitada pela possibilidade de desinsuflação do balão, a passagem de uma nova sonda também é simples dispensando a necessidade de endoscopia para a realização da troca.

A maioria dos pacientes submetidos a GEP necessita dessa via alimentar por períodos muito longos, quando não permanentes, o que requer que realizem algumas trocas da sonda ao longo da vida, implicando tanto em custos mais elevados quanto em necessidade de locomoção para a realiza- 
ção dessas trocas e, daí, a importância de conhecer a durabilidade de diferentes marcas de sondas de troca.

Na rotina do Hospital das Clínicas da Faculdade de Medicina da Universidade de São Paulo (HCFMUSP), os pacientes que realizam GEP retornam para a troca da sonda no Serviço de Endoscopia Gastrointestinal. No acompanhamento diário desses casos, observou-se a precocidade com que ocorriam esses retornos devido à curta durabilidade da sonda de troca disponível no Serviço, e o principal problema detectado era a ruptura do balão interno da sonda. Com base nessas observações, iniciamos um estudo-piloto com a sonda então disponível no Serviço, da marca Silmag ${ }^{\circledR}(100 \%$ silicone, calibre de $20 \mathrm{Fr}$, volume do balão de $20 \mathrm{ml}$ ), composta de três acessos (incluindo o acesso para insuflação do balão) e de duas vias (alimentação e medicação), com comprimento de $20 \mathrm{~cm}$ e acompanhada de adaptador para equipo (Figura 1).

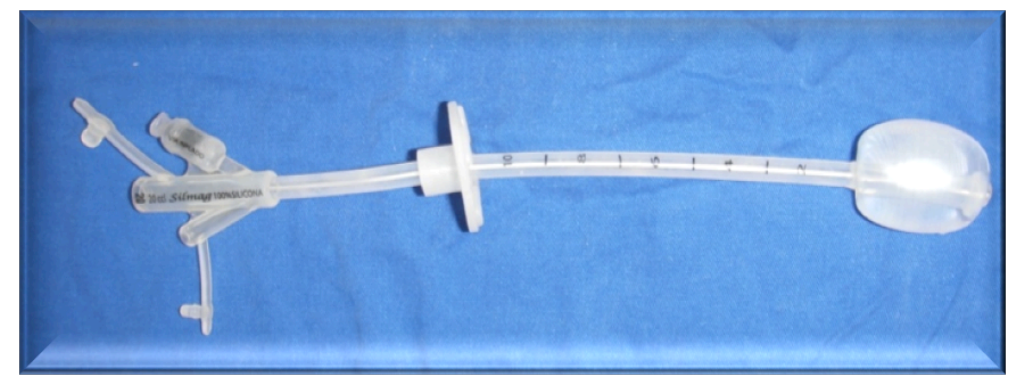

Figura 1. Sonda balonada para troca da marca Silmag ${ }^{\circledR}$ disponível no Serviço de Endoscopia Gastrointestinal do HCFMUSP.

O objetivo daquele estudo-piloto era avaliar a durabilidade da sonda através do acompanhamento dos pacientes por período de seis meses. Para 
tanto, o paciente saía do estudo sempre que era definida a inviabilidade da sonda e a necessidade de nova troca. Como resultado, observou-se que todas as sondas duraram um período significativamente menor do que o esperado: a mediana de duração do balão foi de três dias, com desvio absoluto médio (MAD) de 2,48 dias. Em todos os casos a necessidade de troca se devia à ruptura precoce do balão (Figura 2). Os balões duraram de um a 84 dias (Figura 3). Em nove de 20 pacientes (45\%), a ruptura do balão ocorreu já durante o primeiro dia após a troca.

Considerando tanto os resultados daquele estudo-piloto quanto a dificuldade de locomoção dos pacientes ao ambiente hospitalar (pois muitos pacientes são acamados e/ou apresentam déficit cognitivo importante), ficou clara a importância de se comparar a durabilidade de diferentes modelos de sondas de troca de gastrostomia, com a finalidade de diminuir as despesas da instituição com esse tipo de material e, sobretudo, de melhorar a qualidade de vida dos usuários dessa via alimentar.

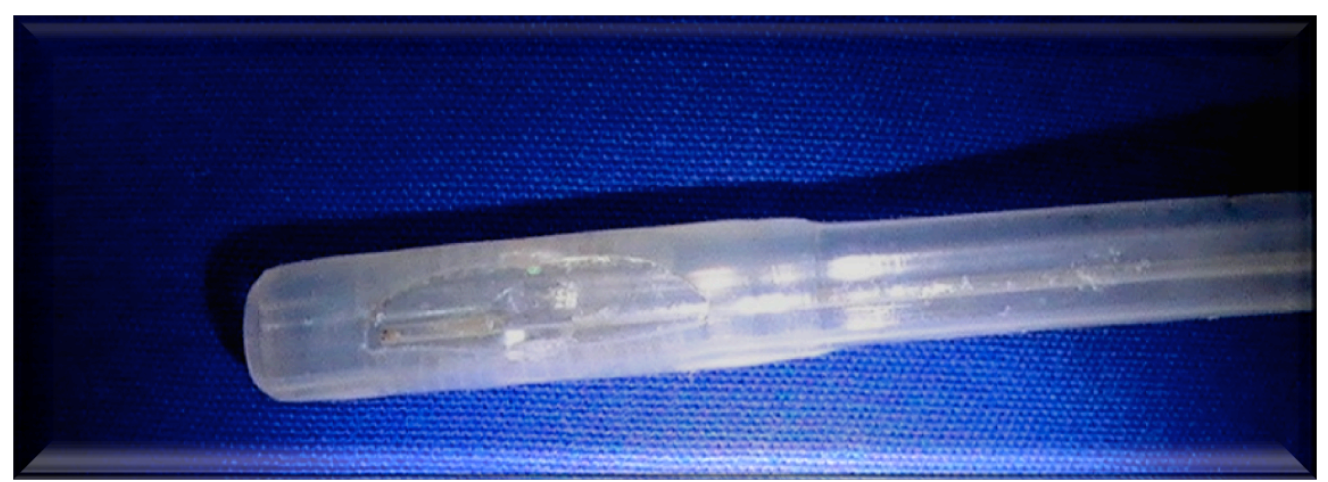

Figura 2. Ruptura de balão interno de sonda de troca de gastrostomia. 


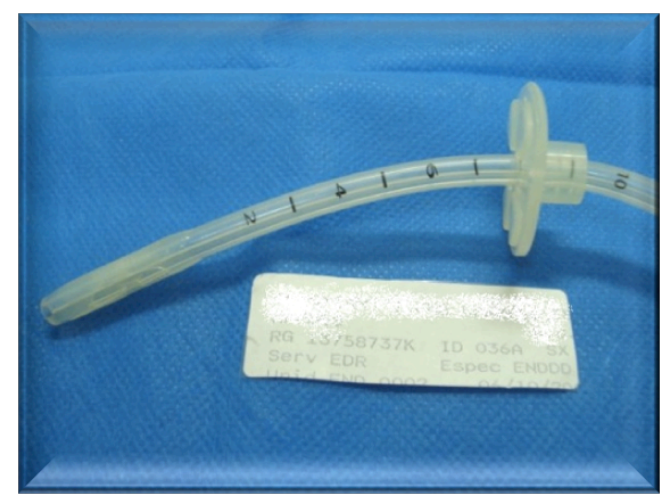

A

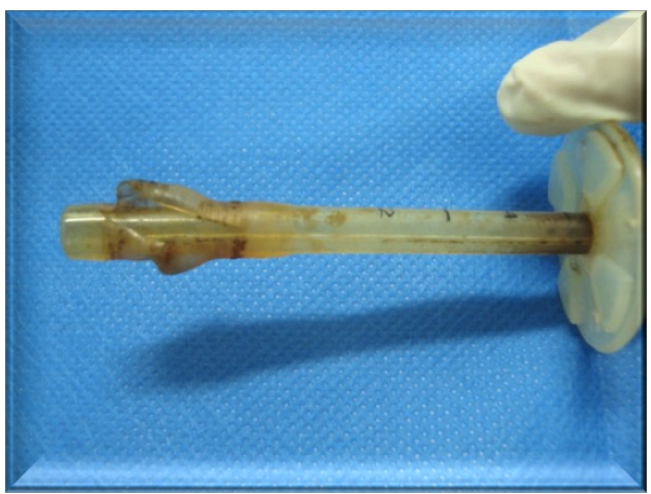

C

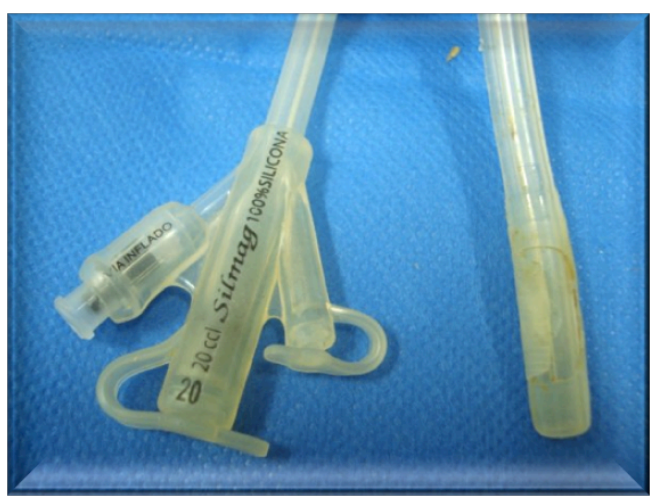

B

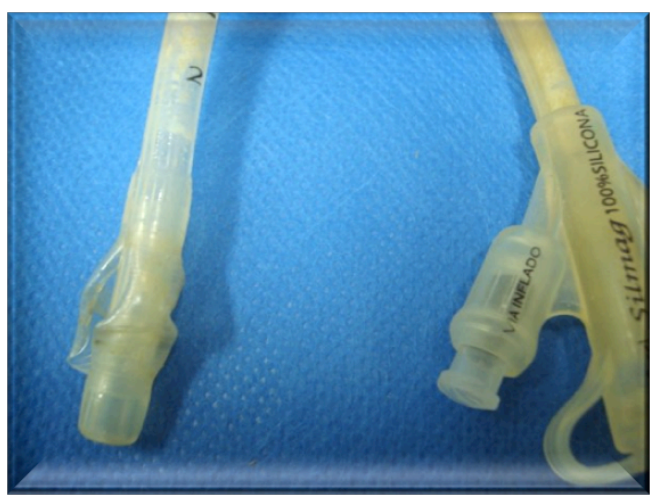

D

Figura 3. Exemplos de sondas que apresentaram ruptura do balão um dia (A), cinco dias (B), 21 dias (C) e 84 dias (D) após a troca.

Atualmente, a despeito da superioridade das sondas de poliuretano, a maioria das sondas de troca disponíveis no mercado é feita de silicone, e não há publicações sobre avaliações da durabilidade de sondas de troca balonadas especificamente, nem dos aspectos técnicos que interferem nessa durabilidade, como problemas nos balões, nos tubos ou nas tampas das sondas. 


\subsection{Objetivo}

1) Comparar a durabilidade das diferentes sondas de troca de gastrostomia balonadas. 


\section{Métodos}

\subsection{Dinâmica do estudo}

Este estudo prospectivo de coorte aberto foi realizado exclusivamente no Serviço de Endoscopia Gastrointestinal do Hospital das Clínicas da Faculdade de Medicina da Universidade de São Paulo, com a devida aprovação da Comissão de Ética para Análise de Projetos de Pesquisa - CAPPesq, em 26 de agosto de 2010, conforme protocolo 0384/10.

Foram inicialmente selecionados cinco modelos de sondas de troca balonadas de gastrostomia para a avaliação de sua durabilidade.

Com base em princípios estatísticos para determinação do tamanho da amostra (Cochran, 1986), estabeleceu-se que seriam avaliadas 100 (cem sondas), distribuídas em grupos de 20 (vinte) sondas de cada modelo, uma vez que, para probabilidade de $5 \%(p=0,05)$ de a hipótese de nulidade ser verdadeira, há uma chance em cada 20 de que o resultado obtido seja consistente com essa hipótese.

Essas sondas foram obtidas junto às empresas que as comercializam. No sentido de evitar qualquer vício de amostragem, estabeleceu-se que, a cada lote de 20 sondas do mesmo modelo liberado pelo fornecedor, essas sondas seriam utilizadas nos 20 pacientes sequenciais que procurassem aleatoriamente o Serviço de Endoscopia Gastrointestinal por necessitar da troca da sonda, atendessem aos critérios de seleção para o estudo, e acei- 
tassem, per se ou por decisão de seus responsáveis, o convite para participar do estudo mediante leitura e assinatura do Termo de Consentimento Livre e Esclarecido (Anexo B). Desse modo, foram criados cinco grupos com 20 pacientes para a avaliação da durabilidade dos cinco modelos de sonda de troca balonada.

Todos os procedimentos para a troca das sondas foram realizados com a mesma técnica rotineiramente usada no Serviço.

\subsection{Seleção da amostra}

Para a composição da amostra deste estudo, foram selecionados pacientes já usuários de sondas de gastrostomia que compareceram sequencialmente ao Serviço de Endoscopia Gastrointestinal com indicação de troca da sonda, e que mostraram, per se ou por meio de seus responsáveis, disposição para comparecer aos retornos previstos no protocolo do estudo.

Como indicações para a troca das sondas foram consideradas:

- a ruptura do balão;

- o desgaste do tubo e/ou das tampas protetoras que inviabilizasse a manutenção da sonda;

- a retirada inadvertida da sonda;

- e a solicitação de troca da sonda pelo médico do paciente.

Dessa seleção foram excluídos tanto pacientes com quadros dermatológicos infecciosos no local da sonda ou com infecção gastrointestinal no momento da troca, quanto pacientes com antecedentes de agitação psicomoto- 
ra e de retirada inadvertida da sonda, cujo comportamento pudesse interferir na avaliação adequada da durabilidade da sonda.

Não foram excluídos desta investigação pacientes que, atendendo aos critérios de inclusão, haviam feito parte de grupo(s) anteriormente formado(s). Em outras palavras, a partir do segundo grupo de estudo assim formado, foram eventualmente incluídos pacientes que já haviam sido submetidos à troca da sonda em grupos anteriores, já que o objeto maior deste estudo foi a durabilidade de sondas de diferentes modelos.

\subsection{Coleta de dados}

Para o protocolo deste estudo interessaram informações tanto dos pacientes quanto de aspectos relativos à durabilidade das sondas, conforme apresentados no Quadro 1

Cada paciente foi acompanhado por seis meses. Nesse período, foram realizadas três reavaliações ao completar o primeiro, o terceiro e o sexto mês a partir da troca da sonda. Nesses retornos, eram avaliados o aspecto clínico do estoma e a integridade da sonda.

Nessas reavaliações, o paciente e/ou seu cuidador também era questionado sobre as dificuldades no manuseio da gastrostomia e sobre a observação de desgaste do material da sonda, de modo que essas informações nos servissem para melhor entendimento e para a discussão dos resultados que viríamos a encontrar.

Os pacientes foram orientados a procurar o serviço ou a entrar em con- 
tato telefônico (atendimento 24 horas) no caso de ocorrer alguma alteração no seu quadro clínico ou na funcionalidade da sonda, para que o diagnóstico adequado e a conduta pertinente fossem rapidamente estabelecidos.

Quadro 1. Dados coletados para análise da durabilidade de cinco modelos sondas de troca balonadas de gastrostomia.

Informações dos pacientes $\left\{\begin{array}{l}\text { Sexo } \\ \text { Idade } \\ \text { Indicação para a gastrostomia } \\ \text { Tempo de uso da gastrostomia (meses) } \\ \text { Número de trocas anteriores }\end{array}\right.$

Tempo de acompanhamento do paciente
lo (dias)
Motivos do término do acompanhamento

Informações
dos aspectos
de durabilidade
das sondas $\quad\left\{\begin{array}{l}\text { Deslizamento do anteparo externo } \\ \text { Resolução após fixação do anteparo externo } \\ \text { Abertura espontânea da tampa } \\ \text { Desgaste da tampa } \\ \text { Desgaste do tubo } \\ \text { Extravasamento periestomal } \\ \text { Obstrução do tubo }\end{array}\right.$

Foram estabelecidos sete motivos para a exclusão do paciente do protocolo, a saber:

(1) término do período proposto para o estudo (seis meses);

(2) problemas no balão da sonda que impedissem a manutenção da 
sonda no paciente;

(3) problemas no tubo da sonda que impedissem a manutenção da sonda no paciente;

(4) problemas na tampa protetora que impedissem a manutenção da sonda no paciente;

(5) interrupção do uso da sonda por indicação clínica (solicitação de retirada da sonda pelo médico do paciente) ou por óbito do paciente;

(6) perda do acompanhamento;

(7) manipulação incorreta da sonda (pelo paciente, por cuidadores ou acompanhantes).

A durabilidade das sondas foi determinada pelos motivos 2 a 4 .

\subsection{Materiais}

Foi avaliada a durabilidade de cinco diferentes modelos de sondas especificados nas páginas seguintes, na ordem cronológica em que foram recebidas pelo fornecedor e em que foram incluídas no protocolo de estudo. 


\section{A) KANGAROO ${ }^{\circledR}$}

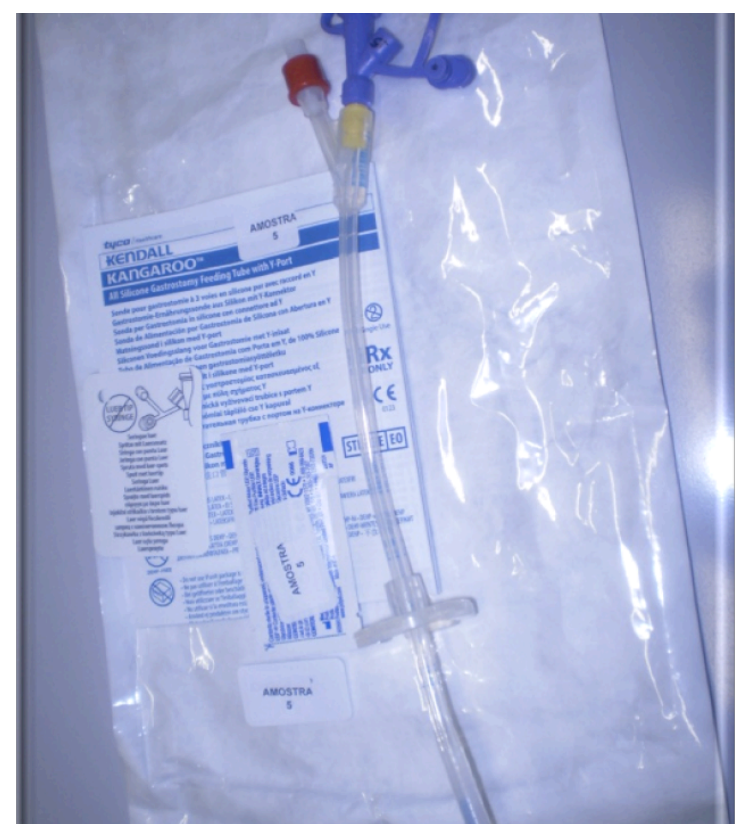

Fabricante: Kendall-Kenmex, Divisão de Tyco, Inc.

País de origem: Patente: EUA; Fabricação: México

Nome comercial: Tubo de alimentação de gastrostomia com porta $Y$

Composição: Silicone

Calibre: $20 \mathrm{Fr}$

Comprimento: $20 \mathrm{~cm}$

Vias alimentares: Duas

Formato do anteparo externo: Circular

Clamp: Não

Braçadeira: Não

Tempo de permanência recomendado: 28 dias

Volume a ser insuflado: $20 \mathrm{ml}$

Tipo de líquido a ser insuflado: Água ou solução salina 


\section{B) WILSON COOK ${ }^{\circledR}$}

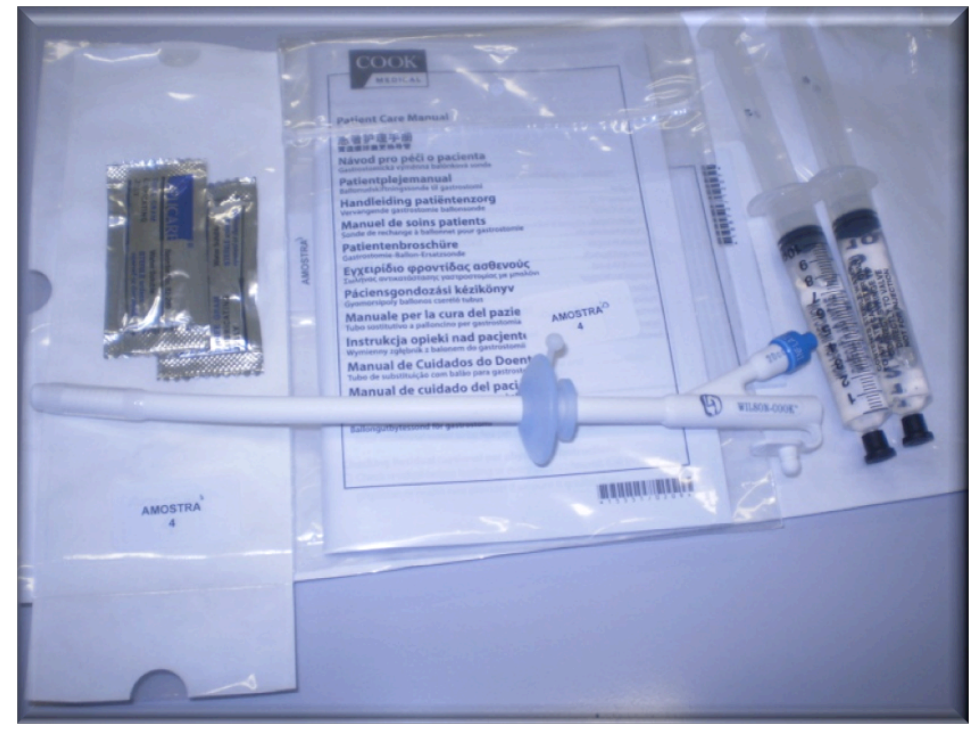

Fabricante: Cook Endoscopy. Inc.

País de origem: EUA

Nome comercial: Tubo de substituição com balão GEP

24-BRT-S

Composição: Silicone

Calibre: $24 \mathrm{Fr}$

Comprimento: $20 \mathrm{~cm}$

Vias alimentares: Uma

Formato do anteparo externo: Circular

Clamp: Não

Braçadeira: Braçadeira rotativa composta de náilon

Tempo de permanência recomendado: 29 dias

Volume a ser insuflado: $20 \mathrm{ml}$

Tipo de líquido a ser insuflado: Água destilada 


\section{C) SILMAG ${ }^{\circledR}$}

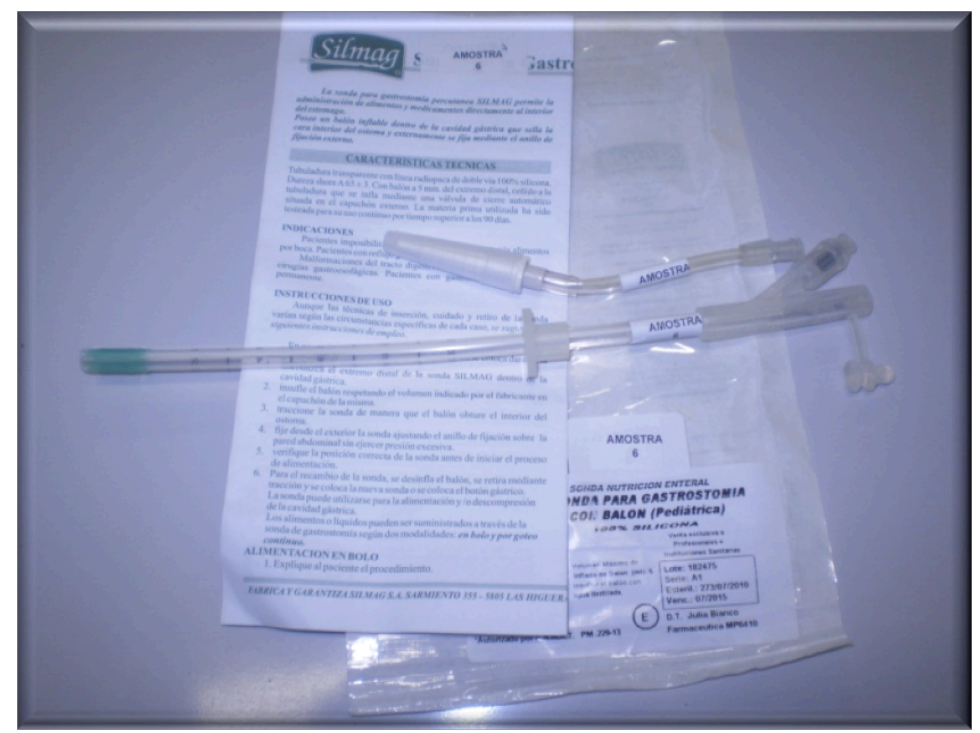

Fabricante: Silmag

País de origem: Argentina

Nome comercial: Sonda para gastrostomia percutânea com balão pediátrico

Composição: Silicone

Calibre: $20 \mathrm{Fr}$

Comprimento: $20 \mathrm{~cm}$

Vias alimentares: Duas

Formato do anteparo externo: Circular

Clamp: Não

Braçadeira: Não

Tempo de permanência recomendado: 90 dias

Volume a ser insuflado: $20 \mathrm{ml}$

Tipo de líquido a ser insuflado: Água destilada 


\section{D) FREKA ${ }^{\circledR}$}

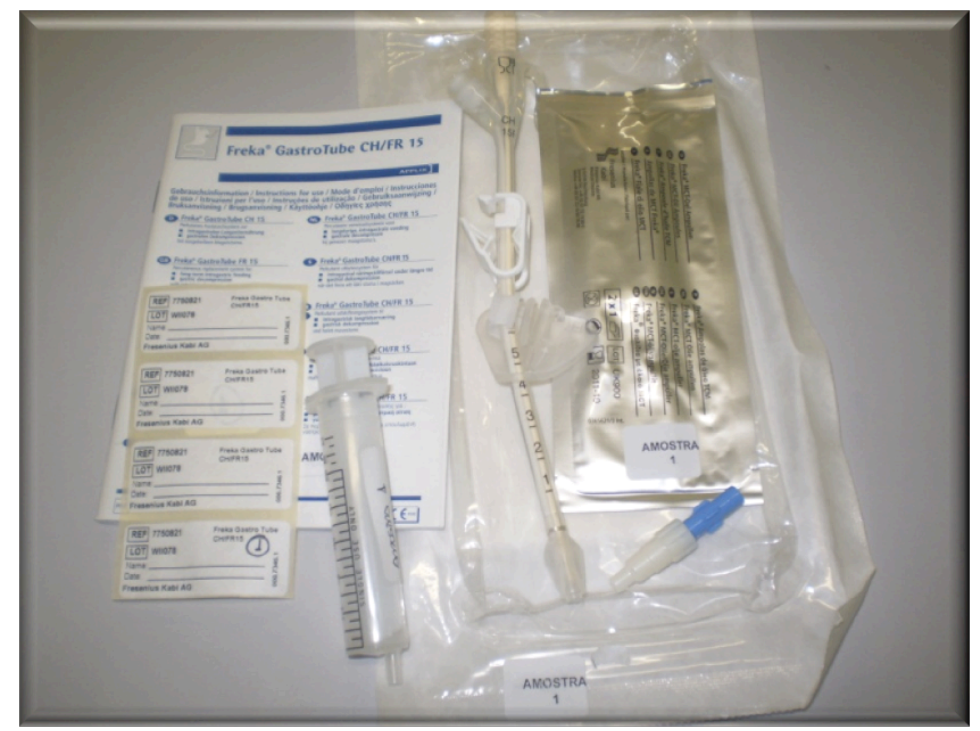

Fabricante: Frenesius Kabi, AG

País de origem: Alemanha

Nome comercial: Freka gastro tube $\mathrm{CH} / \mathrm{Fr} 15$

Composição: Silicone

Calibre: $15 \mathrm{Fr}$

Comprimento: $12 \mathrm{~cm}$

Vias alimentares: Uma

Formato do anteparo externo: Triangular

Clamp: Sim

Braçadeira: Não

Tempo de permanência recomendado: 42 dias

Volume a ser insuflado: $7 \mathrm{ml}$

Tipo de líquido a ser insuflado: Solução salina isotônica ou água destilada 


\section{E) BARD ${ }^{\circledR}$}

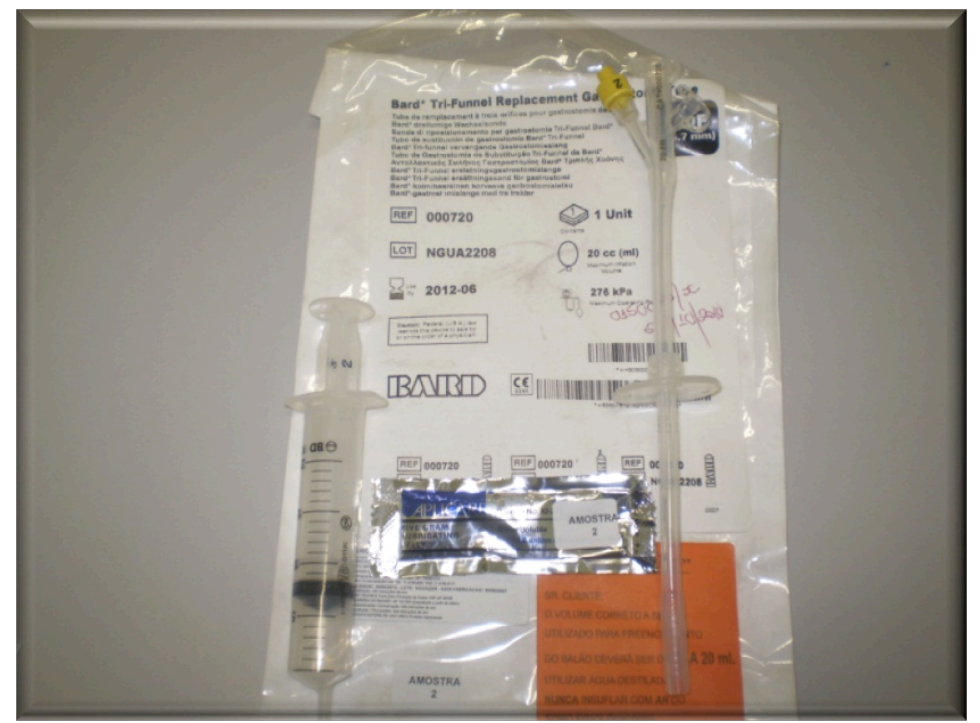

Fabricante: Bard Access Systems

País de origem: Patente USA, fabricado no México

Nome comercial: Tubo de Gastrostomia de reposição 0072

Composição: Silicone

Calibre: $20 \mathrm{Fr}$

Comprimento: $20 \mathrm{~cm}$

Vias alimentares: Duas

Formato do anteparo externo: Circular

Clamp: Não

Braçadeira: Não

Tempo de permanência recomendado: 42 dias

Volume a ser insuflado: $20 \mathrm{ml}$

Tipo de líquido a ser insuflado: Solução salina isotônica ou água destilada 


\subsection{Grupos de estudo}

De acordo com a dinâmica estabelecida para este estudo, com os critérios de seleção e de coleta de dados adotados, e com os materiais especificados, foram acompanhados 100 procedimentos de troca de sondas de gastrostomia, divididos em cinco grupos de 20 procedimentos, de acordo com o modelo de sonda de troca utilizada.

Esses procedimentos foram realizados no total de 65 pacientes, já que 26 deles foram submetidos a dois ou mais procedimentos, conforme ilustra a Figura 4.

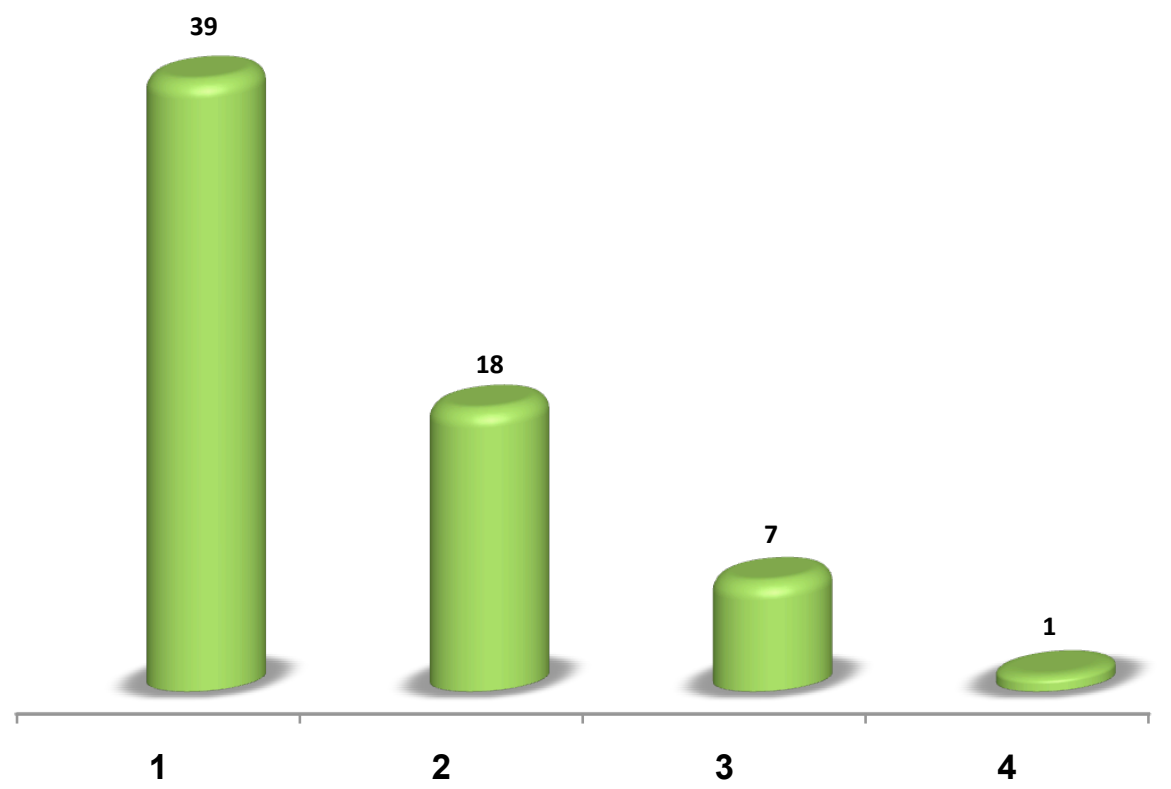

Figura 4. Representação gráfica da distribuição do número absoluto de pacientes de acordo com a quantidade de procedimentos realizados. 
A caracterização dos pacientes de cada um dos cinco grupos de estudo, formados de acordo com a sonda de troca utilizada, está apresentada na Tabela 1. As diferentes indicações para gastrostomia nesses pacientes podem ser conhecidas no Anexo C.

Tabela 1. Caracterização dos pacientes que compuseram os cinco grupos para o estudo de durabilidade de diferentes modelos de sondas de troca de gastrostomia.

\begin{tabular}{|c|c|c|c|c|c|}
\hline \multirow{2}{*}{$\begin{array}{l}\text { Informações } \\
\text { dos pacientes }\end{array}$} & \multicolumn{5}{|c|}{ Grupos de estudo conforme modelos de sondas de troca } \\
\hline & Kangaroo $^{\circledR}$ & Wilson Cook $^{(8)}$ & Silmag $^{(}$ & Freka $^{(}$ & Bard $^{(8)}$ \\
\hline \multicolumn{6}{|l|}{ Gênero } \\
\hline Masculino & $7(35,0 \%)$ & $9(45,0 \%)$ & $7(35,0 \%)$ & $10(50,0 \%)$ & $9(45,0 \%)$ \\
\hline Feminino & $13(65,0 \%)$ & $11(55,0 \%)$ & $13(65,0 \%)$ & $10(50,0 \%)$ & $11(55,0 \%)$ \\
\hline \multicolumn{6}{|l|}{ Idade } \\
\hline Mínima & 13 & 22 & 13 & 22 & 13 \\
\hline Máxima & 89 & 90 & 85 & 81 & 86 \\
\hline Mediana & 57,5 & 58 & 58 & 61,5 & 63 \\
\hline Média_DP & $57,0 \pm 21,7$ & $58,8 \pm 20,5$ & $57,5 \pm 22,6$ & $59,9 \pm 17,7$ & $58,0 \pm 22,7$ \\
\hline \multicolumn{6}{|c|}{ Tempo de uso de GEP (meses) } \\
\hline Mínimo & 2 & 6 & 8 & 3 & 2 \\
\hline Máximo & 84 & 84 & 84 & 96 & 84 \\
\hline Mediana & 30 & 24 & 21,5 & 12,5 & 18,5 \\
\hline Média_DP & $31,6 \pm 27,1$ & $28,2 \pm 18,5$ & $28,7 \pm 20,1$ & $23,8 \pm 27,3$ & $22,6 \pm 19,7$ \\
\hline \multicolumn{6}{|c|}{ Número de trocas anteriores } \\
\hline 1 & $5(25,0 \%)$ & $1(5,0 \%)$ & $2(10,0 \%)$ & $9(45,0 \%)$ & $5(25,0 \%)$ \\
\hline 2 & $1(5,0 \%)$ & $4(20,0 \%)$ & $4(20,0 \%)$ & $1(5,0 \%)$ & $3(15,0 \%)$ \\
\hline 3 & $1(5,0 \%)$ & $2(10,0 \%)$ & $3(15,0 \%)$ & $3(15,0 \%)$ & $4(20,0 \%)$ \\
\hline 4 & $1(5,0 \%)$ & - & $1(5,0 \%)$ & $1(5,0 \%)$ & $2(10,0 \%)$ \\
\hline 5 & $1(5,0 \%)$ & $1(5,0 \%)$ & $1(5,0 \%)$ & - & - \\
\hline$>5$ & $11(55,0 \%)$ & $12(60,0 \%)$ & $9(45,0 \%)$ & $6(30,0 \%)$ & $6(30,0 \%)$ \\
\hline
\end{tabular}




\subsection{Análises fisicoquímicas das sondas balonadas}

No sentido de complementar o estudo da durabilidade de diferentes modelos de sondas de troca balonadas de gastrostomia, quatro unidades de cada modelo foram encaminhadas para a FAGA Medical (Bauru, SP) para a análise fisicoquímica dessas amostras.

Essa análise seguiu um protocolo que incluiu teste visual, teste de resistência do balão da sonda em função da carga volumétrica (padrão nominal e diferencial extranominal) e teste de resistência ao meio em que o material é exposto $(\mathrm{pH}>1,0$ e $<2,0$ e $\mathrm{pH} 5,0)$.

\section{A) TESTE VISUAL}

O teste visual incluiu quatro amostras de cada modelo de sondas balonadas, totalizando 20 amostras. Para a realização desse teste é necessária iluminação mínima de 600 luxes. A distância máxima entre o produto examinado e o examinador deve ser de $30 \mathrm{~cm}$, e os balões devem estar cheios de água destilada ao longo do teste. O teste visual deve indicar se o balão apresenta descontinuidades, fissuras / rasgos ou vazamentos. 


\section{B) TESTE DE RESISTÊNCIA DO BALÃO EM FUNÇÃO}

\section{DA CARGA VOLUMÉTRICA}

Por este teste, é analisada a resistência mecânica do balão com a insuflação do volume determinado pelos fabricantes das amostras (padrão nominal) e posterior sobrecarga volumétrica até a sua ruptura (diferencial extranominal). Para a sua realização, o instrumento de medição deve ter leitura mínima de $1 \mathrm{~mm}$. A insuflação é realizada com água destilada e em seringa com capacidade de até $20 \mathrm{ml}$.

O teste do padrão nominal, ou seja, da carga volumétrica indicada pelo fabricante (Figura 5), foi realizado com quatro amostras de cada modelo de sonda, totalizando 20 amostras, e indicou a porcentagem de expansão do balão (ou seja, a relação entre o perímetro do balão vazio e o perímetro do balão cheio em milímetros), a presença de vazamentos e a homogeneidade da insuflação.

O teste do diferencial extranominal, ou seja, da carga volumétrica superior à recomendada pelo fabricante (Figura 6), foi realizado com três amostras de cada modelo de sonda, totalizando 15 amostras. Para esse teste, partiu-se do padrão nominal insuflado e mensurado (perímetro inicial). Nos passos seguintes, aplicavam-se $4 \mathrm{ml}$ de água destilada e observava-se se havia vazamentos na superfície do balão ou na válvula pela qual o balão era insuflado; esses passos eram repetidos até a ruptura do balão. O teste indicou a porcentagem de expansão do balão (ou seja, a relação entre o perímetro inicial do balão cheio - padrão nominal - e o perímetro máximo do ba- 
lão antes de romper em milímetros), o volume insuflado (em mililitros), a presença de vazamentos e a homogeneidade da insuflação.

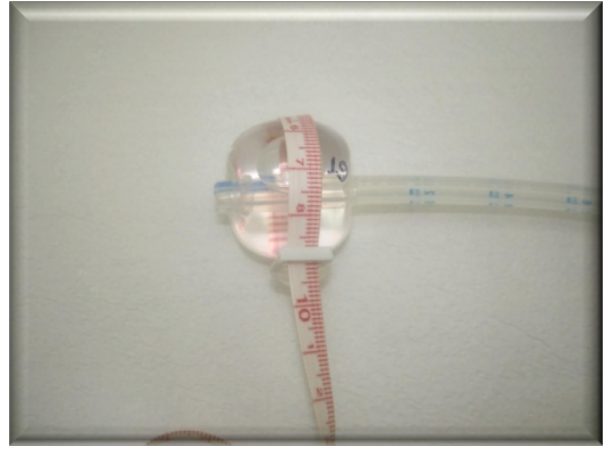

Kangaroo $^{\circledR}$

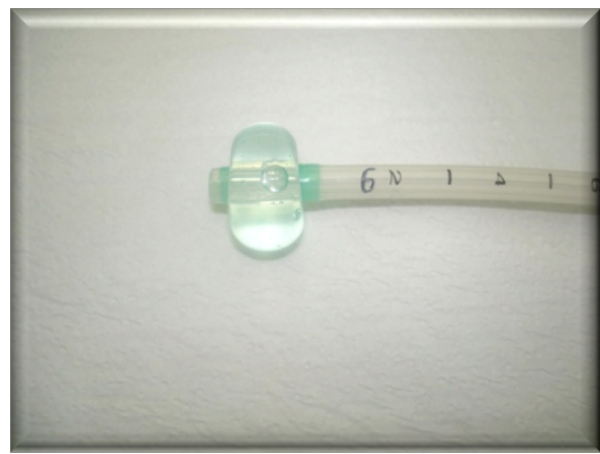

Silmag $^{\circledR}$

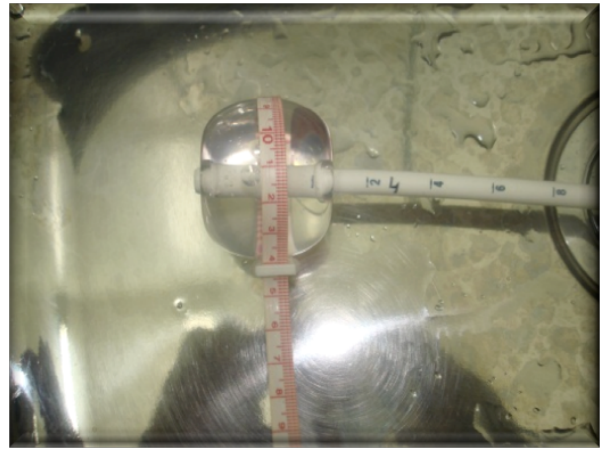

Wilson Cook ${ }^{\circledR}$

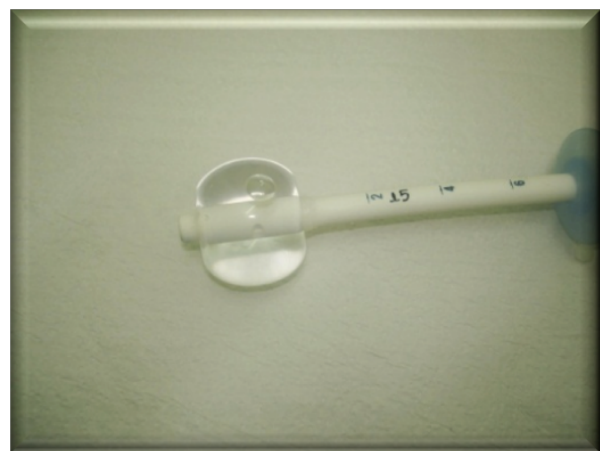

Freka $^{\circledR}$

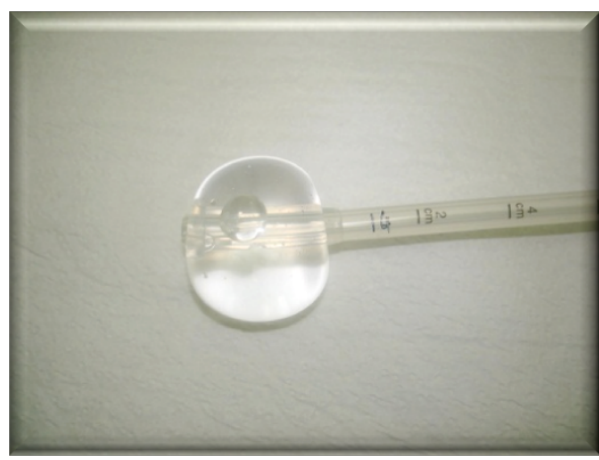

Bard $^{\circledR}$

Figura 5. Fotos ilustrativas do balão cheio no teste de resistência em função do padrão nominal da carga volumétrica em uma amostra de cada modelo de sondas balonadas avaliadas. 

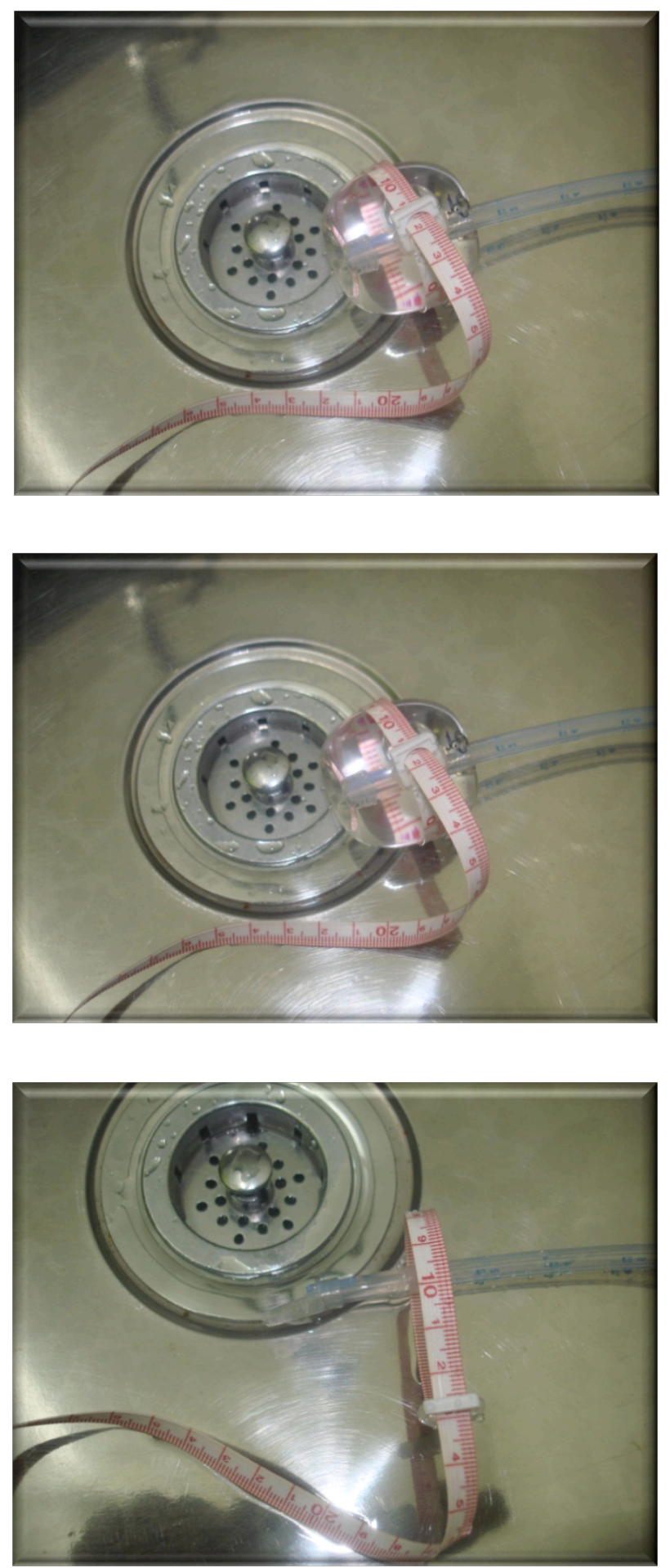

Figura 6. Fotos ilustrativas dos passos para o teste de resistência em função do diferencial extranominal da carga volumétrica em uma amostra de um dos modelos $\left(\right.$ Kangaroo $\left.^{\circledR}\right)$ de sondas balonadas avaliadas. 


\section{C) TESTE DE RESISTÊNCIA AO MEIO EM QUE O MATERIAL É EXPOSTO}

O teste de resistência ao meio em que o material é exposto (Figura 7) foi realizado com duas amostras de cada modelo de sonda. Ao longo de seis meses, uma amostra de cada modelo foi exposta à solução que simula o pH ácido do estômago de indivíduo saudável, ou seja, $\mathrm{pH}>1,0$ e $<2,0$ (Ferreira, 2002) e à solução que simula o pH ácido do estômago de indivíduos em uso de inibidor de bomba de prótons (IBP), ou seja, $\mathrm{pH} \mathrm{5,0} \mathrm{aproximadamente}$ (Sachs et al., 2010). O pH dessas soluções foi regularmente medido a cada três semanas.

Para cada $1.000 \mathrm{ml}$ da solução que simula $\mathrm{pH}>1,0$ e $<2,0$, foram utilizados $7 \mathrm{ml}$ de ácido clorídrico em concentração de 30\% a 34\%, $2 \mathrm{~g}$ de cloreto de sódio, 3,2 g de pepsina, $1.000 \mathrm{~g}$ de água deionizada. Para a simulação de suco gástrico com pH 5,0, adicionou-se a $1 \mathrm{ml}$ da solução antes descrita $200 \mathrm{ml}$ de água deionizada com $\mathrm{pH}$ 7,0. Ambas as soluções foram mantidas em temperatura ambiente.

Em recipientes com $60 \mathrm{~mm}$ de altura foram colocados $250 \mathrm{ml}$ da solução pertinente. As tampas dos vasilhames foram furadas com diâmetro compatível com o tubo de cada amostra que, por sua vez, foi inserida nesse furo, na marca $5 \mathrm{~cm}$. Cada amostra foi insuflada com água destilada e azul de metileno na concentração de $0,025 \mathrm{~g} / \mathrm{l}$, com os volumes de insuflação estabelecidos pelos respectivos fabricantes. A tampa de cada vasilhame foi colocada de modo a submergir totalmente o balão da sonda na solução. Semanalmente, os recipientes eram verificados para detecção de vazamento (identificado pela mancha do corante), quando, então, as amostras eram retiradas dos 
recipientes e os registros do tempo decorrido e do local do vazamento eram registrados no protocolo do estudo.

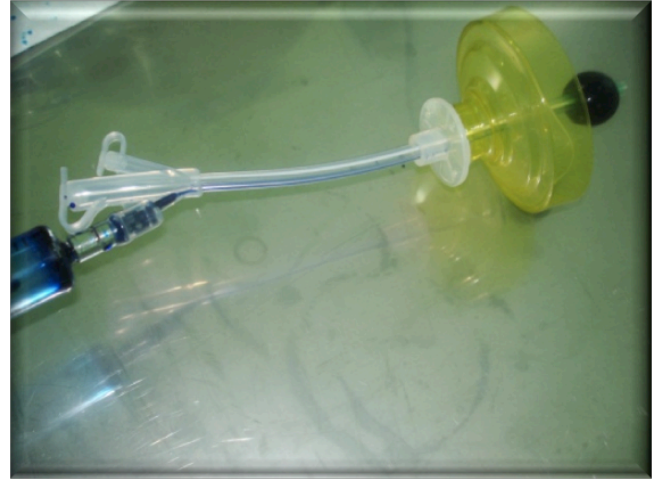

Método de insuflação

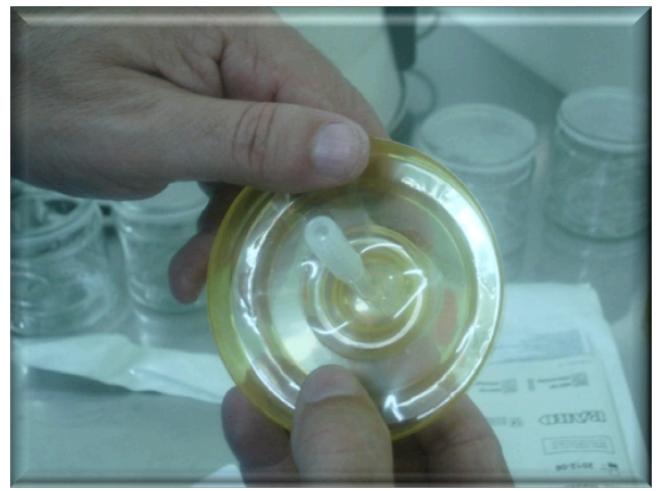

Preparo da tampa do recipiente com película de silicone

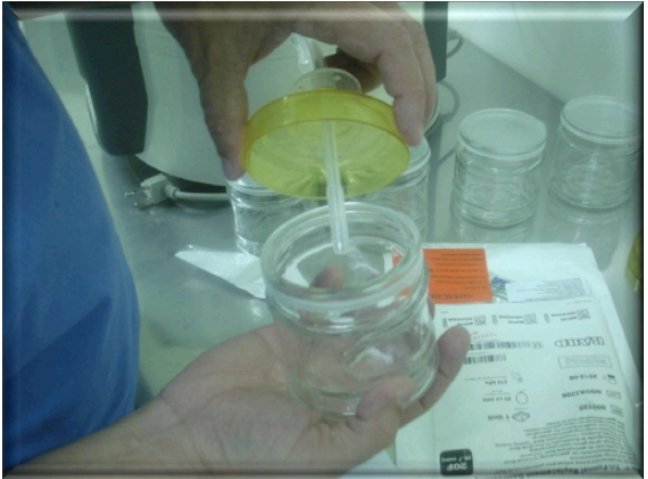

Preparo do recipiente

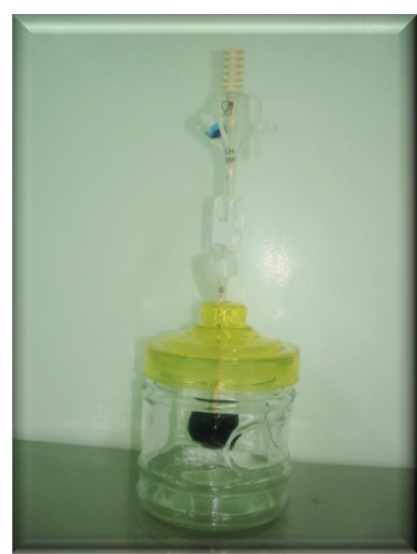

Balão insuflado mergulhado em solução simuladora de suco gástrico

Figura 7. Fotos ilustrativas do processo de preparação para o teste de resistência ao meio em que o material é exposto. 


\subsection{Análises estatísticas}

Análises estatísticas foram realizadas neste estudo no sentido de determinar a durabilidade de cinco diferentes marcas de sondas de troca de gastrostomia. Para tanto, tomou-se como base para essas análises tanto os motivos que levaram o paciente a ser excluído do protocolo quanto o tempo em que permaneceram no protocolo ao longo dos seis meses de estudo. Dentre esses motivos, foram considerados aqueles diretamente relacionados com problemas no balão, no tubo ou na tampa da sonda para determinação da sua durabilidade, e o término do acompanhamento sem que problemas na sonda tenham determinado a exclusão do paciente do protocolo. Os demais motivos foram considerados "censuras".

Dadas as características da amostra e o contingente de dados censurados, as análises foram aplicadas considerando dois desfechos distintos: no primeiro desfecho, foram associados todos os casos de interrupção do uso da sonda por ruptura do balão, desgaste do tubo e desgaste da tampa da sonda. No segundo desfecho, foram considerados apenas os casos de interrupção do uso da sonda por ruptura dos balões.

O método não paramétrico de Kaplan Meier foi aplicado aos dados assim considerados para estimar a função de durabilidade (ou função de sobrevida) das cinco diferentes marcas de sonda e de respectivos errospadrão, e para a interpretação das curvas de durabilidade estimadas por esse método. Em seguida, aplicou-se análise de Log Rank (Mantel-Cox) para verificar a existência de eventuais diferenças significativas entre as fun- 
ções de durabilidade estimada pelo método de Kaplan Meier para cada marca de sonda.

Em uma segunda etapa, aplicou-se o modelo semiparamétrico de regressão de Cox para estimar os efeitos da variável "marca das sondas" e das covariáveis "idade", "gênero", "indicação da GEP", "tempo de uso de GEP" e "número de trocas anteriores" em relação ao tempo de durabilidade das diferentes marcas de sondas. Para essa análise, foram aplicados os métodos FORWARD e AIC, no sentido de determinar o melhor modelo de ajuste dos dados.

A Prova do Qui-quadrado $\left(\mathrm{X}^{2}\right)$ foi aplicada tanto para verificação da adequação das suposições decorrentes do Modelo de regressão de Cox, quanto para comparação de dados descritivos expressos em frequências. Por fim, o Teste $t$ de Student foi aplicado para a comparação de dados descritivos expressos em médias e desvios-padrão.

Em todas essas estatísticas, adotou-se probabilidade de $5 \%(p=0,05)$ para rejeição da hipótese de nulidade. 


\section{Resultados}

\subsection{Motivos de término do acompanhamento}

As frequências relativas aos motivos de término do acompanhamento dos pacientes do protocolo de estudo estão distribuídas na Tabela 2, na qual se observa que o acompanhamento de seis meses foi completado por $45 \%$ de todos os casos. Esse percentual variou de 25\% (no grupo das sondas marca Silmag ${ }^{\circledR}$ ) a $70 \%$ (no grupo das sondas marca Wilson Cook $^{\circledR}$ ).

Dentre os motivos que determinaram a durabilidade das sondas, houve ruptura do balão em $32 \%$ dos casos, problemas com o tubo da sonda em $4,0 \%$, e problemas com a tampa, em $3,0 \%$. 
Tabela 2. Distribuição das frequências relativas aos motivos de término do acompanhamento dos pacientes do protocolo de estudo de acordo com as diferentes marcas de sondas de troca de gastrostomia.

\begin{tabular}{|c|c|c|c|c|c|c|c|c|c|c|c|c|}
\hline \multirow{3}{*}{ Motivos } & \multicolumn{10}{|c|}{ Grupos de estudo } & \multirow{2}{*}{\multicolumn{2}{|c|}{ Totais }} \\
\hline & \multicolumn{2}{|c|}{ Kangaroo $^{\circledR}$} & \multicolumn{2}{|c|}{ Wilson Cook ${ }^{(B)}$} & \multicolumn{2}{|c|}{ Silmag $^{(B)}$} & \multicolumn{2}{|c|}{ Freka $\left.^{(}\right)$} & \multicolumn{2}{|c|}{ Bard $^{(8)}$} & & \\
\hline & $\mathrm{n}$ & $\%$ & $n$ & $\%$ & $n$ & $\%$ & $n$ & $\%$ & $\mathrm{n}$ & $\%$ & $n$ & $\%$ \\
\hline 1 & 9 & 45,0 & 14 & 70,0 & 5 & 25,0 & 10 & 50,0 & 7 & 35,0 & 45 & 45,0 \\
\hline 2 & 7 & 35,0 & 4 & 20,0 & 10 & 50,0 & 3 & 15,0 & 8 & 40,0 & 32 & 32,0 \\
\hline 3 & 1 & 5,0 & 0 & - & 1 & 5,0 & 1 & 5,0 & 1 & 5,0 & 4 & 4,0 \\
\hline 4 & 0 & - & 0 & - & 0 & - & 2 & 10,0 & 1 & 5,0 & 3 & 3,0 \\
\hline 5 & 1 & 5,0 & 1 & 5,0 & 1 & 5,0 & 2 & 10,0 & 0 & - & 5 & 5,0 \\
\hline 6 & 1 & 5,0 & 0 & - & 0 & - & 1 & 5,0 & 3 & 15,0 & 5 & 5,0 \\
\hline 7 & 1 & 5,0 & 1 & 5,0 & 3 & 15,0 & 1 & 5,0 & 0 & - & 6 & 6,0 \\
\hline Totais & 20 & 100,0 & 20 & 100,0 & 20 & 100,0 & 20 & 100,0 & 20 & 100,0 & 100 & 100,0 \\
\hline
\end{tabular}

Legenda dos motivos: (1) Término do período de estudo. (2), (3) e (4) problemas no balão, no tubo e/ou na tampa protetora da sonda, respectivamente, que impediram a manutenção da sonda no paciente. (5) Interrupção do uso da sonda por indicação clínica ou por óbito do paciente. (6) Perda de acompanhamento do paciente. (7) Manipulação incorreta da sonda.

Os cinco óbitos ocorridos ao longo do acompanhamento decorreram da evolução ou de complicações das doenças de base dos pacientes, e não foram relacionados com o uso da sonda ou de suas complicações.

\subsection{Intercorrências nas sondas de troca de gastrostomia}

As frequências percentuais relativas às intercorrências observadas nas sondas de troca de gastrostomia ao longo do acompanhamento de todos os pacientes dos cinco grupos de estudo estão ilustradas na Figura 8. A intercorrência mais frequentemente observada foi o deslizamento do anteparo externo $(57,0 \%)$, enquanto o desgaste do tubo foi observado em sete casos $(7,0 \%)$. 


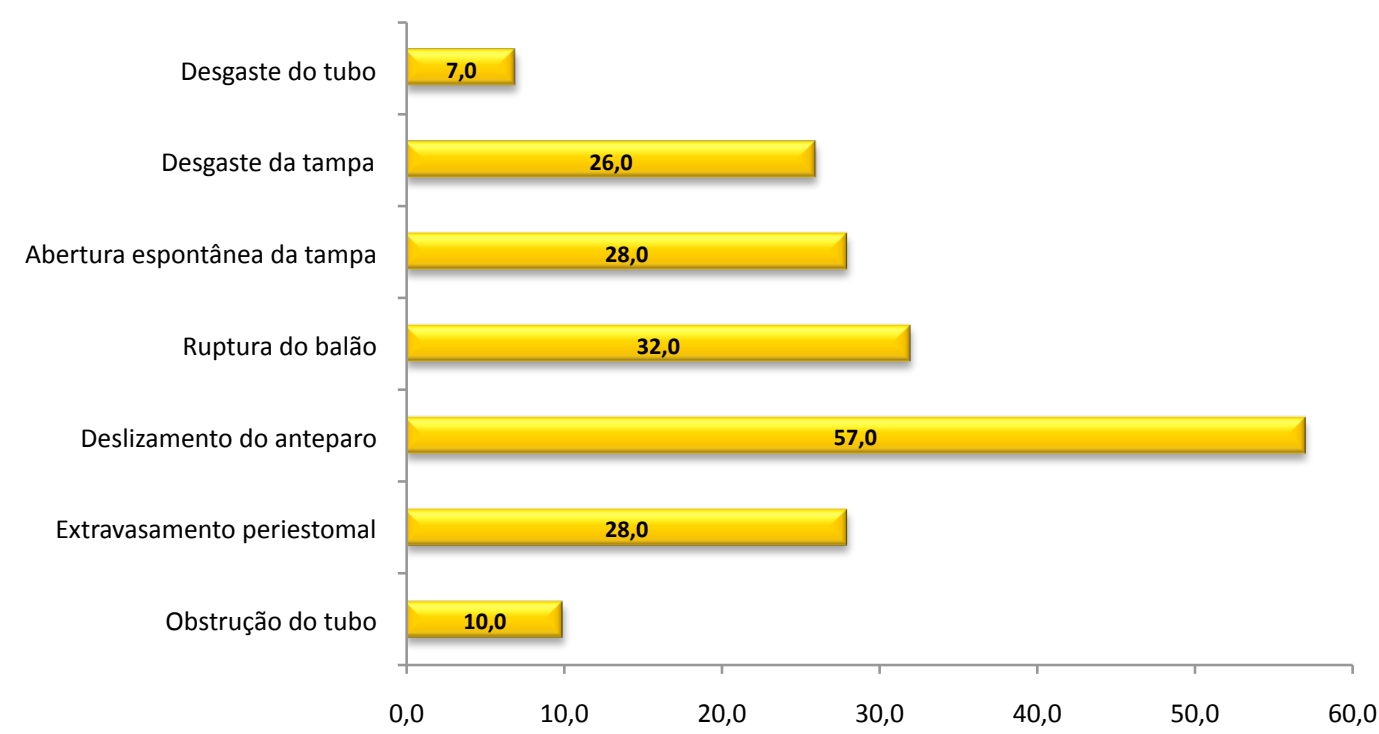

Figura 8. llustração gráfica das frequências percentuais relativas a intercorrências na sonda de troca de gastrostomia observadas ao longo do acompanhamento de todos os 100 procedimentos incluídos no estudo.

Na Figura 9 estão ilustradas algumas das intercorrências encontradas ao longo do estudo. 


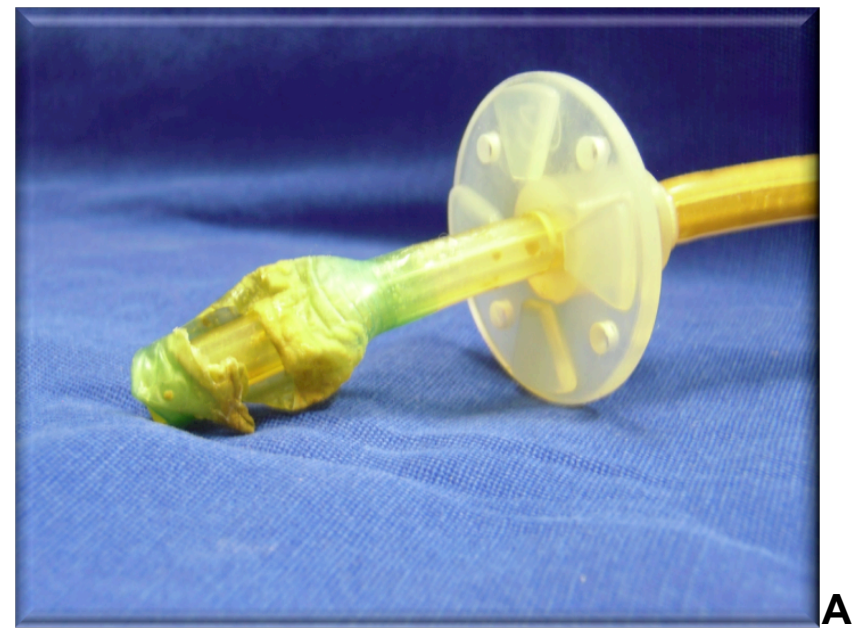

Ruptura do balão

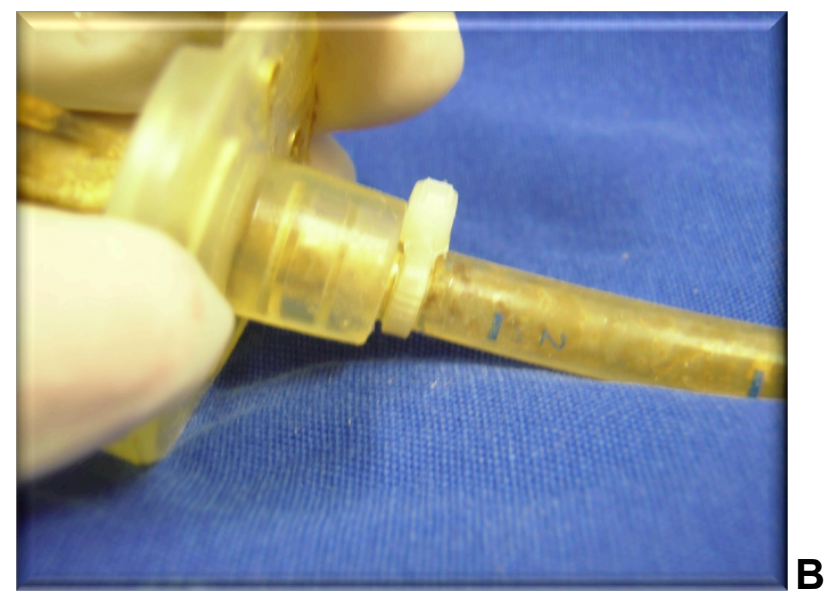

Fixação para corrigir deslizamento do anteparo externo

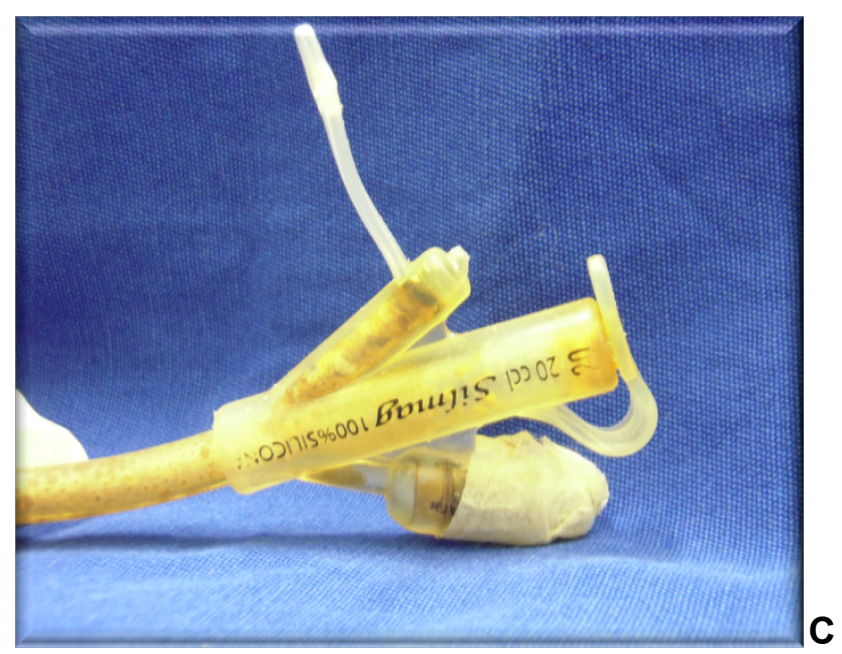

Desgaste da tampa

Figura 9. Exemplos de sondas que apresentaram intercorrências no balão - ruptura (A), no tubo - deslizamento do anteparo externo com fixação do mesmo (B) e na tampa - desgaste $(C)$. 
Nas Figuras 10 a 16 estão ilustradas as distribuições das frequências percentuais de cada intercorrência de acordo com a marca da sonda usada pelo paciente. Ressalte-se que essas intercorrências não determinaram, obrigatoriamente, a o término do acompanhamento do paciente do estudo e, portanto, nem todas foram determinantes da durabilidade das sondas.

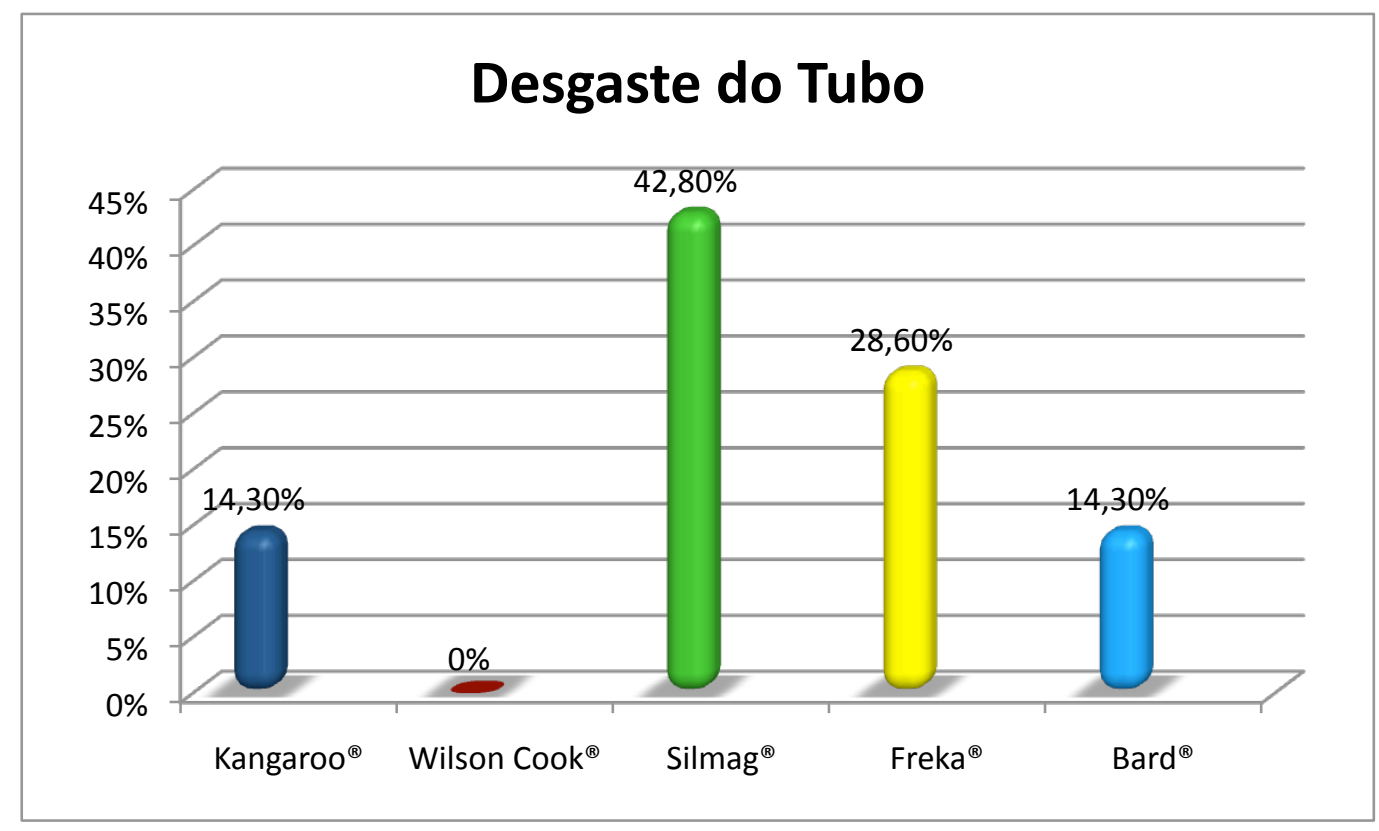

Figura 10. llustração gráfica da distribuição das frequências relativas de desgaste do tubo na sonda de troca de gastrostomia de acordo com a marca de sonda (grupo de estudo) em uso pelos pacientes. 


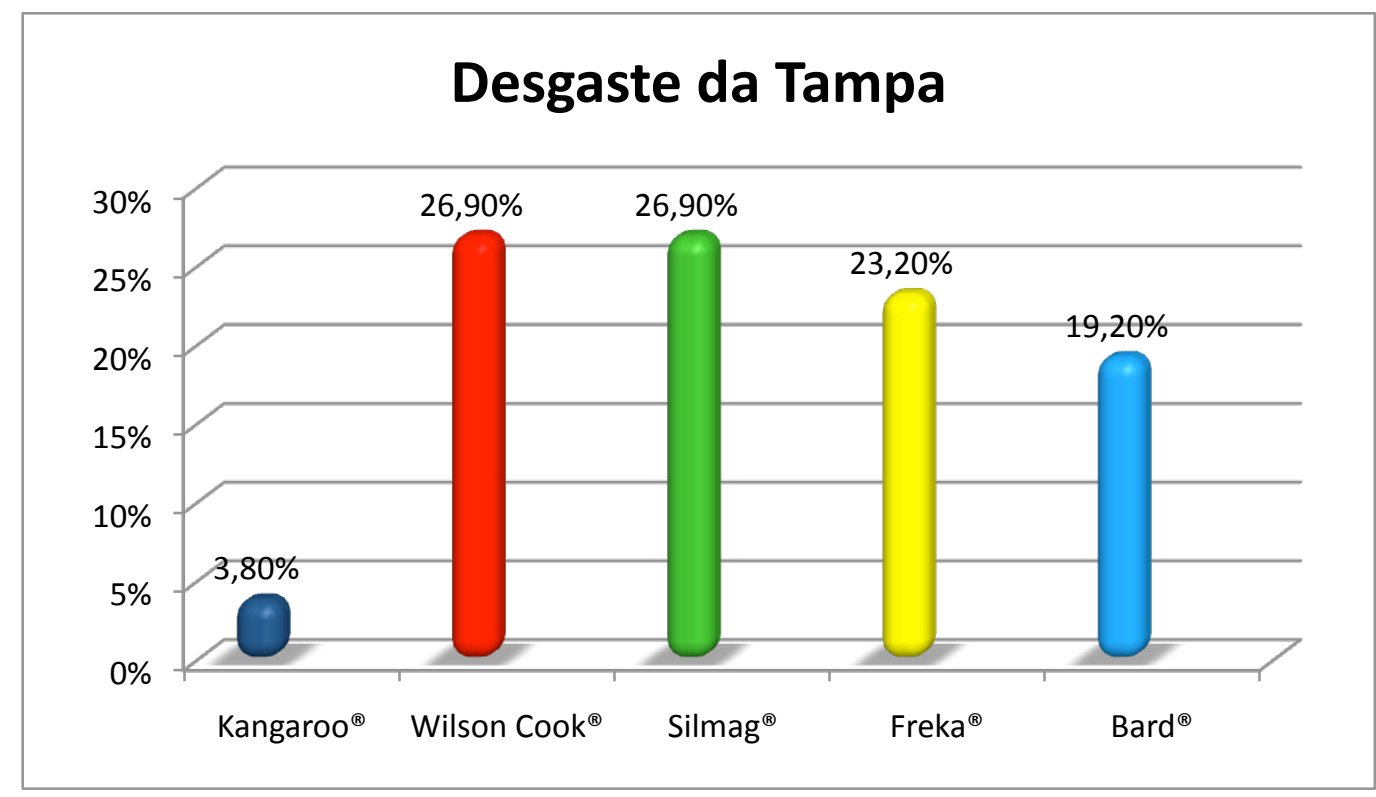

Figura 11. llustração gráfica da distribuição das frequências relativas de desgaste da tampa na sonda de troca de gastrostomia de acordo com a marca de sonda (grupo de estudo) em uso pelos pacientes.

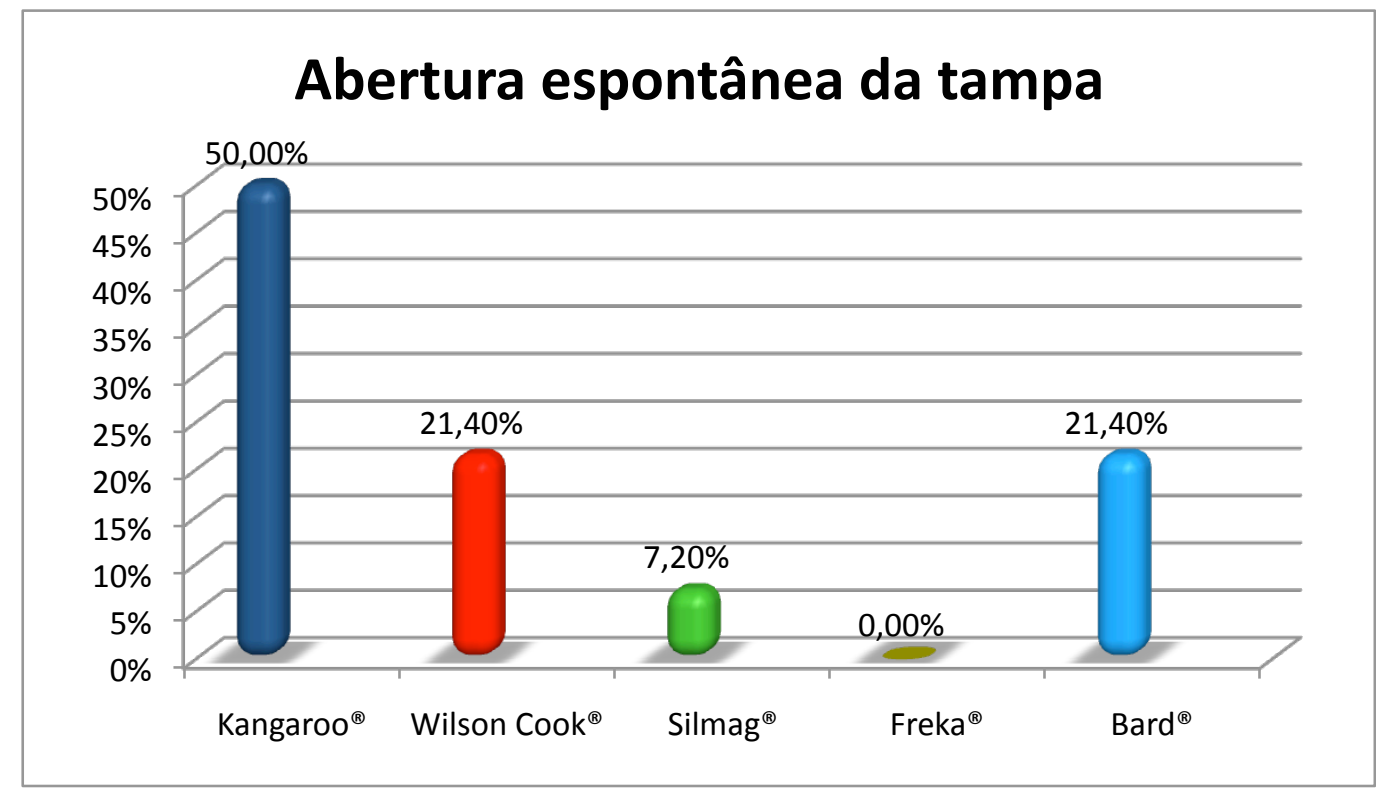

Figura 12. Ilustração gráfica da distribuição das frequências relativas de abertura espontânea da tampa na sonda de troca de gastrostomia de acordo com a marca de sonda (grupo de estudo) em uso pelos pacientes. 


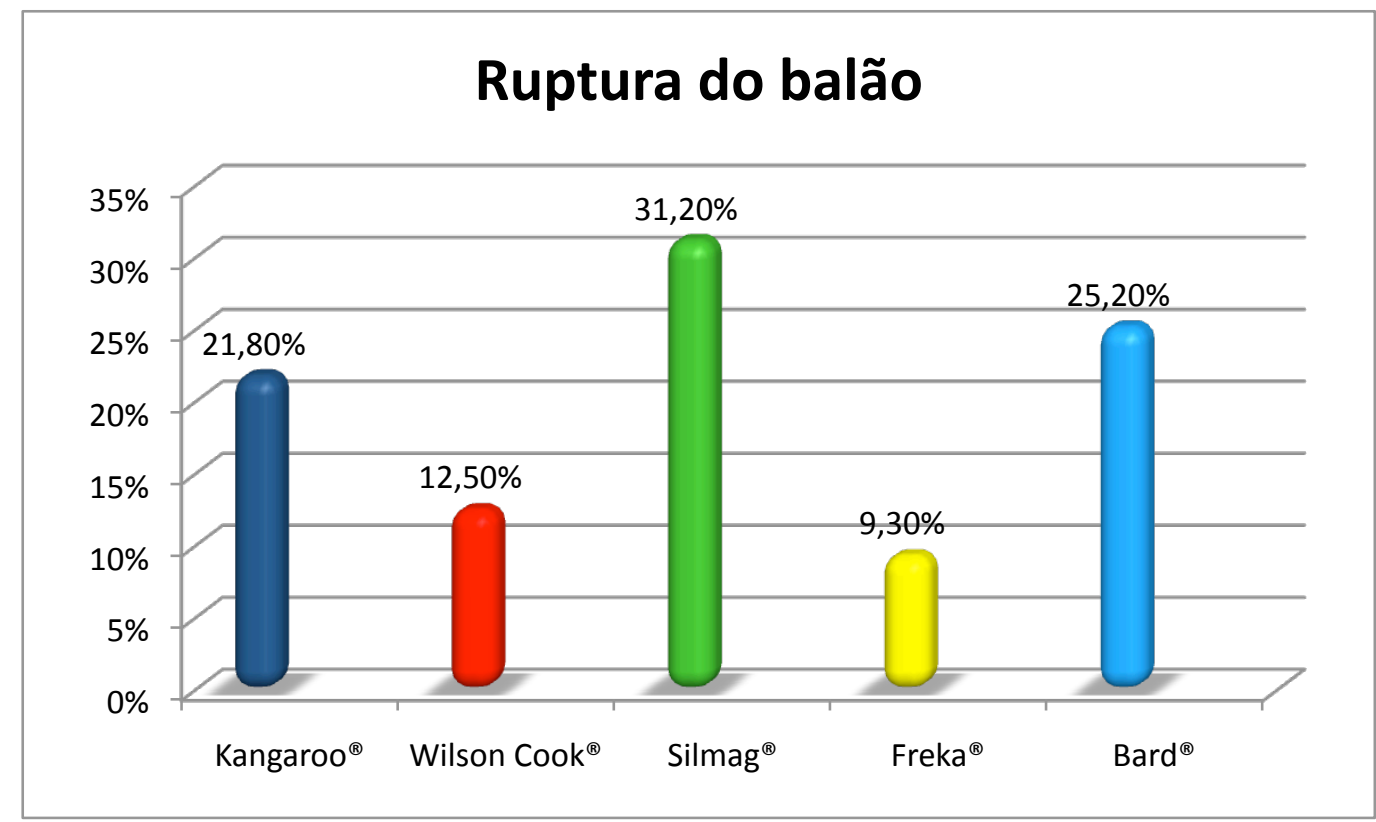

Figura 13. Ilustração gráfica da distribuição das frequências relativas de ruptura do balão na sonda de troca de gastrostomia de acordo com a marca de sonda (grupo de estudo) em uso pelos pacientes.

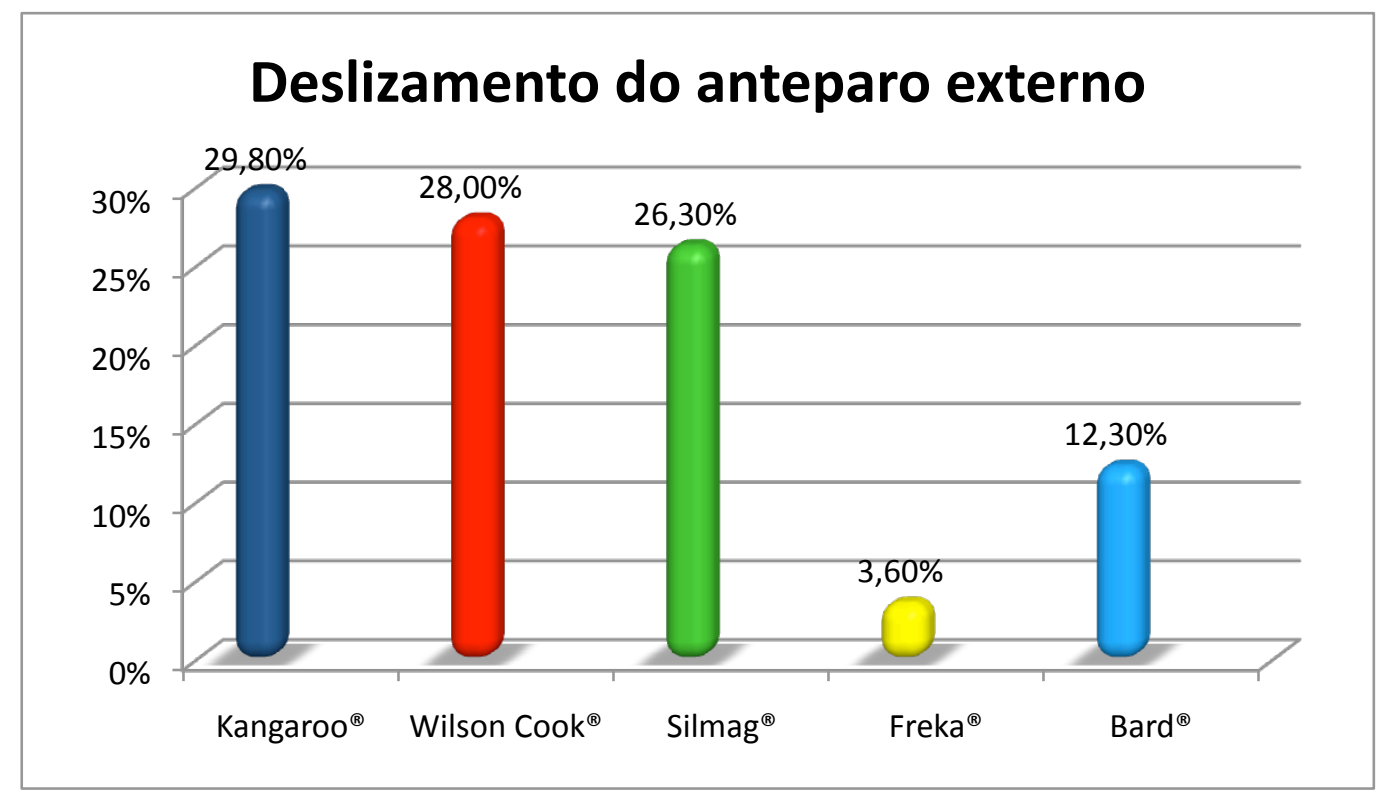

Figura 14. Ilustração gráfica da distribuição das frequências relativas de deslizamento do anteparo externo na sonda de troca de gastrostomia de acordo com a marca de sonda (grupo de estudo) em uso pelos pacientes. 


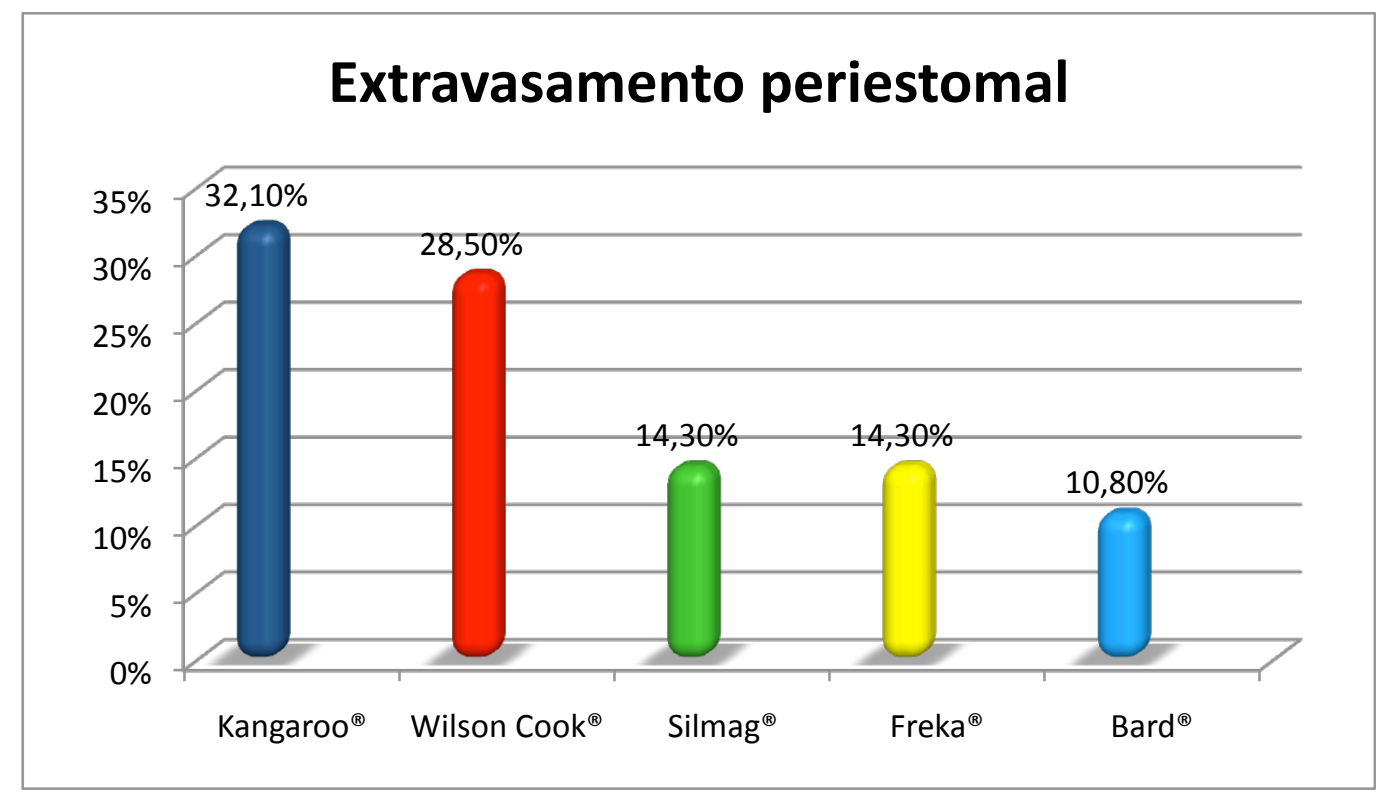

Figura 15. Ilustração gráfica da distribuição das frequências relativas de extravasamento periestomal na sonda de troca de gastrostomia de acordo com a marca de sonda (grupo de estudo) em uso pelos pacientes.

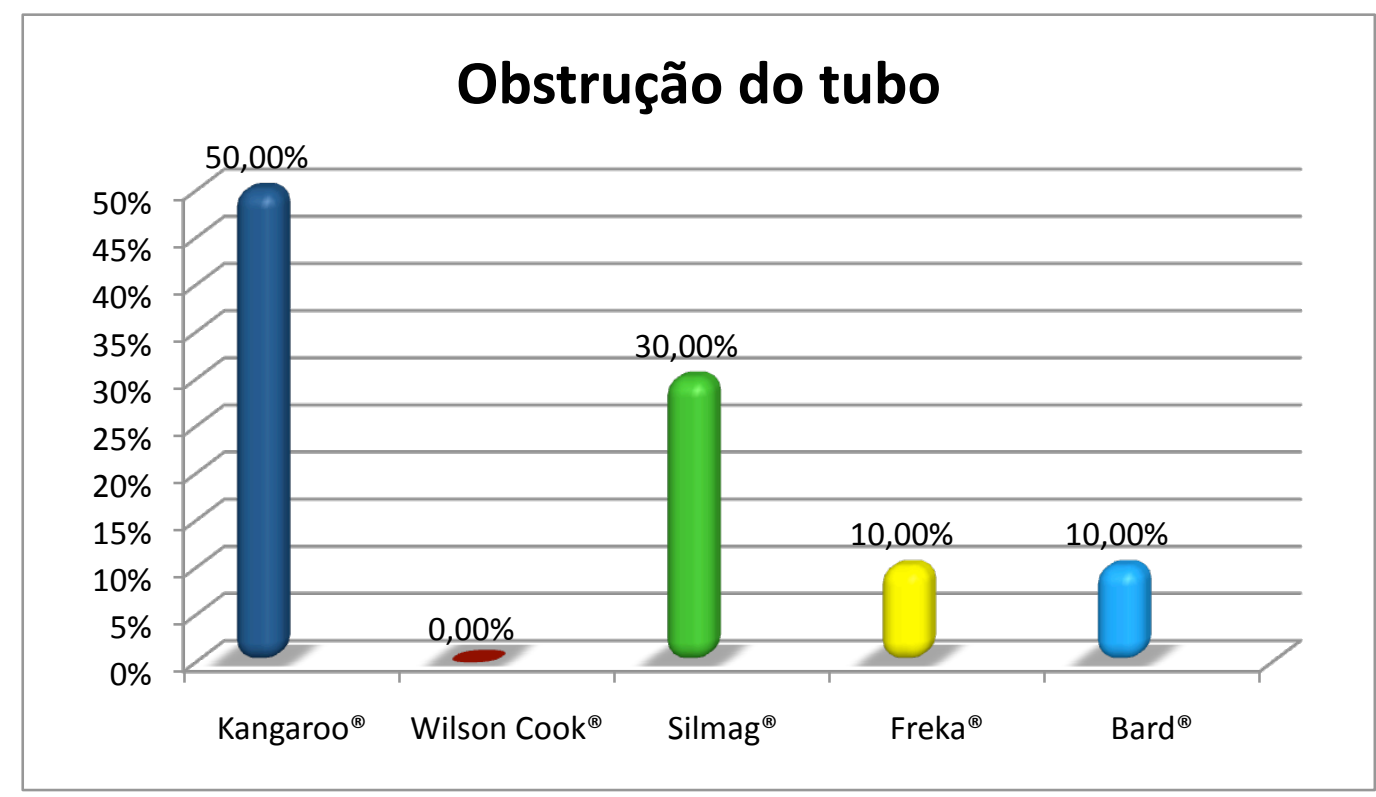

Figura 16. Ilustração gráfica da distribuição das frequências relativas de obstrução do tubo na sonda de troca de gastrostomia de acordo com a marca de sonda (grupo de estudo) em uso pelos pacientes. 
Abertura espontânea da tampa, deslizamento do anteparo externo, extravasamento periestomal e obstrução do tubo foram mais frequentes no grupo de pacientes em uso da sonda Kangaroo ${ }^{\circledR}$, merecendo destaque o fato de $50 \%$ dos casos de abertura espontânea da tampa e de obstrução do tubo terem sido observados nos pacientes em uso dessa marca de sonda. Por outro lado, o desgaste da tampa foi observado em $4 \%$ dos pacientes em uso dessa marca de sonda, enquanto essa intercorrência ocorreu em frequência maior nas demais marcas (de 19\% a $27 \%$ ).

Desgaste do tubo $(42,0 \%)$ e ruptura do balão $(31,2 \%)$ foram intercorrências mais frequentemente observadas nos pacientes em uso da sonda da marca Silmag®.

Não foram observadas intercorrências com os tubos das sondas (desgaste nem obstrução) da marca Wilson Cook $^{\circledR}$, assim como não foi observado nenhum caso de abertura espontânea da tampa nas sondas da marca Freka ${ }^{\circledR}$.

Dos 57 casos de deslizamento do anteparo externo, em 38 houve resolução após a sua fixação, conforme demonstrado na Tabela 3. Embora a menor frequência dessa intercorrência tenha sido observada no grupo de pacientes em uso da sonda da marca Freka ${ }^{\circledR}$, a fixação do anteparo não foi possível devido ao design do produto.

De toda forma, a análise comparativa da distribuição dessas frequências evidenciou diferenças entre as marcas das sondas estudadas apenas no que se refere à abertura espontânea da tampa e ao deslizamento do anteparo externo, intercorrências que foram significativamente menos frequentes 
nas sondas da marca Freka ${ }^{\circledR}$, conforme valores calculados do Qui-quadrado e respectivos valores de $p$ apresentados na Tabela 4.

Tabela 3. Ocorrências de deslizamento do anteparo externo da sonda e de resoluções após fixação nos cinco grupos de estudo.

\begin{tabular}{lccl}
\hline Marca da sonda & $\begin{array}{c}\text { Número de } \\
\text { ocorrências } \\
(\% \text { no grupo) }\end{array}$ & $\begin{array}{c}\text { Número de } \\
\text { resoluções } \\
\text { após fixação }\end{array} \quad$ Observações \\
\hline Kangaroo $^{\circledR}$ & $17(85,0 \%)$ & $15(88,2 \%)$ & \\
Wilson Cook $^{\circledR}$ & $16(80,0 \%)$ & $11(68,7 \%)$ & \\
Silmag $^{\circledR}$ & $15(75,0 \%)$ & $9(60 \%)$ & \\
Freka $^{\circledR}$ & $2(10,0 \%)$ & 0 & Fixação não possível. \\
Bard $^{\circledR}$ & $7(35,0 \%)$ & $5(71,4 \%)$ & \\
\hline
\end{tabular}

Tabela 4. Valores calculados do Qui-quadrado $\left(X^{2}\right)$ e respectivos valores de $p$ na análise comparativa das marcas de sondas no que se refere à distribuição das intercorrências.

\begin{tabular}{lcc}
\hline Intercorrências & $\begin{array}{c}\text { Valor calculado } \\
\text { do X } \mathrm{X}^{2}(\mathrm{gl}=4)\end{array}$ & Valor de $p$ \\
\hline Desgaste do tubo & 3,713 & 0,446 \\
Desgaste da tampa & 4,768 & 0,311 \\
Abertura espontânea da tampa & 20,570 & $<\mathbf{0 , 0 0 1}$ \\
Ruptura do balão & 5,178 & 0,268 \\
Deslizamento do anteparo externo & 15,190 & $\mathbf{0 , 0 0 4}$ \\
Extravasamento periestomal & 5,883 & 0,208 \\
Obstrução do tubo & 8,000 & 0,091 \\
\hline
\end{tabular}

O desgaste do tubo foi determinante da durabilidade da sonda em três dos sete casos em que foi observado $(57,1 \%)$. O desgaste da tampa da sonda determinou a sua durabilidade em três dos 26 casos em que essa 
intercorrência foi registrada (11,5\%). A ruptura do balão, por sua vez, determinou a durabilidade das sondas em todos os 32 casos em que foi observada $(100,0 \%)$.

É importante ressaltar que essas intercorrências foram observadas, muitas vezes, em um mesmo paciente (Figura 17). Assim, em 14 casos (14,0\%), não foi observada qualquer intercorrência com o uso da sonda. Duas ou mais intercorrências associadas foram observadas em $61 \%$ dos casos.

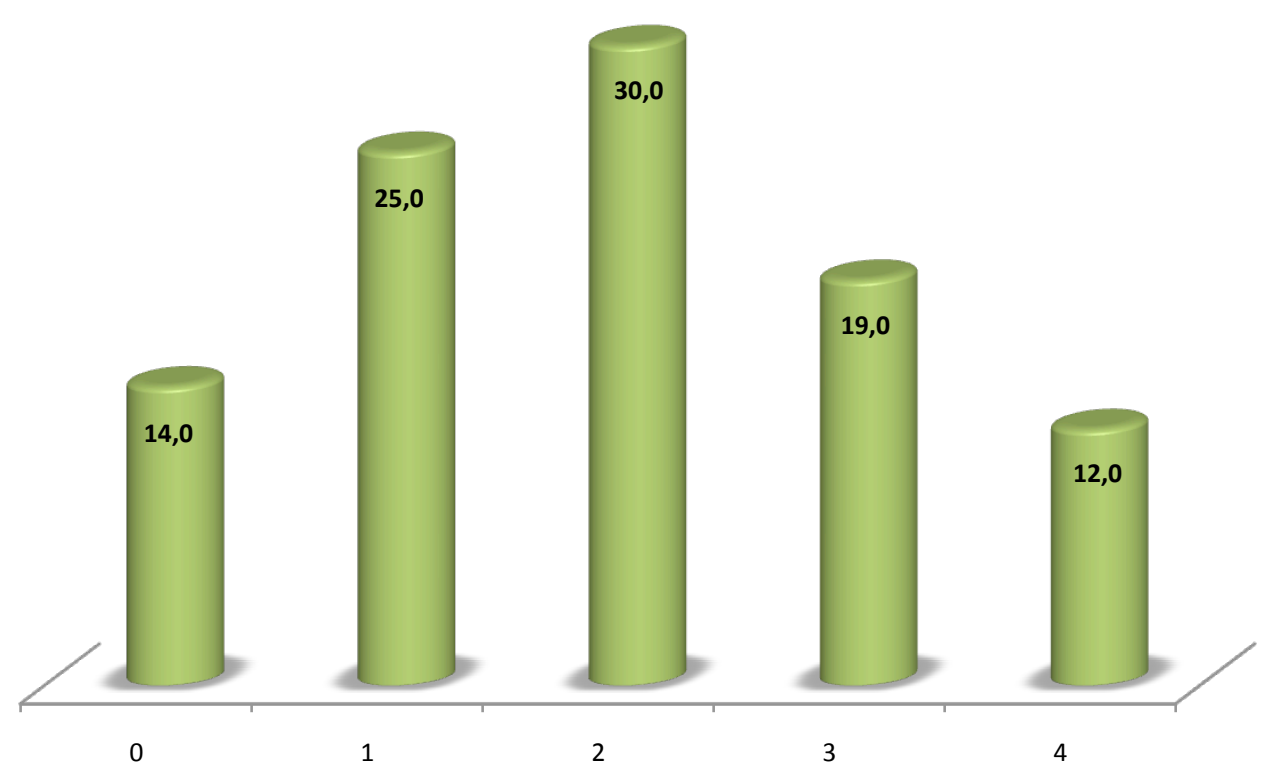

Figura 17. Representação gráfica da distribuição percentual dos pacientes de acordo com a quantidade de intercorrências observadas na sonda de troca de gastrostomia.

Dos 14 casos em que não foram observadas quaisquer intercorrências com o uso da sonda de troca de gastrostomia, sete $(50 \%)$ se referiam ao grupo de pacientes em uso da sonda Freka ${ }^{\circledR}$, com a qual foi observada uma 
única intercorrência em $40 \%$ dos casos. A sonda da marca Silmag® foi a que apresentou a maior frequência de duas ou três intercorrências associadas. Quatro intercorrências associadas foram observadas mais frequentemente nos pacientes em uso das sondas das marcas Kangaroo® e Wilson Cook® (Tabela 5).

Tabela 5. Distribuição das frequências absolutas e percentuais de intercorrências observadas nos pacientes em uso das sondas das diferentes marcas.

\begin{tabular}{lccccc}
\hline $\begin{array}{l}\text { Número de } \\
\text { intercorrências no } \\
\text { mesmo paciente }\end{array}$ & Kangaroo $^{\circledR}$ & Wilson Cook $^{\circledR}$ & Silmag $^{\circledR}$ & Freka $^{\circledR}$ & Bard $^{\circledR}$ \\
\hline 0 & - & $3 / 15 \%$ & - & $7 / 35 \%$ & $4 / 20 \%$ \\
1 & $3 / 15 \%$ & $3 / 15 \%$ & $4 / 20 \%$ & $8 / 40 \%$ & $7 / 35 \%$ \\
2 & $3 / 15 \%$ & $8 / 40 \%$ & $9 / 45 \%$ & $5 / 25 \%$ & $5 / 25 \%$ \\
3 & $9 / 45 \%$ & $2 / 10 \%$ & $6 / 30 \%$ & - & $2 / 10 \%$ \\
4 & $4 / 20 \%$ & $4 / 20 \%$ & $1 / 5 \%$ & - & $2 / 10 \%$ \\
\hline Totais & $20 / 100 \%$ & $20 / 100 \%$ & $20 / 100 \%$ & $20 / 100 \%$ & $20 / 100 \%$ \\
\hline
\end{tabular}

É importante lembrar que 26 pacientes fizeram parte de dois ou mais grupos de estudo. Em 50\% desses casos, a exclusão do paciente do grupo inicial de estudo foi determinada pelo término do prazo de seis meses proposto pelo protocolo de estudo. Esse motivo também foi o determinante do término do acompanhamento de cinco desses mesmos 13 pacientes $(38,5 \%)$ dos grupos subsequentes.

$\mathrm{Na}$ Tabela 6 estão apresentados os motivos que levaram à exclusão desses 26 pacientes dos grupos de estudo em que foram incluídos. Ressal- 
te-se que três pacientes $(11,5 \%)$ foram excluídos dos dois ou três grupos de estudo de que tomaram parte sempre em decorrência da ruptura do balão da gastrostomia, e dois outros pacientes foram excluídos de dois/três dos três/quatro grupos de estudo em que tomaram parte pelo mesmo motivo, o que levanta a questão sobre tais intercorrências estarem de fato associadas com as marcas das sondas de troca analisadas.

Tabela 6. Apresentação dos 26 pacientes que foram incluídos em dois ou mais grupos de estudo e os motivos de sua exclusão dos grupos de que participaram.

\begin{tabular}{|c|c|c|c|c|c|}
\hline & Kangaroo $^{\circledR}$ & Wilson Cook ${ }^{\circledR}$ & Silmag $^{\circledR}$ & Freka $^{\circledR}$ & Bard $^{\circledR}$ \\
\hline caso & motivo & motivo & motivo & motivo & motivo \\
\hline 1 & 1 & & 2 & & 1 \\
\hline 2 & 2 & 1 & & & \\
\hline 3 & 2 & 2 & 2 & 1 & \\
\hline 4 & 2 & & 2 & & \\
\hline 5 & 1 & & 1 & & 3 \\
\hline 6 & 1 & & 3 & & \\
\hline 7 & 1 & & & 1 & \\
\hline 8 & 2 & & 2 & 2 & \\
\hline 9 & 1 & & & 1 & \\
\hline 10 & 3 & & 2 & & \\
\hline 11 & 1 & & & 1 & \\
\hline 12 & 6 & & 1 & & 2 \\
\hline 13 & 2 & 2 & 2 & & \\
\hline 14 & 1 & & & & 2 \\
\hline 15 & & 1 & & 1 & \\
\hline 16 & & 2 & 7 & & 1 \\
\hline 17 & & 1 & & & 4 \\
\hline 18 & & 2 & & 1 & 2 \\
\hline 19 & & & 2 & & 1 \\
\hline 20 & & & 1 & & 2 \\
\hline 21 & & & 2 & & 1 \\
\hline 22 & & & 7 & & 1 \\
\hline 23 & & & 1 & & 6 \\
\hline 24 & & & & 1 & 1 \\
\hline 25 & & & & 1 & 2 \\
\hline 26 & & & & 3 & 6 \\
\hline
\end{tabular}


Na análise das variáveis que pudessem explicar a razão de esses cinco pacientes terem apresentado ruptura do balão da sonda em uso duas ou mais vezes nos diferentes grupos de estudo de que tomaram parte, nenhuma associação foi estabelecida com o gênero $\left(X^{2}=0,468 ; p=0,493\right)$ ou com a média de idade dos pacientes $(p=0,698)$. O tempo médio de uso da GEP $(p=0,698)$ e o número de trocas anteriormente realizadas $\left(X^{2}=2,15 ; p=\right.$ 0,113 ) tampouco puderam ser associados a essa múltipla ocorrência de ruptura do balão. Por outro lado, ao considerar as indicações para uso da gastrostomia, a frequência de múltiplas rupturas do balão foi significativamente maior dentre os pacientes com indicação do uso de gastrostomia por "distúrbios neurológicos sem diagnóstico" $\left(X^{2}=5,610 ; p=0,017\right)$. Neste grupo de quatro pacientes com essa indicação, 50,0\% apresentaram múltiplas rupturas, enquanto nos demais pacientes esta proporção foi significativamente menor $(4,9 \%)$, o que pode estar alertando para o fato de a ruptura do balão, nesta amostra, poder estar associada mais à condição de base dos pacientes do que à marca da sonda utilizada.

De fato, cinco das 32 ocorrências de ruptura do balão $(15,6 \%)$ ocorreram em apenas dois pacientes com essa indicação para uso de gastrostomia. Analisados de outro modo, dos cinco pacientes com essa condição de base, três $(60,0 \%)$ apresentaram ruptura do balão uma ou mais vezes, e em todas essas vezes a intercorrência foi determinante da exclusão do paciente do grupo de estudo. 


\subsection{Análises de durabilidade das sondas de troca de gastrostomia}

\subsubsection{Desfecho 1: Interrupção do uso da sonda por ruptura do balão, desgaste do tubo elou desgaste da tampa}

De acordo com as estimativas das médias de durabilidade das sondas analisadas, calculadas com a aplicação do método de Kaplan Meier (Tabela 7), observou-se durabilidade maior das sondas Wilson Cook ${ }^{\circledR}$, seguidas das sondas Freka ${ }^{\circledR}$, Kangaroo $^{\circledR}$, Silmag $^{\circledR}$ e Bard $^{\circledR}$.

Tabela 7. Estimativas dos tempos médios (em dias) da durabilidade das sondas de troca de gastrostomia considerando problemas ocorridos em balões, tubos e tampas.

\begin{tabular}{|c|c|c|c|}
\hline \multirow{2}{*}{$\begin{array}{l}\text { Marcas das } \\
\text { sondas }\end{array}$} & \multicolumn{3}{|c|}{ Médias } \\
\hline & Estimativa & Erro-padrão & IC (95\%) \\
\hline Kangaroo $^{\circledR}$ & 139,4 & 13,0 & $113,9-164,9$ \\
\hline Wilson Cook ${ }^{\circledR}$ & 157,7 & 10,3 & $137,5-177,9$ \\
\hline Silmag $^{\circledR}$ & 132,4 & 12,3 & $108,4-156,6$ \\
\hline Freka $^{\circledR}$ & 154,8 & 10,2 & $134,8-174,9$ \\
\hline Bard $^{\circledR}$ & 122,9 & 14,1 & $95,3-150,6$ \\
\hline Geral & 141,8 & 5,6 & $130,9-152,7$ \\
\hline
\end{tabular}

A análise das curvas de durabilidade das sondas dessas diferentes marcas evidenciou que a estimativa da função da durabilidade das sondas Bard $^{\circledR}$ foi maior do que a das sondas Silmag ${ }^{\circledR}$ (Tabela 8), fato que pode ser mais bem compreendido na Figura 18, na qual se observa que, a partir do tempo 
$100(t=100)$, uma série de ocorrências relacionadas aos motivos aqui analisados para interrupção do uso da sonda foi mais frequente nas sondas Sil$\operatorname{mag}^{\circledR}$ do que nas sondas Bard $^{\circledR}$.

As curvas de durabilidade das sondas Silmag $^{\circledR}$ e Bard $^{\circledR}$ não apenas mostraram comportamento distinto das sondas Kangaroo ${ }^{\circledR}$, Wilson Cook ${ }^{\circledR}$, Freka $^{\circledR}$, como também evidenciaram indícios de sobreposição (Figura 18).

No entanto, análise de Log Rank revelou que não houve diferença significativa na durabilidade da sonda quando comparadas as cinco diferentes marcas analisadas $\left(X^{2}=1,305 ; g l=1 ; p=0,253\right)$.

Tabela 8. Estimativas da função de durabilidade das sondas de troca de gastrostomia considerando problemas ocorridos em balões, tubos e tampas.

\begin{tabular}{lcc}
\hline \multirow{2}{*}{ Marcas das } & \multicolumn{2}{c}{ Médias } \\
\cline { 2 - 3 } sondas & Estimativa & Erro-padrão \\
\hline Kangaroo $^{\circledR}$ & 0,576 & 0,115 \\
Wilson Cook $^{\circledR}$ & 0,794 & 0,092 \\
Silmag $^{\circledR}$ & 0,396 & 0,118 \\
Freka $^{\circledR}$ & 0,653 & 0,116 \\
Bard $^{\circledR}$ & 0,418 & 0,120 \\
\hline
\end{tabular}




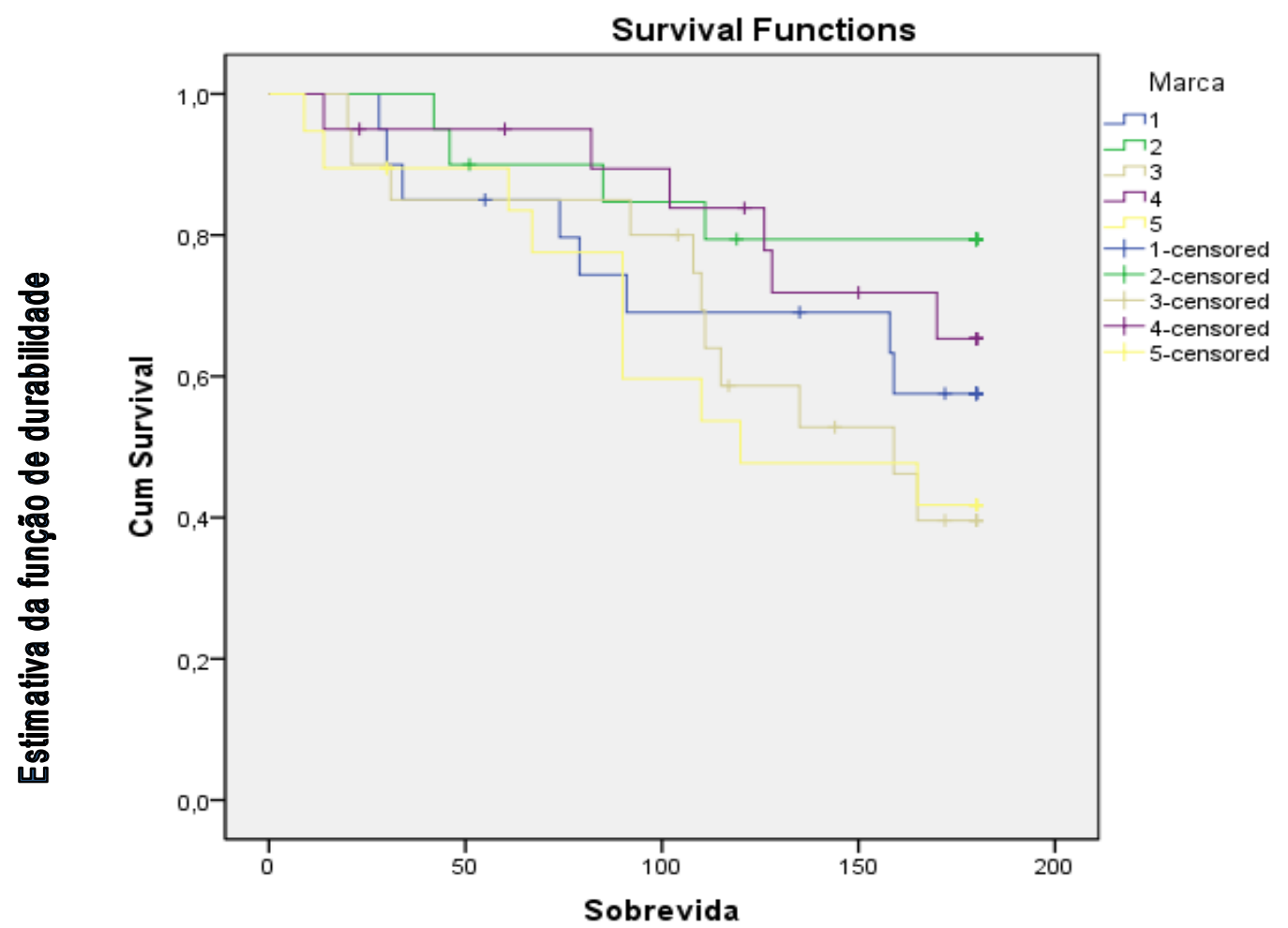

Durabilidade (em dias)

Figura 18. Curvas das estimativas da função de durabilidade das sondas de troca de gastrostomia considerando a interrupção do uso das sondas por ruptura do balão, desgaste do tubo e/ou desgaste da tampa (Método de Kaplan Meier). Marca 1: Kangaroo ${ }^{\circledR}$; marca 2: Wilson Cook $^{\circledR}$; marca 3: Silmag ${ }^{\circledR}$; marca 4: Freka ${ }^{\circledR}$; marca 5: $\operatorname{Bard}^{\circledR}$;

Considerando fatores que, nesta amostra, poderiam estar interferindo nas estimativas da função de durabilidade das sondas, escolheram-se, aleatoriamente, os dados da sonda Bard $^{\circledR}$ (pela menor durabilidade observada) para a aplicação do modelo de regressão de Cox, cujos resultados permitiram determinar que o número de trocas anteriormente realizadas $(p=0,008)$ se mostrou significativamente associado com menor durabilidade da sonda 
de troca de gastrostomia. O risco de interrupção de uso das sondas foi três vezes maior nos paciente que já haviam realizado cinco ou mais trocas anteriores das sondas.

Observou-se, ainda, forte tendência de o tempo de uso da GEP ( $p=$ 0,064) também estar associado com a durabilidade das sondas (Tabela 9). Quanto maior o tempo de PEG, maior a durabilidade das sondas. Nessa análise, não foram evidenciadas associações da durabilidade das sondas com gênero e idade dos pacientes, nem com as indicações para uso da gastrostomia.

Tabela 9. Resultados da aplicação do modelo de regressão de Cox, tomando-se por referência aleatória os dados registrados para o grupo de pacientes em uso das sondas Bard $^{\circledR}$ (devido à sua menor durabilidade determinada pelo método de Kaplan Meier).

\begin{tabular}{|c|c|c|c|c|c|}
\hline Variáveis & Estimativa & Erro-padrão & Valores de $p$ & Risco & IC (95\%) \\
\hline Tempo de uso da GEP & $-0,020$ & 0,011 & 0,064 & 0,980 & $0,960-1,001$ \\
\hline Número de trocas anteriores & 1,103 & 0,413 & 0,008 & 3,012 & $1,340-6,769$ \\
\hline Kangaroo $^{\circledR}$ & $-0,486$ & 0,477 & 0,308 & 0,615 & $0,242-1,565$ \\
\hline Wilson Cook ${ }^{\circledR}$ & -1.459 & 0,598 & 0,015 & 0,232 & $0,072-0,751$ \\
\hline Silmag $^{\circledR}$ & $-0,024$ & 0,440 & 0,956 & 0,976 & $0,412-2,310$ \\
\hline Freka $^{\circledR}$ & $-0,679$ & 0,519 & 0,191 & 0,507 & $0,183-1.402$ \\
\hline
\end{tabular}

Além disso, o modelo de regressão de Cox revelou que apenas as sondas Wilson Cook $^{\circledR}$ apresentaram durabilidade significativamente maior $(p=$ $0,015)$ quando comparadas às sondas $\operatorname{Bard}^{\circledR}$. 
A aplicação da Prova do Qui-quadrado ratificou as suposições decorrentes da regressão de $\operatorname{Cox}\left(X^{2}=14,486 ; g l=6 ; p=0,025\right)$.

Portanto, conforme representado na Figura 19, de acordo com as estimativas de durabilidade determinadas pelo modelo de regressão de Cox, confirmou-se durabilidade maior das sondas Wilson Cook $^{\circledR}$, seguidas das

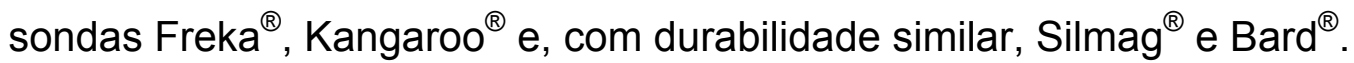

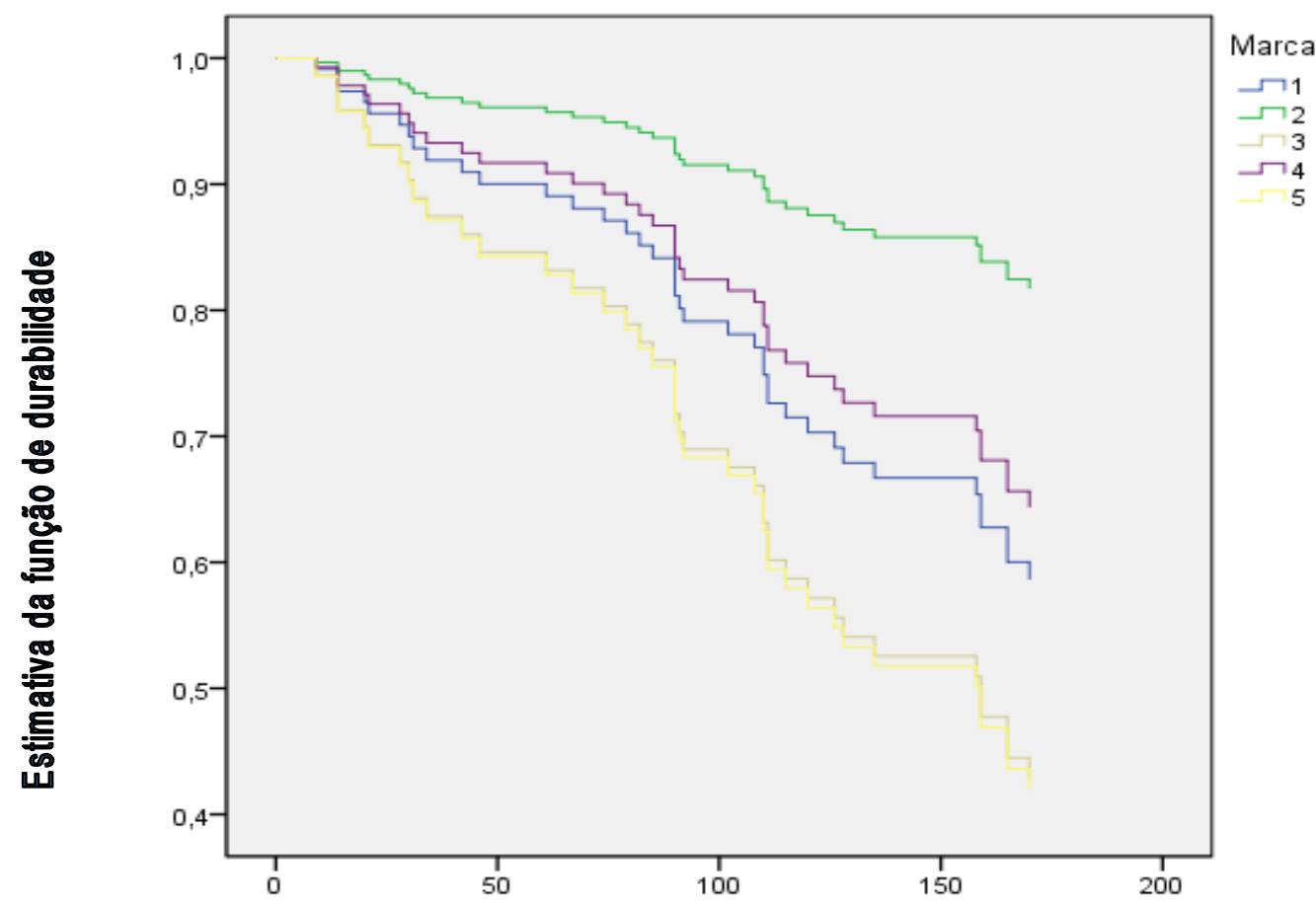

Durabilidade (em dias)

Figura 19. Curvas das estimativas da função de durabilidade das sondas de troca de gastrostomia considerando a interrupção do uso das sondas por ruptura do balão, desgaste do tubo e/ou desgaste da tampa (Modelo de regressão de Cox). Marca 1: Kangaroo ${ }^{\circledR}$; marca 2: Wilson Cook $^{\circledR}$; marca 3: Silmag ${ }^{\circledR}$; marca 4: Freka $^{\circledR}$; marca 5: $\operatorname{Bard}^{\circledR}$. 
Em seguida, foi realizada a aplicação do modelo de regressão de Cox, tomando-se como referência os dados registrados para o grupo de pacientes em uso de cada uma das demais sondas (Tabelas 10, 11, 12 e 13). Essas análises revelaram que as sondas Wilson Cook $^{\circledR}$ também apresentaram durabilidade significativamente maior $(p=0,016)$ quando comparadas às sondas Silmag ${ }^{\circledR}$ (Tabela 12), e que as demais sondas não apresentaram durabilidade significativamente diferentes entre si.

Tabela 10. Resultados da aplicação do modelo de regressão de Cox, tomando-se por referência os dados registrados para o grupo de pacientes em uso das sondas Kangaroo ${ }^{\circledR}$.

\begin{tabular}{lccccc}
\hline Variáveis & Estimativa & Erro-padrão & Valores de $\mathrm{p}$ & Risco & IC (95\%) \\
\hline Tempo de uso da GEP & $-0,020$ & 0,011 & 0,065 & 0,980 & $0,960-1,001$ \\
\hline Número de trocas anteriores & 1,097 & 0,413 & $\mathbf{0 , 0 0 8}$ & 2,996 & $1,333-6,734$ \\
Wilson Cook $^{\circledR}$ & $-0,972$ & 0,615 & 0,114 & 0,378 & $0,113-1,262$ \\
\hline Silmag $^{\circledR}$ & 0,461 & 0,469 & 0,326 & 1,586 & $0,632-3,979$ \\
Freka $^{\circledR}$ & $-0,194$ & 0,546 & 0,723 & 0,824 & $0,283-2,403$ \\
\hline Bard $^{\circledR}$ & 0,494 & 0,476 & 0,299 & 1,639 & $0,644-4,171$ \\
\hline
\end{tabular}

Tabela 11. Resultados da aplicação do modelo de regressão de Cox, tomando-se por referência os dados registrados para o grupo de pacientes em uso das sondas Wilson Cook ${ }^{\circledR}$.

\begin{tabular}{lccccc}
\hline Variáveis & Estimativa & Erro-padrão & Valores de $\mathrm{p}$ & Risco & IC (95\%) \\
\hline Tempo de uso da GEP & $-0,020$ & 0,011 & 0,065 & 0,980 & $0,960-1,001$ \\
\hline Número de trocas anteriores & 1,095 & 0,414 & $\mathbf{0 , 0 0 8}$ & 2,996 & $1,329-6,725$ \\
Kangaroo $^{\circledR}$ & 0,972 & 0,615 & 0,114 & 0,378 & $0,113-1,262$ \\
\hline Bard $^{\circledR}$ & 1,442 & 0,598 & $\mathbf{0 , 0 1 5}$ & 1,586 & $0,632-3,979$ \\
Silmag $^{\circledR}$ & 1,434 & 0,594 & $\mathbf{0 , 0 1 6}$ & 0,824 & $0,283-2,403$ \\
\hline Freka $^{\circledR}$ & 0,778 & 0,658 & 0,237 & 1,639 & $0,644-4,171$ \\
\hline
\end{tabular}


Tabela 12. Resultados da aplicação do modelo de regressão de Cox, tomando-se por referência os dados registrados para o grupo de pacientes em uso das sondas Silmag ${ }^{\circledR}$.

\begin{tabular}{|c|c|c|c|c|c|}
\hline Variáveis & Estimativa & Erro-padrão & Valores de $p$ & Risco & IC (95\%) \\
\hline Tempo de uso da GEP & $-0,020$ & 0,011 & 0,065 & 0,980 & $0,960-1,001$ \\
\hline Número de trocas anteriores & 1,095 & 0,414 & 0,008 & 2,996 & $1,329-6,725$ \\
\hline Kangaroo $^{\circledR}$ & $-0,461$ & 0,469 & 0,326 & 0,630 & $0,251-1,582$ \\
\hline Wilson Cook ${ }^{\circledR}$ & $-1,434$ & 0,594 & 0,016 & 0,238 & $0,074-0,764$ \\
\hline Freka $^{\circledR}$ & $-0,656$ & 0,510 & 0,198 & 0,519 & $0,191-1,410$ \\
\hline Bard $^{\circledR}$ & 0,008 & 0,440 & 0,986 & 1,008 & $0,426-2,386$ \\
\hline
\end{tabular}

Tabela 13. Resultados da aplicação do modelo de regressão de Cox, tomando-se por referência os dados registrados para o grupo de pacientes em uso das sondas Freka ${ }^{\circledR}$.

\begin{tabular}{|c|c|c|c|c|c|}
\hline Variáveis & Estimativa & Erro-padrão & Valores de $p$ & Risco & IC (95\%) \\
\hline Tempo de uso da GEP & $-0,019$ & 0,011 & 0,072 & 0,981 & $0,9601-1,002$ \\
\hline Número de trocas anteriores & 1,049 & 0,414 & 0,011 & 2,855 & $1,269-6,424$ \\
\hline Kangaroo $^{\circledR}$ & 0,204 & 0,546 & 0,708 & 1,227 & $0,421-3,575$ \\
\hline Wilson Cook ${ }^{\circledR}$ & $-0,556$ & 0,618 & 0,368 & 0,574 & $0,171-1,926$ \\
\hline Silmag $^{\circledR}$ & 0,589 & 0,519 & 0,257 & 1,802 & $0,651-4,983$ \\
\hline $\operatorname{Bard}^{\circledR}$ & 0,669 & 0,519 & 0,197 & 1,952 & $0,706-5,397$ \\
\hline
\end{tabular}




\subsubsection{Desfecho 2: Interrupção do uso da sonda por ruptura do balão}

De acordo com as estimativas das médias de durabilidade das sondas analisadas, calculadas com a aplicação do método de Kaplan Meier (Tabela 14), observou-se durabilidade maior das sondas Freka ${ }^{\circledR}$, seguidas das sondas Wilson Cook $^{\circledR}$, Kangaroo $^{\circledR}$, Silmag $^{\circledR}$ e Bard $^{\circledR}$.

Tabela 14. Estimativas dos tempos médios (em dias) da durabilidade das sondas de troca de gastrostomia considerando ruptura dos balões.

\begin{tabular}{lccc}
\hline Marcas das & \multicolumn{3}{c}{ Médias } \\
\cline { 2 - 4 } sondas & Estimativa & Erro-padrão & IC (95\%) \\
\hline Kangaroo $^{\circledR}$ & 140,7 & 13,2 & $114,8-166,4$ \\
Wilson Cook $^{\circledR}$ & 157,7 & 10,3 & $137,5-177,9$ \\
\hline Silmag $^{\circledR}$ & 135,4 & 12,5 & $111,0-159,8$ \\
\hline Freka $^{\circledR}$ & 162,6 & 9,8 & $143,5-181,8$ \\
\hline Bard $^{\circledR}$ & 129,5 & 14,0 & $102,0-157,0$ \\
\hline Geral $^{\circledR}$ & 145,6 & 5,5 & $134,7-156,4$ \\
\hline
\end{tabular}

Como no desfecho anterior, a análise das curvas de durabilidade das sondas dessas diferentes marcas evidenciou que a estimativa da função da durabilidade das sondas Bard $^{\circledR}$ foi maior do que a das sondas Silmag ${ }^{\circledR}$ (Tabela 15). As curvas de durabilidade das sondas Silmag ${ }^{\circledR}$ e Bard $^{\circledR}$ não apenas mostraram comportamento distinto das sondas Kangaroo ${ }^{\circledR}$, Wilson Cook $^{\circledR}$, 
Freka ${ }^{\circledR}$ como também evidenciaram indícios de sobreposição. As curvas de durabilidade da Wilson Cook $^{\circledR}$ e Freka ${ }^{\circledR}$ também evidenciaram indícios de sobreposição (Figura 20).

No entanto, análise de Log Rank revelou que não houve diferença significativa na durabilidade da sonda quando comparadas as cinco diferentes marcas analisadas apenas em função da ruptura dos balões $\left(X^{2}=0,242 ; \mathrm{gl}\right.$ $=1 ; p=0,623)$.

Tabela 15. Estimativas da função de durabilidade das sondas de troca de gastrostomia considerando ruptura dos balões.

\begin{tabular}{|c|c|c|}
\hline \multirow{2}{*}{$\begin{array}{l}\text { Marcas das } \\
\text { sondas }\end{array}$} & \multicolumn{2}{|c|}{ Médias } \\
\hline & Estimativa & Erro-padrão \\
\hline Kangaroo $^{\circledR}$ & 0,633 & 0,111 \\
\hline Wilson Cook ${ }^{\circledR}$ & 0,794 & 0,092 \\
\hline Silmag $^{\circledR}$ & 0,429 & 0,124 \\
\hline Freka $^{\circledR}$ & 0,825 & 0,093 \\
\hline $\operatorname{Bard}^{\circledR}$ & 0,511 & 0,125 \\
\hline
\end{tabular}

A partir dos dados da sonda Bard $^{\circledR}$ (pela menor durabilidade observada), a aplicação do Modelo de regressão de Cox, desta vez, não revelou associações significativas entre as variáveis clínicas (gênero e idade do paciente, indicação para uso da GEP, tempo de uso da GEP e número de trocas anteriores das sondas) e a durabilidade das sondas, nem diferenças significati- 
vas entre as diferentes marcas analisadas em relação às estimativas de durabilidade das sondas em função da ruptura dos balões (Tabela 16).

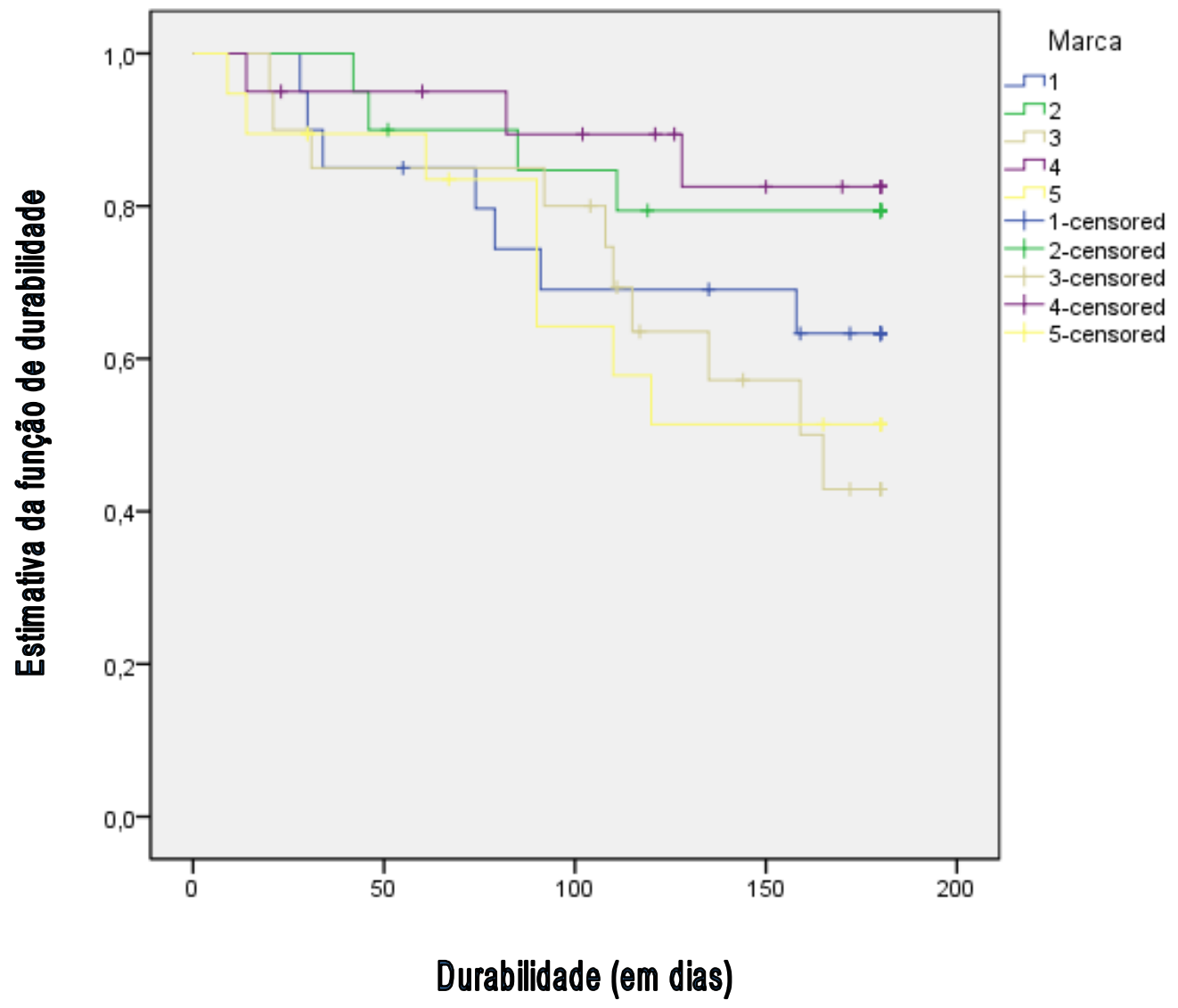

Figura 20. Curvas das estimativas da função de durabilidade das sondas de troca de gastrostomia considerando a interrupção do uso das sondas por ruptura do balão (Método de Kaplan Meier). Marca 1: Kangaroo ${ }^{\circledR}$; marca 2: Wilson Cook $^{\circledR}$; marca 3: Silmag ${ }^{\circledR}$; marca 4: Freka $^{\circledR}$; marca 5: Bard $^{\circledR}$; 
Tabela 16. Resultados da aplicação do modelo de regressão de Cox, tomando-se por referência aleatória os dados registrados para o grupo de pacientes em uso das sondas Bard $^{\circledR}$ (devido à sua menor durabilidade determinada pelo método de Kaplan Meier).

\begin{tabular}{|c|c|c|c|c|c|}
\hline Variáveis & Estimativa & Erro-padrão & Valores de $p$ & Risco & IC $(95 \%)$ \\
\hline Tempo de uso da GEP & $-0,015$ & 0,011 & 0,186 & 0,985 & $0,963-1,007$ \\
\hline Número de trocas anteriores & 0,865 & 0,448 & 0,053 & 2,375 & $0,987-5,714$ \\
\hline Kangaroo $^{\circledR}$ & $-0,373$ & 0,521 & 0,474 & 0,689 & $0,248-1,910$ \\
\hline Wilson Cook ${ }^{\circledR}$ & $-1,163$ & 0,620 & 0,061 & 0,313 & $0,093-1,054$ \\
\hline Silmag $^{\circledR}$ & 0,061 & 0,476 & 0,898 & 1,063 & $0,418-2,704$ \\
\hline Freka $^{\circledR}$ & $-1,165$ & 0,679 & 0,086 & 0,312 & $0,082-1,180$ \\
\hline
\end{tabular}

Todavia, foi evidenciada forte tendência de o número de trocas anteriores ( $p=0,053)$ constituir fator de risco para a interrupção do uso da sonda de gastrostomia em função da ruptura do balão. $O$ risco de interrupção de uso das sondas foi 2,3 vezes maior nos paciente que já haviam realizado mais de cinco trocas anteriores das sondas.

Do mesmo modo, também foi observada forte tendência de as sondas Wilson Cook $^{\circledR}$ e Freka ${ }^{\circledR}$ apresentarem durabilidade maior $(p=0,061$ e $p=$ $0,086)$ quando comparadas às sondas $\operatorname{Bard}^{\circledR}$.

No entanto, a aplicação da Prova do Qui-quadrado revelou que não houve associações significativas entre as variáveis do modelo final e a durabilidade das sondas $\left(X^{2}=14,090 ; g l=6 ; p=0,086\right)$.

Portanto, conforme representado na Figura 21, de acordo com as estimativas de durabilidade determinadas pelo modelo de regressão de Cox, confirmou-se durabilidade maior das sondas Wilson Cook $^{\circledR}$ e Freka ${ }^{\circledR}$ (com durabilidade similar), seguidas das sondas $\operatorname{Kangaroo}^{\circledR}, \operatorname{Bard}^{\circledR}, \operatorname{Silmag}^{\circledR}$. 


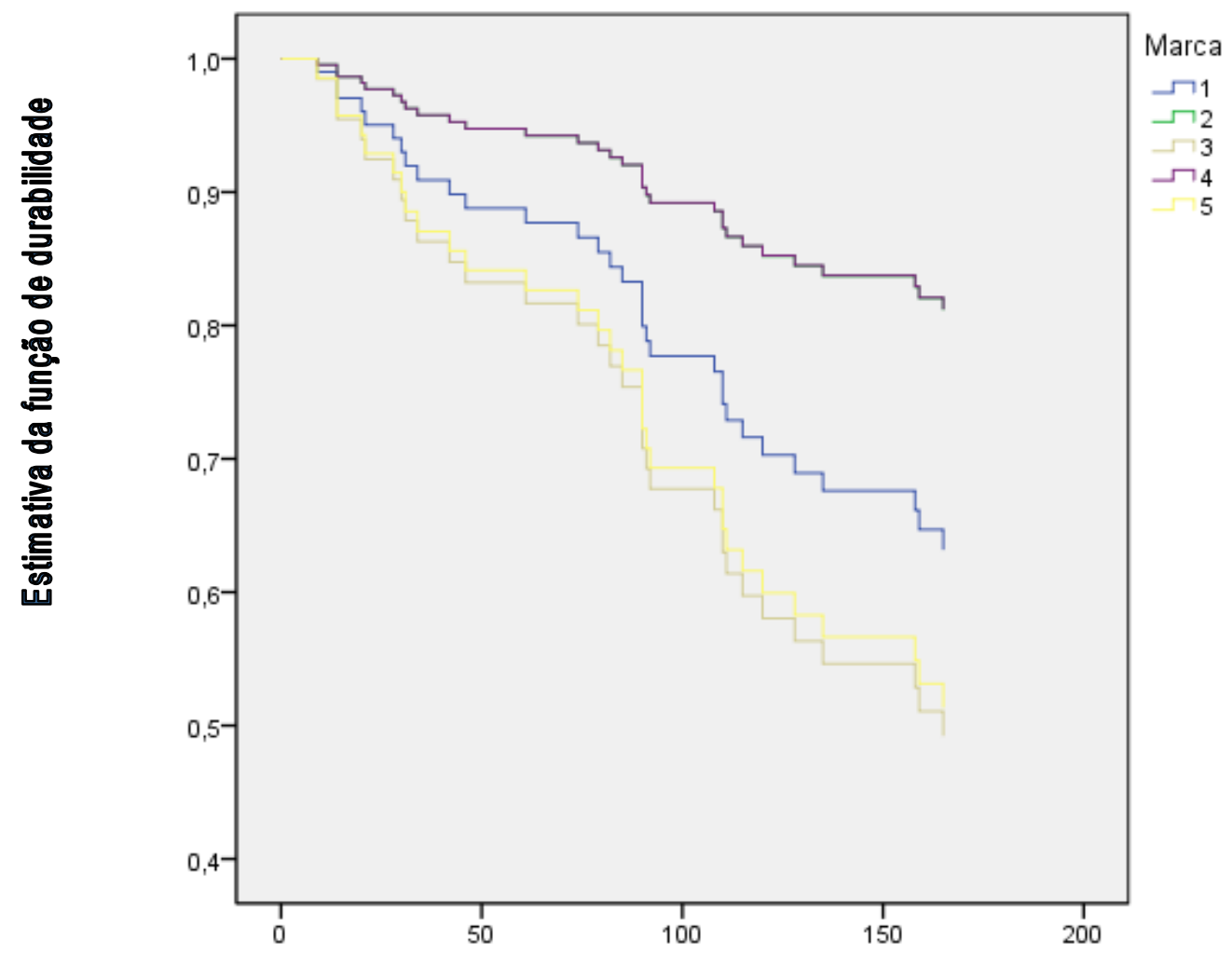

\section{Durabilidade (em dias)}

Figura 21. Curvas das estimativas da função de durabilidade das sondas de troca de gastrostomia considerando a interrupção do uso das sondas por ruptura do baIão (Modelo de regressão de Cox). Marca 1: Kangaroo ${ }^{\circledR}$; marca 2: Wilson Cook $^{\circledR}$; marca 3: Silmag $^{\circledR}$; marca 4: Freka ${ }^{\circledR}$; marca 5: Bard $^{\circledR}$;

Em seguida, foi realizada a aplicação do modelo de regressão de Cox, tomando-se como referência os dados registrados para o grupo de pacientes em uso de cada uma das demais sondas $\left(\right.$ Kangaroo $^{\circledR}$, Wilson Cook ${ }^{\circledR}$, Silmag $^{\circledR}$ e Freka ${ }^{\circledR}$ ). Essa análises não revelaram diferença significativa de durabilidade. 


\subsection{Análises fisicoquímicas das sondas de troca de gastrostomia}

No teste visual, nenhuma das 20 amostras analisadas apresentou descontinuidades, fissuras ou rasgos nem vazamentos.

Os resultados do teste de resistência dos balões em função do padrão nominal da carga volumétrica se encontram na Tabela 17.

Os perímetros médios dos balões vazios de cada modelo de sonda variaram de 17,0 \pm 0,0 mm $\left(\right.$ Freka $^{\circledR}$ ) a 28,9 \pm 0,0 mm (Wilson Cook ${ }^{\circledR}$ ). Os perímetros médios dos balões vazios das amostras das sondas Kangaroo ${ }^{\circledR}$ foram os que apresentaram maior variância $(0,8 \mathrm{~mm})$.

Os perímetros médios dos balões cheios de cada modelo de sonda variaram de $83,5 \pm 14,3 \mathrm{~mm}\left(\right.$ Freka $\left.^{\circledR}\right)$ a 106,15 $\pm 1,0 \mathrm{~mm}\left(\right.$ Wilson Cook $\left.^{\circledR}\right)$. O perímetro médio dos balões cheios das amostras das sondas Freka ${ }^{\circledR}$ foram os que apresentaram maior variância (14,3 mm).

As porcentagens médias de expansão de cada modelo de sonda variaram de $357 \pm 0,5 \%\left(\right.$ Silmag $\left.^{\circledR}\right)$ a $492 \pm 0,8 \%\left(\right.$ Freka $\left.^{\circledR}\right)$. As médias dessas medidas se encontram ilustradas na Figura 22.

Não foram observados vazamentos em nenhuma das amostras analisadas. Todas as amostras dos modelos Wilson Cook $^{\circledR}$ e Freka ${ }^{\circledR}$ apresentaram insuflação homogênea, que não foi observada em nenhuma das amostras dos modelos Kangaroo ${ }^{\circledR}$ e Bard $^{\circledR}$. Das quatro amostras do modelo Silmag ${ }^{\circledR}$, duas apresentaram insuflação homogênea. 
Tabela 17. Resultados do teste de resistência dos balões em função do padrão nominal da carga volumétrica.

\begin{tabular}{|c|c|c|c|c|c|c|}
\hline \multirow{2}{*}{ Modelo } & \multirow{2}{*}{ Amostra } & \multicolumn{2}{|c|}{ Perímetros (mm) } & \multirow[b]{2}{*}{$\begin{array}{l}\text { Porcentagem } \\
\text { de expansão }\end{array}$} & \multirow{2}{*}{ Vazamentos } & \multirow[b]{2}{*}{$\begin{array}{l}\text { Insuflação } \\
\text { homogênea }\end{array}$} \\
\hline & & $\begin{array}{l}\text { Balão } \\
\text { vazio }\end{array}$ & $\begin{array}{l}\text { Balão } \\
\text { cheio }\end{array}$ & & & \\
\hline \multirow{6}{*}{ Kangaroo $^{\circledR}$} & 1 & 24,2 & 99,2 & $410 \%$ & Não & Não \\
\hline & 2 & 23,6 & 96,6 & $410 \%$ & Não & Não \\
\hline & 3 & 23,9 & 100,9 & $422 \%$ & Não & Não \\
\hline & 4 & 22,3 & 92,3 & $414 \%$ & Não & Não \\
\hline & Média & 23,5 & 97,3 & $414 \%$ & & \\
\hline & vio-padrão & 0,8 & 3,7 & 0,1 & & \\
\hline \multirow{6}{*}{$\begin{array}{l}\text { Wilson } \\
\text { Cook }^{\circledR}\end{array}$} & 1 & 28,9 & 106,9 & $370 \%$ & Não & Sim \\
\hline & 2 & 28,9 & 105,9 & $366 \%$ & Não & Sim \\
\hline & 3 & 28,9 & 106,9 & $370 \%$ & Não & Sim \\
\hline & & 28,9 & 104,9 & $363 \%$ & Não & Sim \\
\hline & Média & 28,9 & 106,2 & $367 \%$ & & \\
\hline & vio-padrão & 0,0 & 1,0 & 0,0 & & \\
\hline \multirow{6}{*}{ Silmag ${ }^{\circledR}$} & 1 & 23,2 & 74,2 & $319 \%$ & Não & Sim \\
\hline & 2 & 24,2 & 98,2 & $406 \%$ & Não & Não \\
\hline & 3 & 24,5 & 74,5 & $304 \%$ & Não & Sim \\
\hline & 4 & 24,5 & 97,5 & $398 \%$ & Não & Não \\
\hline & Média & 24,1 & 86,1 & $357 \%$ & & \\
\hline & vio-padrão & 0,6 & 13,6 & 0,5 & & \\
\hline \multirow{5}{*}{ Freka $^{\circledR}$} & 1 & 17,0 & 76,0 & $448 \%$ & Não & Sim \\
\hline & 2 & 17,0 & 77,0 & $454 \%$ & Não & Sim \\
\hline & 3 & 17,0 & 76,0 & $448 \%$ & Não & Sim \\
\hline & 4 & 17,0 & 105,0 & $619 \%$ & Não & Sim \\
\hline & $\begin{array}{r}\text { Média } \\
\text { gio-padrão }\end{array}$ & $\begin{array}{c}17,0 \\
0,0\end{array}$ & $\begin{array}{l}83,5 \\
14,3 \\
\end{array}$ & $\begin{array}{c}492 \% \\
0,8\end{array}$ & & \\
\hline \multirow{6}{*}{$\operatorname{Bard}^{\circledR}$} & 1 & 25,4 & 104,4 & $410 \%$ & Não & Não \\
\hline & 2 & 25,1 & 105,1 & $418 \%$ & Não & Não \\
\hline & 3 & 25,8 & 105,8 & $411 \%$ & Não & Não \\
\hline & 4 & 26,1 & 107,1 & $411 \%$ & Não & Não \\
\hline & Média & 25,6 & 105,6 & $413 \%$ & & \\
\hline & fio-padrão & 0,4 & 1,2 & 0,0 & & \\
\hline
\end{tabular}



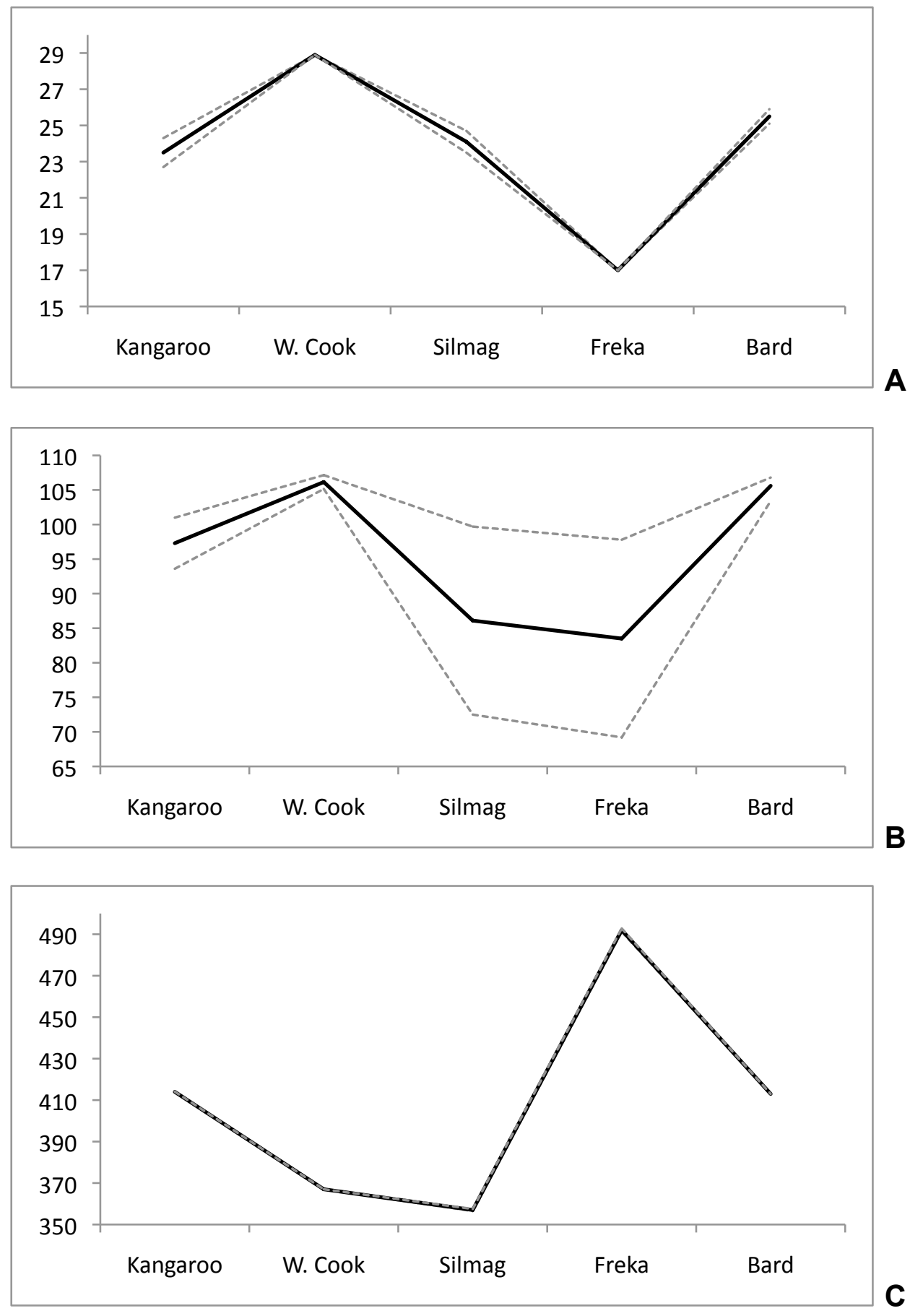

Figura 22. Médias (linha contínua) e desvios-padrão (linhas pontilhadas) dos perímetros dos balões vazios (A) e cheios (B) e das porcentagens de expansão dos balões $(C)$ das quatro amostras de cada modelo de sondas analisadas. 
Os resultados do teste de resistência dos balões em função do diferencial extranominal da carga volumétrica se encontram nas Tabelas 18 e 19.

Os perímetros médios iniciais de cada modelo de sonda variaram de $82,1 \pm 13,4 \mathrm{~mm}\left(\right.$ Silmag $\left.^{\circledR}\right)$ a 106,2 $\pm 1,2 \mathrm{~mm}\left(\right.$ Wilson Cook $\left.{ }^{\circledR}\right)$. O perímetro médio inicial das amostras das sondas Freka ${ }^{\circledR}$ foram os que apresentaram maior variância $(16,7 \mathrm{~mm})$.

Os perímetros médios dos balões cheios de cada modelo de sonda variaram de 111,3 \pm 16,2 $\mathrm{mm}\left(\right.$ Silmag $\left.^{\circledR}\right)$ a 169,0 $\pm 3,6 \mathrm{~mm}\left(\right.$ Bard $\left.^{\oplus}\right)$. O perímetro médio dos balões cheios das amostras das sondas Silmag ${ }^{\circledR}$ foram os que apresentaram maior variância $(16,2 \mathrm{~mm})$. Ressalte-se que, neste teste, deve-se entender por balão cheio a sua expansão máxima antes de romper-se.

As porcentagens médias de expansão de cada modelo de sonda variaram de $131 \pm 3,2 \%\left(\right.$ Kangaroo $\left.^{\oplus}\right)$ a $174,7 \pm 10,3 \%\left(\right.$ Freka $\left.^{\circledR}\right)$. As amostras das sondas Freka ${ }^{\circledR}$ foram as que apresentaram maior variância $(10,3 \%)$.

As médias do volume insuflado variaram de $28,7 \pm 23,7 \mathrm{ml}\left(\right.$ Silmag $\left.^{\circledR}\right)$ a $137,3 \pm 32,3\left(\operatorname{Bard}^{\circledR}\right)$. As amostras da sonda Bard ${ }^{\circledR}$ foram as que mostraram maior variância em mililitros $(32,3 \mathrm{ml})$ e as da sonda Freka ${ }^{\circledR}$ em porcentagem $(10,3 \%)$

As médias dessas medidas se encontram ilustradas na Figura 23.

Não foram observados vazamentos em nenhuma das amostras analisadas. Todas as amostras dos modelos Wilson Cook $^{\circledR}$ e Freka ${ }^{\circledR}$ apresentaram insuflação homogênea, que não foi observada em nenhuma das amostras dos modelos Kangaroo ${ }^{\circledast}$ e Bard $^{\circledR}$. Das três amostras do modelo Silmag ${ }^{\circledR}$, duas apresentaram insuflação homogênea. 
Tabela 18. Resultados das medidas do teste de resistência dos balões em função do diferencial extranominal da carga volumétrica.

\begin{tabular}{|c|c|c|c|c|c|}
\hline \multirow{2}{*}{ Modelo } & \multirow{2}{*}{ Amostra } & \multicolumn{2}{|c|}{ Perímetros $(\mathrm{mm})$} & \multirow[b]{2}{*}{$\begin{array}{l}\text { Porcentagem } \\
\text { de expansão }\end{array}$} & \multirow{2}{*}{$\begin{array}{c}\text { Volume } \\
\text { insuflado } \\
\text { (ml) }\end{array}$} \\
\hline & & Inicial & $\begin{array}{l}\text { Balão } \\
\text { cheio }\end{array}$ & & \\
\hline $\begin{array}{r}\text { Kangaroo }^{\circledR} \\
\text { Des }\end{array}$ & $\begin{array}{c}1 \\
2 \\
3 \\
\text { Média } \\
\text { vio-padrão } \\
\end{array}$ & $\begin{array}{c}99,2 \\
100,9 \\
92,3 \\
\mathbf{9 7 , 5} \\
\mathbf{4 , 6} \\
\end{array}$ & $\begin{array}{c}123 \\
131 \\
130 \\
\mathbf{1 2 8 , 0} \\
\mathbf{4 , 4} \\
\end{array}$ & $\begin{array}{c}129 \\
135 \\
130 \\
\mathbf{1 3 1 , 3} \\
\mathbf{3 , 2} \\
\end{array}$ & $\begin{array}{c}52 \\
52 \\
72 \\
\mathbf{5 8 , 7} \\
\mathbf{1 1 , 5} \\
\end{array}$ \\
\hline $\begin{array}{l}\text { Wilson } \\
\text { Cook }^{\circledR} \\
\\
\end{array}$ & $\begin{array}{c}1 \\
2 \\
3 \\
\text { Média } \\
\text { vio-padrão }\end{array}$ & $\begin{array}{c}106,9 \\
106,9 \\
104,9 \\
\mathbf{1 0 6 , 2} \\
\mathbf{1 , 2}\end{array}$ & $\begin{array}{c}166 \\
155 \\
166 \\
\mathbf{1 6 2 , 3} \\
\mathbf{6 , 4}\end{array}$ & $\begin{array}{c}157 \\
146 \\
160 \\
\mathbf{1 5 4 , 3} \\
\mathbf{7 , 4}\end{array}$ & $\begin{array}{c}82 \\
64 \\
94 \\
\mathbf{8 0 , 0} \\
\mathbf{1 5 , 1}\end{array}$ \\
\hline $\begin{array}{r}\text { Silmag }^{\circledR} \\
\text { Des }\end{array}$ & $\begin{array}{c}1 \\
2 \\
3 \\
\text { Média } \\
\text { vio-padrão }\end{array}$ & $\begin{array}{l}74,2 \\
74,5 \\
97,5 \\
\mathbf{8 2 , 1} \\
\mathbf{1 3 , 4} \\
\end{array}$ & $\begin{array}{c}102 \\
102 \\
130 \\
\mathbf{1 1 1 , 3} \\
\mathbf{1 6 , 2} \\
\end{array}$ & $\begin{array}{c}144 \\
146 \\
140 \\
\mathbf{1 4 3 , 3} \\
\mathbf{3 , 1} \\
\end{array}$ & $\begin{array}{c}15 \\
15 \\
56 \\
\mathbf{2 8 , 7} \\
\mathbf{2 3 , 7} \\
\end{array}$ \\
\hline Freka $^{\circledR}$ & $\begin{array}{c}1 \\
2 \\
3 \\
\text { Média } \\
\text { vio-padrão }\end{array}$ & $\begin{array}{c}76,0 \\
76,0 \\
105,0 \\
\mathbf{8 5 , 7} \\
\mathbf{1 6 , 7}\end{array}$ & $\begin{array}{c}131 \\
126 \\
141 \\
\mathbf{1 3 2 , 7} \\
\mathbf{7 , 6}\end{array}$ & $\begin{array}{c}172 \\
166 \\
186 \\
\mathbf{1 7 4 , 7} \\
\mathbf{1 0 , 3}\end{array}$ & $\begin{array}{c}36 \\
32 \\
52 \\
\mathbf{4 0 , 0} \\
\mathbf{1 0 , 6}\end{array}$ \\
\hline $\operatorname{Bard}^{\circledR}$ & $\begin{array}{c}1 \\
2 \\
3 \\
\text { Média } \\
\text { vio-padrão }\end{array}$ & $\begin{array}{c}104,4 \\
105,1 \\
107,1 \\
\mathbf{1 0 5 , 5} \\
\mathbf{1 , 4}\end{array}$ & $\begin{array}{c}165 \\
172 \\
170 \\
\mathbf{1 6 9 , 0} \\
\mathbf{3 , 6}\end{array}$ & $\begin{array}{c}159 \\
167 \\
162 \\
\mathbf{1 6 2 , 7} \\
\mathbf{4 , 0}\end{array}$ & $\begin{array}{c}108 \\
172 \\
132 \\
\mathbf{1 3 7 , 3} \\
\mathbf{3 2 , 3}\end{array}$ \\
\hline
\end{tabular}

Tabela 19. Resultados das observações do teste de resistência dos balões em função do diferencial extranominal da carga volumétrica.

\begin{tabular}{lcccc}
\hline \multirow{2}{*}{ Modelo } & \multicolumn{2}{c}{ Vazamentos } & \multicolumn{2}{c}{$\begin{array}{c}\text { Insuflação } \\
\text { homogênea }\end{array}$} \\
& Sim & Não & Sim & Não \\
\hline Kangaroo $^{\circledR}$ & 0 & 3 & 0 & 3 \\
Wilson Cook $^{\circledR}$ & 0 & 3 & 3 & 0 \\
Silmag $^{\circledR}$ & 0 & 3 & 2 & 1 \\
Freka $^{\circledR}$ & 0 & 3 & 3 & 0 \\
Bard $^{\circledR}$ & 0 & 3 & 0 & 3 \\
\hline
\end{tabular}



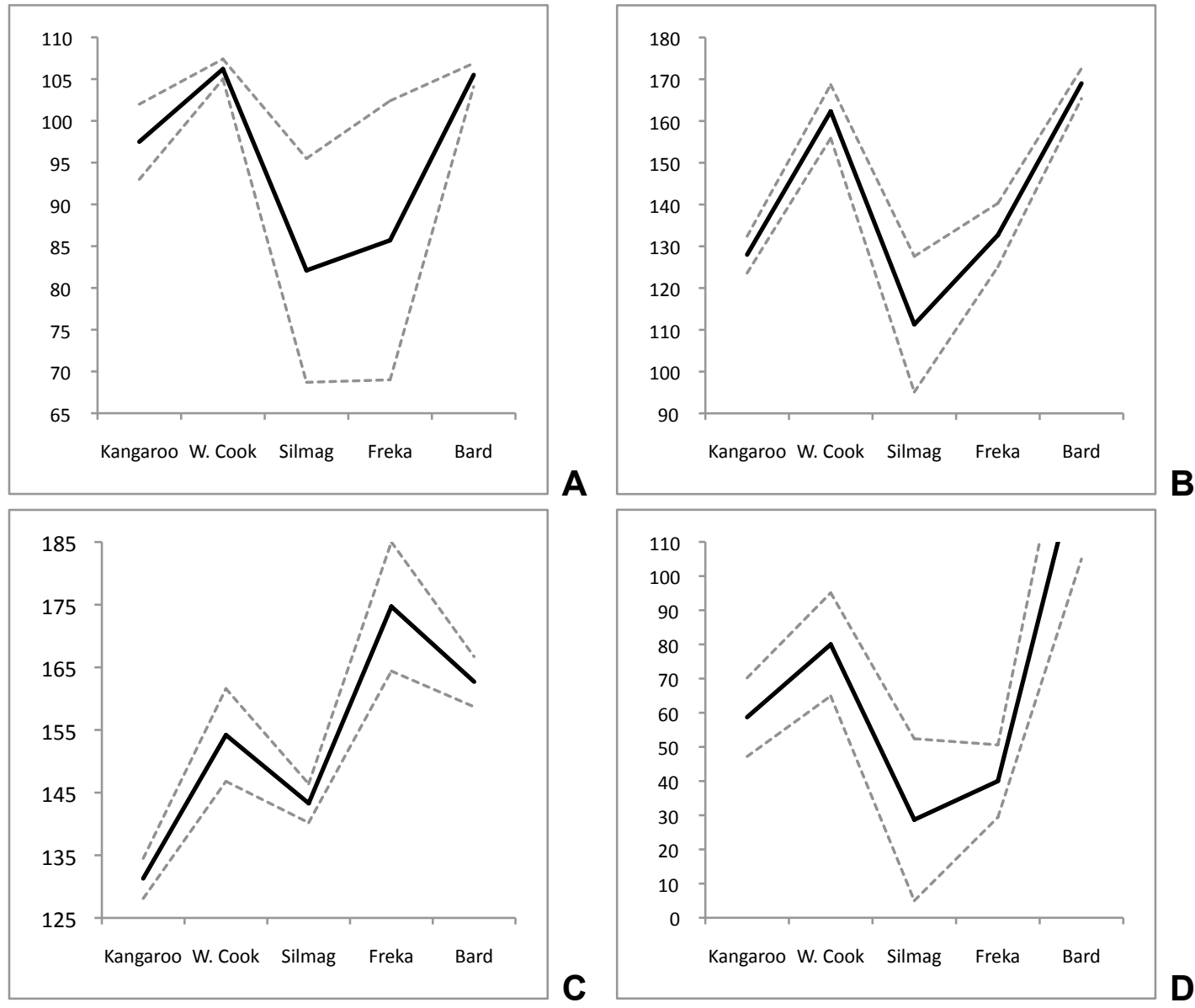

Figura 23. Médias (linha contínua) e desvios-padrão (linhas pontilhadas) dos perímetros dos balões iniciais (A) e cheios (B), das porcentagens de expansão dos balões (C) e dos volumes insuflados (D) das três amostras de cada modelo de sondas analisadas.

Os resultados do teste de resistência ao meio ao qual o material é exposto estão apresentados na Tabela 20. 
Tabela 20. Resultados do teste de resistência do meio ao qual o material é exposto em soluções que simulam o pH ácido do estômago de indivíduos saudáveis $(\mathrm{pH}$ $>1,0$ e $<2,0)$ e de pacientes em uso de inibidor de bombas de prótons - IBP $(\mathrm{pH}$ $5,0)$.

\begin{tabular}{|c|c|c|c|c|}
\hline \multirow{2}{*}{ Modelo } & \multicolumn{2}{|c|}{ Recomendações do fabricante } & \multicolumn{2}{|c|}{ Tempo de resistência } \\
\hline & Volume insuflado & Tempo de permanência & $\mathrm{pH}>1,0<2,0$ & pH 5,0 \\
\hline \multirow[t]{2}{*}{ Kangaroo $^{\circledR}$} & $20 \mathrm{ml}$ & 4 semanas & 24 semanas & 24 semanas \\
\hline & & 28 dias & 168 dias & 168 dias \\
\hline \multirow[t]{2}{*}{ Wilson Cook ${ }^{\circledR}$} & $20 \mathrm{ml}$ & 29 dias & 13 semanas & 24 semanas \\
\hline & & & 91 dias & 168 dias \\
\hline \multirow[t]{2}{*}{ Silmag ${ }^{\circledR}$} & $20 \mathrm{ml}$ & 90 dias & 24 semanas & 24 semanas \\
\hline & & & 168 dias & 168 dias \\
\hline \multirow[t]{2}{*}{ Freka $^{\circledR}$} & $7,5 \mathrm{ml}$ & 6 semanas & 24 semanas & 24 semanas \\
\hline & & 42 dias & 168 dias & 168 dias \\
\hline \multirow[t]{2}{*}{$\operatorname{Bard}^{\circledR}$} & $20 \mathrm{ml}$ & 4 meses & 6 semanas & 24 semanas \\
\hline & & 120 dias & 42 dias & 168 dias \\
\hline
\end{tabular}

Quando exposta ao meio com $\mathrm{pH}>1,0$ e $<2,0$, simulando o $\mathrm{pH}$ ácido do estômago de indivíduo saudável, a sonda que apresentou vazamento mais precocemente foi a Bard $^{\circledR} \operatorname{com} 6$ semanas, seguida da Wilson Cook $^{\circledR} \operatorname{com}^{13}$ semanas. As demais sondas não apresentaram vazamento durante todo o período de acompanhamento (24 semanas).

Quando expostas ao meio com $\mathrm{pH} 5,0$, simulando o $\mathrm{pH}$ ácido do estômago de indivíduos em uso de inibidor de bomba de prótons (IBP), não foi detectado vazamento em nenhumas das sondas durante todo o período de acompanhamento (24 semanas). 


\section{Discussão}

No acompanhamento das trocas de gastrostomia realizadas no Serviço de Endoscopia do Hospital das Clínicas da Faculdade de Medicina da Universidade de São Paulo (HCFMUSP), observamos a curta durabilidade da sonda de troca disponível no Serviço, comprovada pelo estudo-piloto.

Deve-se ressaltar, no entanto, que o modelo de sonda da marca Sil$\operatorname{mag}^{\circledR}$ que era utilizado no Serviço quando da realização daquele estudopiloto foi substituído por um novo modelo que, segundo informação dos fabricantes, deveria ter maior durabilidade devido a pequenas diferenças na sua industrialização, diferenças essas que não foram bem esclarecidas pelos mesmos fabricantes. Esse novo modelo foi o modelo incluído no estudo clínico experimental que ora é apresentado.

Foi com base nessas observações iniciais que nos propusemos a investigar tanto a durabilidade de diferentes marcas de sondas, seguindo os mesmos procedimentos de estudo adotados para o referido estudo-piloto, de maneira a poder discutir as vantagens e desvantagens de cada marca.

Desse modo, cem pacientes consecutivos com indicação de troca de sonda de GEP foram sendo incluídos em subgrupos de 20 pacientes para cada marca de sonda analisada. Todos os pacientes foram acompanhados por seis meses (término do período proposto para o estudo) ou até que outros motivos determinassem a sua exclusão do grupo de estudo. Dentre esses 
motivos, a ruptura do balao, o desgaste do tubo e o desgaste da tampa determinaram a durabilidade das diferentes marcas de sondas.

De modo geral, as estimativas de durabilidade das diferentes sondas mostraram variações importantes, e a durabilidade das sondas Bard ${ }^{\circledR}$ e Sil$\mathrm{mag}^{\circledR}$ se mostrou significativamente menor do que a das sondas Wilson Co$\mathrm{ok}^{\circledR}$, quando os motivos de exclusão do paciente do protocolo foram analisados em conjunto (ou seja, ruptura do balão, desgaste do tubo e desgaste da tampa). Esse fenômeno não foi observado quando se considerou a exclusão dos pacientes do protocolo apenas em função da ruptura do balão da sonda.

Devemos ressaltar que $16 \%$ dos pacientes foram excluídos dos seus grupos de estudo por motivos que não dizem respeito ao escopo da investigação. A exclusão de outros $45 \%$ foi decorrente do término do período de estudo (seis meses) e, neste aspecto, destaca-se que a maior frequência de exclusões pelo término do período de estudo foi observada no grupo em uso das sondas Wilson Cook $^{\circledR}(70 \%)$. Os motivos determinantes da durabilidade das sondas responderam por $39 \%$ das exclusões, sendo que o desgaste do tubo e o desgaste da tampa determinaram, respectivamente, 4,0\% e 3,0\% dessas exclusões. Assim, a ruptura do balão foi o motivo que mais frequentemente determinou a durabilidade das sondas, valendo ratificar que a maior freqüência dessa ocorrência foi observada nas sondas Silmag ${ }^{\circledR}(50 \%)$, imediatamente seguidas das sondas $\operatorname{Bard}^{\circledR}(40 \%)$, Kangaroo ${ }^{\circledR}(35 \%)$, Wison Cook $^{\circledR}(20 \%)$ e Freka ${ }^{\circledR}(15 \%)$.

Esses achados merecem delongada reflexão. Antes de tudo, porém, há que se enfatizar que os resultados deste estudo, no geral, não serão discuti- 
dos exatamente à luz da literatura, uma vez que não encontramos publicações de estudos em que tenham sido analisadas as mesmas variáveis investigadas neste estudo. Já está bem estabelecido que as sondas de silicone são, de um lado, inferiores às sondas de poliuretano (Guedon et al.I, 1993, 1999; Sartori et al., 2003; Blacka et al., 2004) e, de outro, estudo recente (Campoli et al., 2001) evidenciou que são superiores às de látex. Todas as sondas analisadas neste estudo são de silicone e, assim, não será possível estabelecer paralelos sobre o material de que são feitas as sondas.

Voltando à ruptura do balão como o determinante mais frequente da interrupção do uso das sondas pelos pacientes desta amostra, é importante lembrar que $25,0 \%$ dessas ocorrências foram observadas em apenas três pacientes que, pelo desenho do estudo, acabaram por fazer parte de dois ou três grupos de estudo, sendo sempre excluídos por esse motivo. Outros 15,6\% dessas ocorrências foram observados em dois pacientes. O primeiro foi excluído dos três primeiros grupos de estudo pela ruptura do balão, mas conseguiu concluir o período de acompanhamento de seis meses no quarto grupo de estudo (ou seja, no grupo de pacientes em uso de sonda Freka ${ }^{\circledR}$ ). O outro foi excluído de dois grupos de estudo (Wilson Cook $^{\circledR}$ e Bard $^{\circledR}$ ) pela ruptura do balão, mas também concluiu o acompanhamento quando em uso da sonda Freka ${ }^{\circledR}$.

De fato, essa marca de sonda foi a que apresentou a maior estimativa de durabilidade $(162,6 \pm 9,8$ dias $)$ quando considerada apenas a ruptura do balão como motivo de exclusão do estudo, e a segunda maior estimativa $(154,8 \pm 10,2$ dias $)$ quando considerados os três motivos determinantes da 
durabilidade das sondas (ruptura do balão, desgaste do tubo e desgaste da tampa).

Além disso, as análises fisicoquímicas das sondas revelaram que as sondas Freka ${ }^{\circledR}$ foram as que apresentaram menores perímetros dos balões. Em todas as amostras dessa marca submetidas às análises fisicoquímicas, a insuflação se mostrou homogênea.

Assim, a menor frequência de ruptura do balão e consequente maior durabilidade verificada no grupo em uso das sondas Freka ${ }^{\circledR}(15 \%)$ pode ter sido decorrência do fato de balões com menor volume apresentarem menos pontos de irregularidade em sua superfície.

Com relação a todas as intercorrências observadas ao longo do estudo, mesmo aquelas que não determinaram a exclusão do paciente do protocolo e, portanto, a durabilidade das sondas, foi bastante alta a frequência de deslizamento do anteparo externo (57\%), que ocorreu igualmente em todas as marcas de sondas, mas com frequência significativamente menor $(p=0,004)$ nas sondas Freka $^{\circledR}(3,6 \%)$, o que provavelmente se deva ao seu formato triangular, que é uma característica diferenciada dessa marca em relação às outras. Por outro lado, nos casos em que essa intercorrência foi observada nos pacientes em uso de sondas dessa marca, o design desse dispositivo não permitiu a fixação do anteparo.

Apesar de o anteparo externo das sondas Wilson Cook $^{\circledR}$ vir acompanhado de uma braçadeira rotativa, esse fixador próprio da marca não evitou o seu deslizamento em $28 \%$ dos casos.

Abertura espontânea da tampa e extravasamento periestomal foram in- 
tercorrências observadas em frequências iguais (28\%). Metade das observações de abertura espontânea da tampa e $32,1 \%$ dos casos de extravasamento periestomal se referiram ao grupo de pacientes em uso das sondas Kangaroo $^{\circledR}$, enquanto a primeira intercorrência não foi observada no grupo de pacientes em uso de sondas Freka ${ }^{\circledR}$.

As sondas Kangaroo ${ }^{\circledR}$ são feitas com um tipo diferente de silicone nos segmentos de conexão (vias alimentares e tampas), ou seja, trata-se de material visivelmente mais duro e, por consequência, provavelmente mais resistente a rasgos. Essa característica dessa marca de sonda, contudo, não impediu a alta frequência de abertura espontânea da tampa, embora, provavelmente, tenha sido a razão de ter sido a marca de sonda com a menor frequência de desgaste da tampa $(3,8 \%$, contra cerca de $19 \%$ a $27 \%$ nas outras marcas). Entendemos que a frequente abertura espontânea da tampa das sondas Kangaroo ${ }^{\circledR}$ poderia ser reduzida ou mesmo evitada se apresentasse um tipo de trava diferente, e sugerimos, como exemplo, o fechamento em rosca.

Muitos pacientes referiram sua preferência pela sonda introduzida por ocasião da realização da GEP, pois essa primeira sonda possui um clamp que auxilia a infusão da dieta com seringa, além de reduzir a ocorrência de problemas relacionados com a tampa da sonda, como vazamentos peritampa e abertura espontânea da tampa. Dentre as sondas analisadas, esse tipo de dispositivo só é disponibilizado nas sondas Freka ${ }^{\circledR}$, o que justifica tanto o fato de essa intercorrência não ter sido observada nos pacientes em uso dessa marca de sondas, quanto a opinião desses pacientes ou de seus cui- 
dadores de que essa era a principal vantagem dessa marca de sonda. Em outras palavras, o clamp tem a vantagem de evitar o retorno alimentar pela sonda, o que diminui ou mesmo impede a ocorrência de abertura espontânea de sua tampa.

Todas as sondas analisadas têm comprimento de $20 \mathrm{~cm}$, à exceção das sondas Freka ${ }^{\circledR}$, que são mais curtas $(12 \mathrm{~cm})$. Esse menor comprimento dessas sondas foi considerado como vantagem para alguns cuidadores e como desvantagem para outros. A despeito dos resultados observados com essa marca de sondas de troca, a opinião dos cuidadores leva a crer que a sonda ideal deveria apresentar alternativas de diferentes comprimentos para adequação de acordo com a comodidade de cada paciente.

A via única de alimentação foi queixa freqüente dos pacientes e cuidadores. Esta via possui um maior diâmetro e não é possível conectar a seringa de $20 \mathrm{ml}$. A seringa de $60 \mathrm{ml}$ utilizada para a infusão de dieta por esta abertura de maior diâmetro é um material de difícil disponibilidade e custo mais elevado. Por esse motivo, a via dupla de alimentação nos parece vantajosa.

Com relação ao desgaste do tubo, embora $42,8 \%$ dos casos em que se observou essa intercorrência se referissem a pacientes em uso das sondas Silmag ${ }^{\circledR}$, enquanto nenhuma observação dessa intercorrência tenha sido registrada para pacientes em uso das sondas Wilson Cook ${ }^{\circledR}$, não houve diferença significativa na comparação das marcas de sondas nesse quesito. Provavelmente, o fato de não ter havido qualquer registro de desgaste do tubo nas sondas Wilson Cook $^{\circledR}$ se deva ao silicone visivelmente de maior 
dureza de que essa sonda é feita.

Houve obstrução do tubo em $10 \%$ dos casos acompanhados. Novamente, essa intercorrência não foi observada nas sondas Wilson Cook $^{\circledR}$, e metade dessas ocorrências foram observadas nos pacientes em uso das sondas Kangaroo $^{\circledR}$. Embora não tenhamos procedido a uma análise mais cuidadosa que pudesse relacionar a obstrução do tubo com os calibres das diferentes marcas de sondas, pudemos observar que não houve uma relação diretamente proporcional entre os calibres das sondas e as intercorrências. De fato, as sondas Wilson Cook $^{\circledR}$ são as de maior calibre (24 Fr) dentre as sondas analisadas, o que pode respaldar a não ocorrência de obstrução no tubo dessa marca de sondas. Por outro lado, as sondas Kangaroo ${ }^{\circledR}$ apresentam calibre intermediário (20 Fr), e a maior frequência de obstrução de tubo foi observada justamente nessa marca, enquanto essa intercorrência foi observada em frequência bastante menor $(10 \%)$ nas sondas Freka ${ }^{\circledR}$, que apresentam o menor calibre (15 Fr).

Em estudo realizado por Leachter et al. (2006), no qual um dos parâmetros avaliados em 100 pacientes usuários de GEP por mais de seis meses foi justamente a qualidade do tubo de duas marcas distintas de sonda de troca $\left(\right.$ Bard $^{\circledR}$ e Sandoz ${ }^{\circledR}$ ), foi observada obstrução de pelo menos $50 \%$ em $12 \%$ dos casos; tubos minimamente ocluídos $(<50 \%)$ foram observados em $59 \%$ dos pacientes, sem que se tenha evidenciado qualquer diferença nessas frequências quando consideradas as marcas das sondas. No entanto, essa ocorrência foi significativamente maior nos pacientes com indicação de uso da sonda por sequelas de AVC ou por demência do que nos casos de 
indicação por traumas.

Em nossa amostra, observamos dez ocorrências de obstrução do tubo em oito pacientes. Em seis casos, a indicação para uso da sonda se referia a sequelas de AVC (dois casos), doença de Alzheimer (dois casos) e distúrbios neurológicos não diagnosticados (dois casos). Os demais pacientes usavam a GEP por ataxia (um caso) e sequela neurológica de atropelamento (um caso). Duas ocorrências de obstrução do tubo foram observadas em um mesmo paciente com indicação de GEP por sequela de atropelamento, e outras duas, em paciente com AVC. Desse modo, embora a frequência de obstruções do tubo encontrada em nosso estudo esteja próxima daquela relatada por Leachter et al. (2006), não nos parece que essa ocorrência tenha tido relação com a indicação de uso da GEP em nossa amostra.

Assim, no que concerne à indicação do uso de sonda na amostra deste estudo, achado curioso chamou a atenção. Quando analisamos os dados dos cinco pacientes nos quais ocorreram cerca de $40 \%$ dos casos de ruptura do balão, essa intercorrência pôde ser significativamente associada apenas com o motivo de indicação de uso da sonda, ou seja, com indicação por distúrbios neurológicos sem diagnóstico. Como não houve diferença nas frequências de ruptura do balão quando comparadas as diferentes marcas de sondas, mas houve associação significativa da ocorrência múltipla desse defecho com a indicação citada para uso da sonda referida, nos parece lícito inferir que condições idiossincráticas dos pacientes talvez causem maior impacto na durabilidade da sonda de GEP do que as diferentes marcas de 
sondas.

O anteparo balonado, além da fácil remoção, apresenta grande facilidade para a reposição de uma nova sonda. A presença do balão permite o manuseio da sonda por médicos menos experientes e dispensa a realização de endoscopia. Desse modo, possibilita a realização ambulatorial da troca, ou mesmo em ambiente de pronto atendimento quando necessária. Em contrapartida, com este modelo, ocorre a saída espontânea da sonda com maior freqüência devido ao risco de ruptura inadvertida do balão. Portanto, em pacientes que ocorre a ruptura do balão repetidas vezes, uma boa opção é a utilização de sondas com anteparo flexível (não balonado).

No teste de resistência ao meio que o material é exposto, todas as amostras não apresentaram vazamento durante as 24 semanas de acompanhamento quando expostas ao meio com pH 5,0. O mesmo não foi reproduzido quando expostas ao meio com $\mathrm{pH}>1,0$ e $<2,0$.

Com esses resultados, acreditamos que a durabilidade da sonda, em especial do balão, possa ser influenciada pelo $\mathrm{pH}$ mais ácido no estômago de pacientes que dela fazem uso. Tal dado sugere que haja benefício do uso de inibidores da bomba de prótons na durabilidade das sondas balonadas, porém é necessário confirmar esta hipótese in vivo, o que não foi realizado no presente estudo.

Em termos de dados clínicos dos pacientes que possam de alguma forma ter influenciado a durabilidade das sondas, a única associação significativa evidenciada pelas estatísticas aplicadas foi estabelecida com o número de trocas anteriores da sonda, ou seja, cinco ou mais trocas anteriores de- 
terminaram menor durabilidade desses dispositivos.

Através dos nossos resultados, sugerimos que a avaliação da durabilidade da sonda deve ser um fator importante a ser considerado pelas instituições na escolha deste material. Com isso, pode-se ter uma melhor avaliação custo x benefício de cada modelo, otimizando os recursos financeiros e evitando trocas repetidas e desnecessárias em pacientes que apresentam, em sua maioria, dificuldade de locomoção para se dirigir ao hospital para a realização destes procedimentos.

\section{Considerações finais:}

Após a avaliação da durabilidade das diferentes sondas analisadas e considerando as intercorrências demonstradas na presente amostra, sugerese o conjunto de seis características que comporiam uma sonda de troca de gastrostomia balonada ideal:

1) Tampa de silicone de maior dureza com fechamento em rosca.

2) Duas vias de alimentação com diâmetros diferentes

3) Presença de clamp

4) Anteparo externo triangular

5) Diferentes opções de comprimento

6) Balão de menor volume 


\section{Conclusões}

As sondas Wilson Cook ${ }^{\circledR}$ apresentaram maior durabilidade.

O número de trocas anteriores se mostrou fator determinante de menor durabilidade das sondas.

Ruptura do balão da sonda foi mais frequente em pacientes com distúrbios neurológicos não diagnosticados.

6. Anexos 
Anexo A. Aprovação da Comissão de Ética para Análise de Projetos de Pesquisa - CAPPesq da Diretoria Clínica do Hospital das Clínicas da Faculdade de Medicina da Universidade de São Paulo.

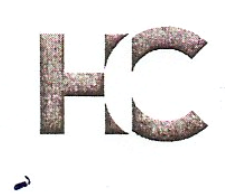

\section{APROVAÇĀO}

A Comissão de Ética para Análise de Projetos de Pesquisa CAPPesq da Diretoria Clínica do Hospital das Clínicas e da Faculdade de Medicina da Universidade de São Paulo, em sessão de 25/08/2010, APROVOU o Protocolo de Pesquisa $n^{\circ}$ 0384/10, intitulado: "AVALIAÇÃO DOS DIFERENTES MODELOS DE SONDAS DE TROCA DE GASTROSTOMIA. DURABILIDADE E DESPESAS." apresentado pelo Departamento de GASTROENTEROLOGIA, inclusive o Termo de Consentimento Livre e Esclarecido.

Cabe ao pesquisador elaborar e apresentar à CAPPesq, os relatórios parciais e final sobre a pesquisa (Resolução do Conselho Nacional de Saúde n 196, de 10/10/1996, inciso IX.2, letra "c").

Pesquisador (a) Responsável: Dr Eduardo Guimarāes Hourneaux de Moura Pesquisador (a) Executante: Emanuele Lima Villela

CAPPesq, 26 de Agosto de 2010

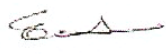

Prof. Dr. Eduardio Minassad Presidente da Comissāo de Ética para Análise de Projetos de Pesquisa 
Anexo B. Termo de Consentimento Livre e Esclarecido.

hOSPITAL dAS CLÍnicas da faculdade de medicina da

UNIVERSIDADE dE SÃO PAULO - HCFMUSP

\section{DADOS DE IDENTIFICAÇÃO DO SUJEITO DA PESQUISA OU RESPONSÁVEL LEGAL}

1. Nome:

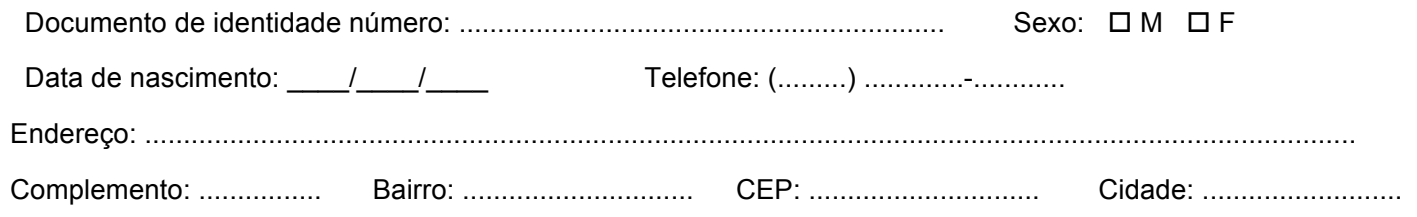

2. Responsável legal:

Natureza (grau de parentesco, tutot, curador et.):

Documento de identidade número:

Sexo: $\square \mathrm{M} \square \mathrm{F}$

Data de nascimento:

I

Telefone: $(\ldots \ldots . . .$.

Endereço:

Complemento:

Bairro:

CEP:

Cidade:

\section{DADOS SOBRE A PESQUISA}

TÍTULO DO PROTOCOLO DE PESQUISA:

AVALIAÇÃO DOS DIFERENTES MODELOS DE SONDAS DE TROCA DE GASTROSTOMIA.

DURABILIDADE E DESPESAS

PESQUISADORES:

DR. PAULO SAKAI / PESQUISADORA EXECUTANTE: DRA. EMANUELE LIMA VILLELA

CARGO/FUNÇÃO: PROFESSOR ASSOCIADO DO DEPARTAMENTO DE GASTROENTEROLOGIA DA FACULDADE DE MEDICINA DA UNIVERSIDADE DE SÃO PAULO

INSCRIÇÃO CONSELHO REGIONAL: 17.927

UNIDADE DO HCFMUSP: ENDOSCOPIA

AVALIAÇÃO DO RISCO DA PESQUISA:

$\begin{array}{llll}\text { RISCO MÍNIMO } & x & \text { RISCO MÉDIO } & \square \\ \text { RISCO BAIXO } & \square & \text { RISCO MAIOR } & \square\end{array}$

DURAÇÃO DA PESQUISA:

12 MESES

TERMO DE CONSENTIMENTO LIVRE E ESCLARECIDO

Estas informações estão sendo fornecidas para sua participação voluntária neste estudo, que visa comparar a durabilidade das principais sondas de troca de gastrostomia balonadas disponíveis atualmente no mercado e comparar a despesa estimada para o HCFMUSP com o uso de cada uma destas sondas, em um paciente, no período de seis meses.

Você tem indicação de troca da sonda de gastrostomia e está sendo convidado a participar desse estudo que avalia diferentes modelos de sondas de troca de gastrostomia. Todas as sondas são colocadas da mesma forma: realiza-se a introdução pelo orifício previamente existente na parede abdominal e o balão é insuflado no interior do estômago com o líquido e volume especificados por cada fabricante $(7 \mathrm{ml}$ a $20 \mathrm{ml})$. Em seguida aproxima-se o anteparo externo da parede abdominal para que a sonda não se desloque e checa-se a funcionalidade da 
sonda injetando $20 \mathrm{ml}$ de água por todas as vias do tubo. A dieta será orientada por um nutricionista e, caso ainda não tenha acompanhamento com tal profissional, você receberá uma guia de encaminhamento.

Geralmente, não é necessária sedação, tampouco endoscopia para o procedimento. Tais intervenções ficam restritas aos casos em que houver dúvida se a sonda encontra-se na posição adequada e em alguns casos de estenose (estreitamento) do orifício de gastrostomia. Nestes casos de estenose, é tentado inicialmente realizar a dilatação com sondas de Savary-Gilliard sem sedação ou endoscopia. No caso de dor moderada ou intensa, é realizada analgesia com fentanil (dose apropriada para o paciente). Se, apesar disso, não for possível realizar a dilatação do pertuito, o paciente será submetido à endoscopia com sedação consciente, como é realizada habitualmente, e realizará a dilatação com sondas de Savary-Gilliard sob visão direta.

Caso você decida participar deste estudo, será realizada a troca da sonda da mesma forma que é feita rotineiramente e o acompanhamento será feito por um período de seis meses, sendo que serão programados três retornos ao serviço (após 1 mês, 3 meses e 6 meses da colocação da sonda). Em cada retorno, serão realizadas perguntas com o objetivo de detectar as possíveis dificuldades no manuseio da sonda. Serão examinados: sonda e aspectos clínicos. O objetivo é detectar desgaste do material e possíveis complicações clínicas locais e/ou sistêmicas.

Caso haja qualquer dúvida ou problema com a sonda de troca de gastrostomia, em qualquer período, você poderá entrar em contato com a equipe pelos números de telefone: 3069-6460, 3069-6221 ou 3069-7175, ou poderá comparecer pessoalmente ao setor onde realizou a troca da sonda.

Estes problemas podem incluir: 1) dificuldades no manuseio da sonda, como dificuldade para infundir a dieta, ou de usar os conectores, ou saída não proposital da sonda; 2) alterações na integridade da sonda, como rachaduras nas tampas ou no próprio tubo, ruptura do balão; 3) alterações no local onde a sonda fica posicionada como saída de secreção, vermelhidão local, coceira e lesões de pele.

Se, antes dos seis meses, você apresentar indicação de troca da sonda, a mesma será substituída e não será necessário completar os retornos previstos até o sexto mês.

Seu médico deve continuar lhe acompanhando e avaliando a necessidade da manutenção da sonda de gastrostomia. Caso, em qualquer momento do estudo, for indicada a retirada da sonda de gastrostomia, tal procedimento será realizado e também não será necessário manter o acompanhamento até o término dos seis meses.

Ao cumprir os seis meses de estudo, você será reavaliado (retorno de 6 meses). Neste momento será realizada a troca da sonda, caso indicada, ou será orientado o momento correto de um novo retorno para realização da troca.

Não há benefício direto para o participante. Trata-se de estudo clínico testando a hipótese de que as diferentes sondas de gastrostomia apresentam diferenças de durabilidade, porém, somente no final do estudo poderemos concluir a presença de algum benefício no uso de determinadas sondas.

Você pode optar por não participar deste estudo. Se você não quiser participar deste estudo, será realizada a substituição com a sonda de troca de gastrostomia padronizada no Serviço de Endoscopia Gastrointestinal do Hospital das Clínicas da Faculdade de Medicina da Universidade de São Paulo, tantas vezes quanto necessário. A negativa da participação neste estudo, em nada irá prejudicar o seu atendimento em nosso Serviço.

Em qualquer etapa do estudo, você terá acesso aos profissionais responsáveis pela pesquisa para esclarecimento de eventuais dúvidas. O principal investigador é o Dr. Eduardo Guimarães Hourneaux de Moura e da investigadora executante é Dra Emanuele Lima Villela. Ambos podem ser encontrados no endereço: Rua Enéas de Carvalho Aguiar, 155 - Prédio dos Ambulatórios, 6ª andar, bloco 3. Telefone(s) 3069-6460 e 3069-6221. Se você tiver alguma consideração ou dúvida sobre a ética da pesquisa, entre em contato com o Comitê de Ética em Pesquisa (CEP) - Rua Ovídio Pires de Campos, 225 - 5 andar - tel: 3069-6442 ramais 16, 17, 18 ou 20, FAX: 30696442 ramal 26 - E-mail: cappesq@hcnet.usp.br.

Sua participação no presente estudo é voluntária. Você pode optar por não participar ou interromper sua participação no estudo a qualquer momento, sem sanção nem perda de benefícios aos quais pudesse ter direito. Se decidir interromper antes de terminar o estudo, será solicitado um retorno ao Serviço para uma visita final.

As informações obtidas serão analisadas em conjunto com outros pacientes, não sendo divulgada a identificação de nenhum paciente. Comprometemo-nos a utilizar os dados e o material coletado somente para esta pesquisa.

$\mathrm{O}(\mathrm{a})$ senhor(a) será mantido(a) atualizado(a) sobre os resultados parciais das pesquisas.

Não há despesas pessoais para o participante em qualquer fase do estudo, incluindo exames e consultas. Também não há compensação financeira relacionada à sua participação. Se existir qualquer despesa adicional, ela será absorvida pelo orçamento da pesquisa. 
Acredito ter sido suficientemente informado a respeito das informações que li, ou que foram lidas para mim, descrevendo o estudo "AVALIAÇÃO DOS DIFERENTES MODELOS DE SONDAS DE TROCA DE GASTROSTOMIA. DURABILIDADE E DESPESAS".

Eu discuti com o Dr. Paulo Sakai e com a Dra. Emanuele Lima Villela sobre a minha decisão em participar nesse estudo. Ficaram claros para mim quais são os propósitos do estudo, os procedimentos a serem realizados, seus desconfortos e riscos, as garantias de confidencialidade e de esclarecimentos permanentes. Ficou claro também que minha participação é isenta de despesas e que tenho garantia do acesso a tratamento hospitalar quando necessário. Concordo voluntariamente em participar deste estudo e poderei retirar o meu consentimento a qualquer momento, antes ou durante o mesmo, sem penalidades ou prejuízo ou perda de qualquer benefício que eu possa ter adquirido, ou no meu atendimento neste Serviço.

$\begin{array}{ll}\text { Data: } . . . . / . . . . / \ldots . . . & \text { Assinatura do paciente / representante legal } \\ \text { Data: } . . . . / . . . . / \ldots . . & \text { Assinatura da testemunha }\end{array}$

Para casos de pacientes menores de 18 anos, analfabetos, semianalfabetos ou portadores de deficiência auditiva ou visual.

(Somente para o responsável do projeto)

Declaro que obtive de forma apropriada e voluntária o Consentimento Livre e Esclarecido deste paciente ou representante legal para a participação neste estudo.

Data: .................

Assinatura do responsável pelo estudo 
Anexo C. Dados individuais dos pacientes incluídos no estudo.

\begin{tabular}{|c|c|c|c|c|c|}
\hline $\begin{array}{l}\text { Marca da } \\
\text { sonda }\end{array}$ & Caso & $\begin{array}{l}\text { Iniciais } \\
\text { do nome }\end{array}$ & Sexo & Idade & Indicação para gastrostomia \\
\hline \multirow{20}{*}{ KANGAROO $^{\circledR}$} & 1 & NCS & $\mathrm{F}$ & 58 & Distúrbio de deglutição s/ diagnóstico \\
\hline & 2 & RRA & $\mathrm{F}$ & 23 & Tumor cerebral \\
\hline & 3 & MJC & $\mathrm{F}$ & 71 & $\begin{array}{l}\text { Estenose pós-cirurgia + radioterapia por } \\
\text { câncer de laringe }\end{array}$ \\
\hline & 4 & RBA & $\mathrm{F}$ & 81 & Acidente Vascular Cerebral \\
\hline & 5 & GOTL & $\mathrm{F}$ & 53 & Esclerose lateral amiotrófica \\
\hline & 6 & DPS & $\mathrm{F}$ & 37 & $\begin{array}{l}\text { Distúrbio neurológico progressivo s/ } \\
\text { diag. }\end{array}$ \\
\hline & 7 & ALS & $\mathrm{F}$ & 57 & Esclerose lateral amiotrófica \\
\hline & 8 & MNA & $\mathrm{F}$ & 79 & Doença de Alzheimer \\
\hline & 9 & MRS & M & 21 & Ataxia \\
\hline & 10 & DSF & M & 55 & Neoplasia de laringe \\
\hline & 11 & MRS & $\mathrm{F}$ & 89 & Doença de Alzheimer \\
\hline & 12 & GFS & $\mathrm{F}$ & 60 & Acidente Vascular Cerebral \\
\hline & 13 & MTR & $\mathrm{F}$ & 87 & Doença de Alzheimer \\
\hline & 14 & ECD & $\mathrm{F}$ & 50 & Acidente Vascular Cerebral \\
\hline & 15 & $\mathrm{CHF}$ & M & 58 & $\begin{array}{l}\text { Estenose pós-cirurgia + radioterapia por } \\
\text { câncer de cavidade oral }\end{array}$ \\
\hline & 16 & SB & M & 62 & Neoplasia de laringe \\
\hline & 17 & FCS & M & 54 & Acidente Vascular Cerebral \\
\hline & 18 & DPS & M & 13 & Sequela de atropelamento \\
\hline & 19 & OA & M & 48 & $\begin{array}{l}\text { Distúrbio neurológico progressivo s/ } \\
\text { diag. }\end{array}$ \\
\hline & 20 & MSS & $\mathrm{F}$ & 85 & Doença de Alzheimer \\
\hline \multirow{20}{*}{$\begin{array}{l}\text { WILSON } \\
\text { COOK }^{\circledR}\end{array}$} & 1 & CA & M & 54 & $\begin{array}{l}\text { Pós-cirúrgico de neoplasia de cavidade } \\
\text { oral }\end{array}$ \\
\hline & 2 & BLS & $\mathrm{F}$ & 87 & Acidente Vascular Cerebral \\
\hline & 3 & MACC & M & 81 & $\begin{array}{l}\text { Pós-cirúrgico de neoplasia de cavidade } \\
\text { oral }\end{array}$ \\
\hline & 4 & CMS & $\mathrm{F}$ & 72 & Acidente Vascular Cerebral \\
\hline & 5 & FFS & $\mathrm{F}$ & 80 & Acidente Vascular Cerebral \\
\hline & 6 & MJC & $\mathrm{F}$ & 71 & $\begin{array}{l}\text { Estenose pós-cirurgia + radioterapia por } \\
\text { câncer de laringe }\end{array}$ \\
\hline & 7 & DLS & M & 31 & Disgerminoma cerebral \\
\hline & 8 & RBA & $\mathrm{F}$ & 81 & Acidente Vascular Cerebral \\
\hline & 9 & TSS & $\mathrm{F}$ & 26 & $\begin{array}{l}\text { Distúrbio neurológico progressivo s/ } \\
\text { diag. }\end{array}$ \\
\hline & 10 & YY & $\mathrm{F}$ & 70 & Acidente Vascular Cerebral \\
\hline & 11 & JS & M & 64 & $\begin{array}{l}\text { Pós-cirúrgico de neoplasia de cavidade } \\
\text { oral }\end{array}$ \\
\hline & 12 & $\mathrm{HBL}$ & $\mathrm{F}$ & 52 & Doença de Wilson \\
\hline & 13 & $\mathrm{OA}$ & M & 48 & $\begin{array}{l}\text { Distúrbio neurológico progressivo s/ } \\
\text { diag. }\end{array}$ \\
\hline & 14 & PRC & M & 54 & $\begin{array}{l}\text { Pós-cirúrgico de neoplasia de cavidade } \\
\text { oral }\end{array}$ \\
\hline & 15 & APS & $\mathrm{F}$ & 62 & Doença de Alzheimer \\
\hline & 16 & JFN & M & 53 & Neoplasia de cavidade oral \\
\hline & 17 & YT & M & 90 & Neuropatia alcoólica \\
\hline & 18 & CJR & M & 45 & Sequela de cirurgia pulmonar \\
\hline & 19 & SAGS & $\mathrm{F}$ & 33 & Esclerose múltipla \\
\hline & 20 & ASG & $\mathrm{F}$ & 22 & Doença de Wilson \\
\hline
\end{tabular}


Anexo C. Dados individuais dos pacientes incluídos no estudo.

\begin{tabular}{|c|c|c|c|c|c|}
\hline $\begin{array}{l}\text { Marca da } \\
\text { sonda }\end{array}$ & Caso & $\begin{array}{l}\text { Iniciais } \\
\text { do nome }\end{array}$ & Sexo & Idade & Indicação para gastrostomia \\
\hline \multirow{20}{*}{ SILMAG $^{\circledR}$} & 1 & $\mathrm{MCM}$ & $\mathrm{F}$ & 78 & Acidente Vascular Cerebral \\
\hline & 2 & MACC & $\mathrm{F}$ & 81 & $\begin{array}{l}\text { Pós-cirúrgico de neoplasia de cavidade } \\
\text { oral }\end{array}$ \\
\hline & 3 & GFS & $\mathrm{F}$ & 60 & Acidente Vascular Cerebral \\
\hline & 4 & CMCF & $\mathrm{F}$ & 36 & Desmielinização Monofásica Aguda \\
\hline & 5 & DPS & M & 13 & Sequela de atropelamento \\
\hline & 6 & BSV & $\mathrm{F}$ & 19 & Sequela de acidente de motocicleta \\
\hline & 7 & GOTL & $\mathrm{F}$ & 53 & Esclerose lateral amiotrófica \\
\hline & 8 & JAS & M & 85 & Acidente Vascular Cerebral \\
\hline & 9 & $\mathrm{OA}$ & M & 48 & $\begin{array}{l}\text { Distúrbio neurológico progressivo s/ } \\
\text { diag. }\end{array}$ \\
\hline & 10 & FDS & M & 55 & $\begin{array}{l}\text { Pós-cirúrgico de neoplasia de cavidade } \\
\text { oral }\end{array}$ \\
\hline & 11 & RBA & $\mathrm{F}$ & 81 & Acidente Vascular Cerebral \\
\hline & 12 & NCS & $\mathrm{F}$ & 58 & $\begin{array}{l}\text { Distúrbio neurológico progressivo s/ } \\
\text { diag. }\end{array}$ \\
\hline & 13 & $\mathrm{RR}$ & M & 78 & Neoplasia de laringe \\
\hline & 14 & $\mathrm{CHF}$ & M & 58 & $\begin{array}{l}\text { Pós-cirúrgico de neoplasia de cavidade } \\
\text { oral }\end{array}$ \\
\hline & 15 & DPS & $\mathrm{F}$ & 37 & $\begin{array}{l}\text { Distúrbio neurológico progressivo s/ } \\
\text { diag. }\end{array}$ \\
\hline & 16 & LGR & $\mathrm{F}$ & 74 & Doença de Alzheimer \\
\hline & 17 & SLC & $\mathrm{F}$ & 81 & Acidente Vascular Cerebral \\
\hline & 18 & MNA & $\mathrm{F}$ & 79 & Doença de Alzheimer \\
\hline & 19 & ACS & M & 54 & Acidente Vascular Cerebral \\
\hline & 20 & NAA & $\mathrm{F}$ & 22 & Neoplasia de laringe \\
\hline \multirow{20}{*}{ FREKA $^{\circledR}$} & 1 & OMG & $\mathrm{F}$ & 77 & $\begin{array}{l}\text { Distúrbio neurológico progressivo s/ } \\
\text { diag. }\end{array}$ \\
\hline & 2 & ARP & $\mathrm{F}$ & 75 & Meningioma \\
\hline & 3 & SB & M & 62 & $\begin{array}{l}\text { Estenose pós-cirurgia + radioterapia por } \\
\text { câncer de laringe }\end{array}$ \\
\hline & 4 & ACC & M & 54 & Esclerose lateral amiotrófica \\
\hline & 5 & MRS & M & 22 & Ataxia \\
\hline & 6 & TRPC & $\mathrm{F}$ & 53 & Esclerose lateral amiotrófica \\
\hline & 7 & ECD & $\mathrm{F}$ & 50 & Acidente Vascular Cerebral \\
\hline & 8 & TSS & $\mathrm{F}$ & 27 & $\begin{array}{l}\text { Distúrbio neurológico progressivo s/ } \\
\text { diag. }\end{array}$ \\
\hline & 9 & AAC & M & 71 & Neoplasia de laringe \\
\hline & 10 & MAD & M & 77 & Doença de Parkinson \\
\hline & 11 & POB & M & 52 & Acidente Vascular Cerebral \\
\hline & 12 & RBA & $\mathrm{F}$ & 81 & Acidente Vascular Cerebral \\
\hline & 13 & MCSS & $\mathrm{F}$ & 28 & Sequela de intoxicação por chumbinho \\
\hline & 14 & APT & $\mathrm{F}$ & 74 & Acidente Vascular Cerebral \\
\hline & 15 & FMS & M & 76 & Estenose péptica \\
\hline & 16 & JO & M & 68 & Esclerose lateral amiotrófica \\
\hline & 17 & FJS & M & 74 & $\begin{array}{l}\text { Estenose pós-cirurgia + radioterapia por } \\
\text { câncer de laringe }\end{array}$ \\
\hline & 18 & RSB & $\mathrm{F}$ & 61 & Acidente Vascular Cerebral \\
\hline & 19 & GFS & $\mathrm{F}$ & 61 & Acidente Vascular Cerebral \\
\hline & 20 & $\mathrm{CA}$ & M & 54 & $\begin{array}{l}\text { Pós-cirúrgico de neoplasia de cavidade } \\
\text { oral }\end{array}$ \\
\hline
\end{tabular}


Anexo C. Dados individuais dos pacientes incluídos no estudo.

\begin{tabular}{|c|c|c|c|c|c|}
\hline $\begin{array}{l}\text { Marca da } \\
\text { sonda }\end{array}$ & Caso & $\begin{array}{l}\text { Iniciais } \\
\text { do nome }\end{array}$ & Sexo & Idade & Indicação para gastrostomia \\
\hline \multirow{20}{*}{ BARD $^{\circledR}$} & 1 & SLC & $\mathrm{F}$ & 81 & Acidente Vascular Cerebral \\
\hline & 2 & NCS & $\mathrm{F}$ & 59 & $\begin{array}{l}\text { Distúrbio neurológico progressivo s/ } \\
\text { diag. }\end{array}$ \\
\hline & 3 & DPS & $M$ & 13 & Sequela de atropelamento \\
\hline & 4 & MACC & $\mathrm{F}$ & 82 & Tumor de face \\
\hline & 5 & LGR & $\mathrm{F}$ & 74 & Doença de Alzheimer \\
\hline & 6 & MSS & $\mathrm{F}$ & 86 & Doença de Alzheimer \\
\hline & 7 & CSF & $\mathrm{F}$ & 45 & Neurofibromatose \\
\hline & 8 & OMG & $\mathrm{F}$ & 78 & Broncoaspirações de repetição \\
\hline & 9 & AAN & $M$ & 28 & Disfagia idiopática \\
\hline & 10 & DPS & $\mathrm{F}$ & 38 & $\begin{array}{l}\text { Distúrbio neurológico progressivo s/ } \\
\text { diag. }\end{array}$ \\
\hline & 11 & ASL & M & 68 & Acidente Vascular Cerebral \\
\hline & 12 & SEM & M & 52 & Tumor de cabeça e pescoço \\
\hline & 13 & BAS & $\mathrm{F}$ & 67 & Doença de Alzheimer \\
\hline & 14 & TSS & $\mathrm{F}$ & 27 & $\begin{array}{l}\text { Distúrbio neurológico progressivo s/ } \\
\text { diag. }\end{array}$ \\
\hline & 15 & FJS & M & 74 & Tumor de laringe \\
\hline & 16 & JAS & M & 86 & Acidente Vascular Cerebral \\
\hline & 17 & DLS & M & 32 & Disgerminoma \\
\hline & 18 & CMCF & $\mathrm{F}$ & 37 & $\begin{array}{l}\text { Doença desmielinizante sem diagnósti- } \\
\text { co }\end{array}$ \\
\hline & 19 & ACS & M & 55 & Acidente Vascular Cerebral \\
\hline & 20 & MAD & M & 78 & Doença de Parkinson \\
\hline
\end{tabular}


Anexo D. Dados do acompanhamento dos pacientes.

\begin{tabular}{|c|c|c|c|c|c|}
\hline $\begin{array}{l}\text { Marca da } \\
\text { sonda }\end{array}$ & Caso & $\begin{array}{c}\text { Tempo de PEG } \\
\text { (em meses) }\end{array}$ & Trocas & $\begin{array}{l}\text { Término } \\
\text { (em dias) }\end{array}$ & Motivo \\
\hline \multirow{20}{*}{ KANGAROO $^{\circledR}$} & 1 & 5 & 1 & 180 & 1 \\
\hline & 2 & 10 & 1 & 55 & 5 \\
\hline & 3 & 84 & $>5$ & 34 & 2 \\
\hline & 4 & 60 & $>5$ & 28 & 2 \\
\hline & 5 & 6 & 1 & 158 & 2 \\
\hline & 6 & 10 & 4 & 180 & 1 \\
\hline & 7 & 48 & 5 & 180 & 1 \\
\hline & 8 & 36 & $>5$ & 180 & 1 \\
\hline & 9 & 84 & $>5$ & 180 & 1 \\
\hline & 10 & 4 & 1 & 172 & 7 \\
\hline & 11 & 48 & $>5$ & 79 & 2 \\
\hline & 12 & 10 & $>5$ & 30 & 2 \\
\hline & 13 & 2 & 1 & 91 & 2 \\
\hline & 14 & 36 & 3 & 180 & 1 \\
\hline & 15 & 36 & $>5$ & 159 & 3 \\
\hline & 16 & 7 & 2 & 180 & 1 \\
\hline & 17 & 36 & $>5$ & 180 & 1 \\
\hline & 18 & 72 & $>5$ & 135 & 6 \\
\hline & 19 & 14 & $>5$ & 74 & 2 \\
\hline & 20 & 24 & $>5$ & 180 & 1 \\
\hline \multirow{20}{*}{$\begin{array}{l}\text { WILSON } \\
\text { COOK }^{\circledR}\end{array}$} & 1 & 24 & $>5$ & 180 & 1 \\
\hline & 2 & 6 & 2 & 180 & 1 \\
\hline & 3 & 24 & $>5$ & 46 & 2 \\
\hline & 4 & 24 & $>5$ & 180 & 1 \\
\hline & 5 & 19 & 5 & 180 & 1 \\
\hline & 6 & 84 & $>5$ & 180 & 1 \\
\hline & 7 & 36 & $>5$ & 180 & 1 \\
\hline & 8 & 60 & $>5$ & 85 & 2 \\
\hline & 9 & 8 & 2 & 111 & 2 \\
\hline & 10 & 21 & 2 & 119 & 5 \\
\hline & 11 & 10 & 3 & 180 & 1 \\
\hline & 12 & 36 & $>5$ & 51 & 7 \\
\hline & 13 & 17 & $>5$ & 42 & 2 \\
\hline & 14 & 14 & 1 & 180 & 1 \\
\hline & 15 & 36 & $>5$ & 180 & 1 \\
\hline & 16 & 24 & $>5$ & 180 & 1 \\
\hline & 17 & 24 & $>5$ & 180 & 1 \\
\hline & 18 & 24 & 2 & 180 & 1 \\
\hline & 19 & 24 & 3 & 180 & 1 \\
\hline & 20 & 48 & $>5$ & 180 & 1 \\
\hline
\end{tabular}


Anexo D. Dados do acompanhamento dos pacientes.

\begin{tabular}{|c|c|c|c|c|c|}
\hline $\begin{array}{l}\text { Marca da } \\
\text { sonda }\end{array}$ & Caso & $\begin{array}{c}\text { Tempo de GEP } \\
\text { (em meses) }\end{array}$ & Trocas & $\begin{array}{l}\text { Término } \\
\text { (em dias) }\end{array}$ & Motivo \\
\hline \multirow{20}{*}{ SILMAG ${ }^{\circledR}$} & 1 & 36 & $>5$ & 31 & 2 \\
\hline & 2 & 36 & $>5$ & 144 & 7 \\
\hline & 3 & 14 & $>5$ & 110 & 2 \\
\hline & 4 & 36 & $>5$ & 20 & 2 \\
\hline & 5 & 84 & $>5$ & 180 & 1 \\
\hline & 6 & 18 & 3 & 172 & 7 \\
\hline & 7 & 8 & 2 & 165 & 2 \\
\hline & 8 & 10 & 2 & 180 & 1 \\
\hline & 9 & 19 & $>5$ & 108 & 2 \\
\hline & 10 & 24 & 2 & 180 & 1 \\
\hline & 11 & 60 & $>5$ & 21 & 2 \\
\hline & 12 & 11 & 2 & 135 & 2 \\
\hline & 13 & 36 & 4 & 104 & 5 \\
\hline & 14 & 36 & $>5$ & 115 & 2 \\
\hline & 15 & 13 & 5 & 180 & 1 \\
\hline & 16 & 8 & 1 & 159 & 2 \\
\hline & 17 & 12 & 1 & 117 & 7 \\
\hline & 18 & 48 & $>5$ & 111 & 3 \\
\hline & 19 & 48 & 3 & 180 & 1 \\
\hline & 20 & 17 & 3 & 92 & 2 \\
\hline \multirow{20}{*}{$\mathrm{FREKA}^{\circledR}$} & 1 & 15 & 2 & 180 & 1 \\
\hline & 2 & 18 & 3 & 128 & 2 \\
\hline & 3 & 13 & 3 & 180 & 1 \\
\hline & 4 & 6 & 1 & 60 & 7 \\
\hline & 5 & 96 & $>5$ & 180 & 1 \\
\hline & 6 & 6 & 1 & 23 & 7 \\
\hline & 7 & 48 & 4 & 180 & 1 \\
\hline & 8 & 12 & 3 & 180 & 1 \\
\hline & 9 & 6 & 1 & 14 & 2 \\
\hline & 10 & 6 & 1 & 180 & 1 \\
\hline & 11 & 7 & 1 & 150 & 6 \\
\hline & 12 & 60 & $>5$ & 180 & 1 \\
\hline & 13 & 24 & $>5$ & 102 & 4 \\
\hline & 14 & 4 & 1 & 126 & 4 \\
\hline & 15 & 7 & 1 & 180 & 1 \\
\hline & 16 & 3 & 1 & 121 & 5 \\
\hline & 17 & 8 & 1 & 170 & 3 \\
\hline & 18 & 84 & $>5$ & 180 & 1 \\
\hline & 19 & 18 & $>5$ & 82 & 2 \\
\hline & 20 & 36 & $>5$ & 180 & 1 \\
\hline
\end{tabular}


Anexo D. Dados do acompanhamento dos pacientes.

\begin{tabular}{|c|c|c|c|c|c|}
\hline $\begin{array}{l}\text { Marca da } \\
\text { sonda }\end{array}$ & Caso & $\begin{array}{l}\text { Tempo de GEP } \\
\text { (em meses) }\end{array}$ & Trocas & $\begin{array}{l}\text { Término } \\
\text { (em dias) }\end{array}$ & Motivo \\
\hline \multirow{20}{*}{ BARD $^{\circledR}$} & 1 & 16 & 2 & 180 & 1 \\
\hline & 2 & 16 & 3 & 180 & 1 \\
\hline & 3 & 84 & $>5$ & 61 & 2 \\
\hline & 4 & 36 & $>5$ & 180 & 1 \\
\hline & 5 & 13 & 2 & 180 & 1 \\
\hline & 6 & 36 & $>5$ & 90 & 2 \\
\hline & 7 & 4 & 1 & 9 & 2 \\
\hline & 8 & 20 & 3 & 180 & 1 \\
\hline & 9 & 13 & 1 & 14 & 2 \\
\hline & 10 & 23 & $>5$ & 165 & 3 \\
\hline & 11 & 2 & 1 & 180 & 1 \\
\hline & 12 & 4 & 1 & 30 & 6 \\
\hline & 13 & 3 & 1 & 120 & 2 \\
\hline & 14 & 18 & 4 & 90 & 2 \\
\hline & 15 & 13 & 2 & $x$ & 6 \\
\hline & 16 & 19 & 3 & 110 & 2 \\
\hline & 17 & 24 & 4 & 67 & 4 \\
\hline & 18 & 48 & $>5$ & 180 & 1 \\
\hline & 19 & 36 & $>5$ & $x$ & 6 \\
\hline & 20 & 24 & 3 & 90 & 2 \\
\hline
\end{tabular}


Anexo E. Dados de durabilidade das sondas de troca de gastrostomia.

\begin{tabular}{|c|c|c|c|c|c|}
\hline $\begin{array}{l}\text { Marca da } \\
\text { sonda }\end{array}$ & Caso & $\begin{array}{l}\text { Deslizamento } \\
\text { do anteparo }\end{array}$ & $\begin{array}{l}\text { Resolução após } \\
\text { fixação }\end{array}$ & $\begin{array}{c}\text { Abertura } \\
\text { espontânea } \\
\text { da tampa }\end{array}$ & $\begin{array}{c}\text { Desgaste da } \\
\text { tampa }\end{array}$ \\
\hline \multirow{20}{*}{ KANGAROO $^{\circledR}$} & 1 & $\diamond$ & Sim & $\diamond$ & \\
\hline & 2 & 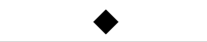 & Sim & & \\
\hline & 3 & $\diamond$ & Sim & $\diamond$ & \\
\hline & 4 & $\diamond$ & Sim & & \\
\hline & 5 & $\diamond$ & Sim & $\diamond$ & \\
\hline & 6 & $\nabla$ & Sim & $\diamond$ & \\
\hline & 7 & $\diamond$ & Sim & $\diamond$ & $\diamond$ \\
\hline & 8 & $\diamond$ & Sim & $\diamond$ & \\
\hline & 9 & & & $\diamond$ & \\
\hline & 10 & 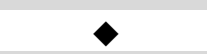 & Sim & 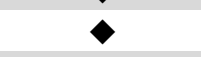 & \\
\hline & 11 & & & $\diamond$ & \\
\hline & 12 & & & & \\
\hline & 13 & 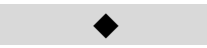 & Sim & $\diamond$ & \\
\hline & 14 & $\diamond$ & Não & $\diamond$ & \\
\hline & 15 & $\diamond$ & Sim & & \\
\hline & 16 & $\diamond$ & Sim & & \\
\hline & 17 & $\diamond$ & Sim & $\diamond$ & \\
\hline & 18 & $\diamond$ & Não & & \\
\hline & 19 & $\diamond$ & Sim & $\diamond$ & \\
\hline & 20 & $\diamond$ & Sim & $\diamond$ & \\
\hline \multirow{20}{*}{$\begin{array}{l}\text { WILSON } \\
\text { COOK }^{\circledR}\end{array}$} & 1 & $\diamond$ & Sim & & \\
\hline & 2 & 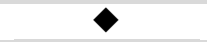 & Não & & $\diamond$ \\
\hline & 3 & $\bullet$ & Sim & 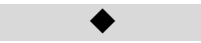 & \\
\hline & 4 & $\diamond$ & Sim & & 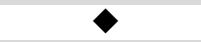 \\
\hline & 5 & $\bullet$ & Não & $\diamond$ & \\
\hline & 6 & $\diamond$ & Sim & $\diamond$ & 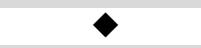 \\
\hline & 7 & $\diamond$ & Não & $\diamond$ & $\diamond$ \\
\hline & 8 & $\diamond$ & Sim & $\diamond$ & \\
\hline & 9 & $\diamond$ & Não & 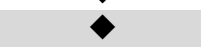 & \\
\hline & 10 & $\diamond$ & Sim & & \\
\hline & 11 & $\diamond$ & Sim & & \\
\hline & 12 & & & & \\
\hline & 13 & $\diamond$ & Sim & & \\
\hline & 14 & & & & \\
\hline & 15 & & & & \\
\hline & 16 & $\diamond$ & Sim & & $\diamond$ \\
\hline & 17 & $\diamond$ & Sim & & \\
\hline & 18 & $\diamond$ & Não & & \\
\hline & 19 & & & & $>$ \\
\hline & 20 & $\diamond$ & Sim & & $\diamond$ \\
\hline
\end{tabular}


Anexo E. Dados de durabilidade das sondas de troca de gastrostomia.

\begin{tabular}{|c|c|c|c|c|c|}
\hline $\begin{array}{l}\text { Marca da } \\
\text { sonda }\end{array}$ & Caso & $\begin{array}{l}\text { Deslizamento } \\
\text { do anteparo }\end{array}$ & $\begin{array}{c}\text { Resolução após } \\
\text { fixação }\end{array}$ & $\begin{array}{c}\text { Abertura } \\
\text { espontânea } \\
\text { da tampa }\end{array}$ & $\begin{array}{c}\text { Desgaste da } \\
\text { tampa }\end{array}$ \\
\hline \multirow{20}{*}{ SILMAG ${ }^{\circledR}$} & 1 & & Sim & & \\
\hline & 2 & & Não & & \\
\hline & 3 & & Sim & & \\
\hline & 4 & & Sim & & \\
\hline & 5 & & & & \\
\hline & 6 & & Sim & & \\
\hline & 7 & & Não & & $>$ \\
\hline & 8 & $\nabla$ & Sim & & \\
\hline & 9 & $>$ & Não & & \\
\hline & 10 & & & $>$ & \\
\hline & 11 & & & & \\
\hline & 12 & $>$ & Sim & & $>$ \\
\hline & 13 & $>$ & $\mathrm{Nao}$ & & $>$ \\
\hline & 14 & & & & \\
\hline & 15 & $>$ & Não & & \\
\hline & 16 & $>$ & Sim & 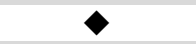 & 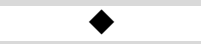 \\
\hline & 17 & 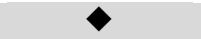 & Não & & $>$ \\
\hline & 18 & 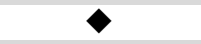 & Sim & & \\
\hline & 19 & $\diamond$ & Sim & & $>$ \\
\hline & 20 & & & & \\
\hline \multirow{20}{*}{ FREKA $^{\circledR}$} & 1 & & & & 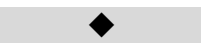 \\
\hline & 2 & & & & $\diamond$ \\
\hline & 3 & & & & \\
\hline & 4 & & & & \\
\hline & 5 & & & & \\
\hline & 6 & & & & \\
\hline & 7 & & & & \\
\hline & 8 & & & & \\
\hline & 9 & & & & \\
\hline & 10 & & & & $>$ \\
\hline & 11 & $\diamond$ & & & \\
\hline & 12 & & & & \\
\hline & 13 & & & & 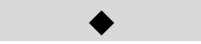 \\
\hline & 14 & $\diamond$ & & & 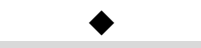 \\
\hline & 15 & & & & \\
\hline & 16 & & & & 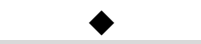 \\
\hline & 17 & & & & \\
\hline & 18 & & & & \\
\hline & 19 & & & & \\
\hline & 20 & & & & \\
\hline
\end{tabular}


Anexo E. Dados de durabilidade das sondas de troca de gastrostomia.

\begin{tabular}{|c|c|c|c|c|c|}
\hline $\begin{array}{l}\text { Marca da } \\
\text { sonda }\end{array}$ & Caso & $\begin{array}{l}\text { Deslizamento } \\
\text { do anteparo }\end{array}$ & $\begin{array}{l}\text { Resolução após } \\
\text { fixação }\end{array}$ & $\begin{array}{c}\text { Abertura } \\
\text { espontânea } \\
\text { da tampa }\end{array}$ & $\begin{array}{c}\text { Desgaste da } \\
\text { tampa }\end{array}$ \\
\hline \multirow{20}{*}{ BARD $^{\circledR}$} & 1 & & & & $\diamond$ \\
\hline & 2 & 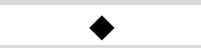 & Sim & 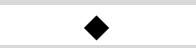 & $\diamond$ \\
\hline & 3 & & & & \\
\hline & 4 & 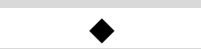 & Sim & 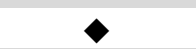 & \\
\hline & 5 & & & & \\
\hline & 6 & & & & \\
\hline & 7 & & & & \\
\hline & 8 & $\diamond$ & Sim & & \\
\hline & 9 & & & $\diamond$ & \\
\hline & 10 & & & & \\
\hline & 11 & 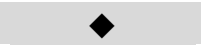 & Sim & & $\diamond$ \\
\hline & 12 & & & & \\
\hline & 13 & & & & \\
\hline & 14 & & & $\diamond$ & \\
\hline & 15 & & & & \\
\hline & 16 & 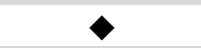 & Não & & \\
\hline & 17 & & & $\diamond$ & $\diamond$ \\
\hline & 18 & $\diamond$ & Sim & & \\
\hline & 19 & & & & \\
\hline & 20 & 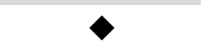 & Não & $\diamond$ & $\diamond$ \\
\hline
\end{tabular}


ANEXO F. DADOS INDIVIDUAIS DOS PACIENTES.

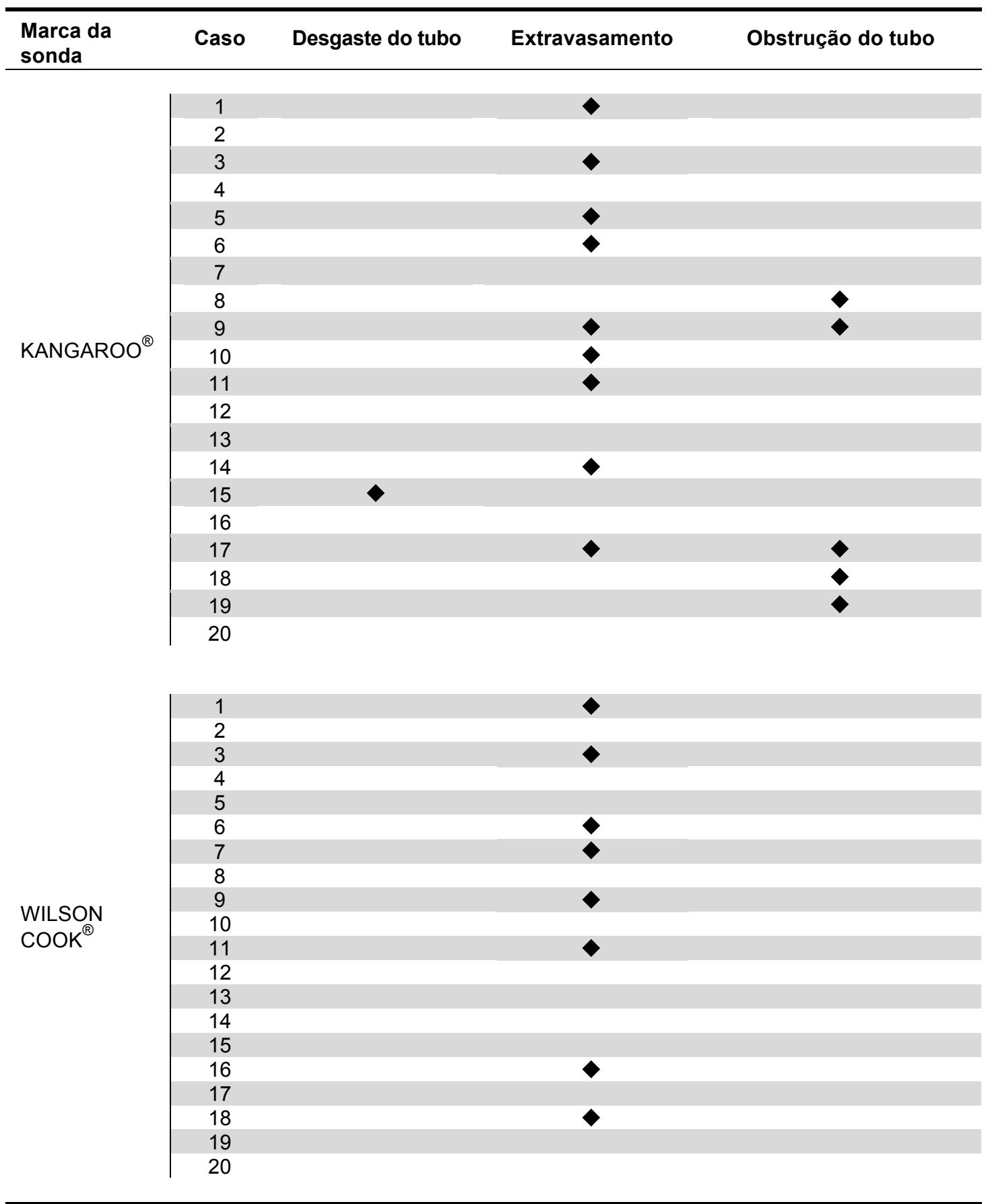




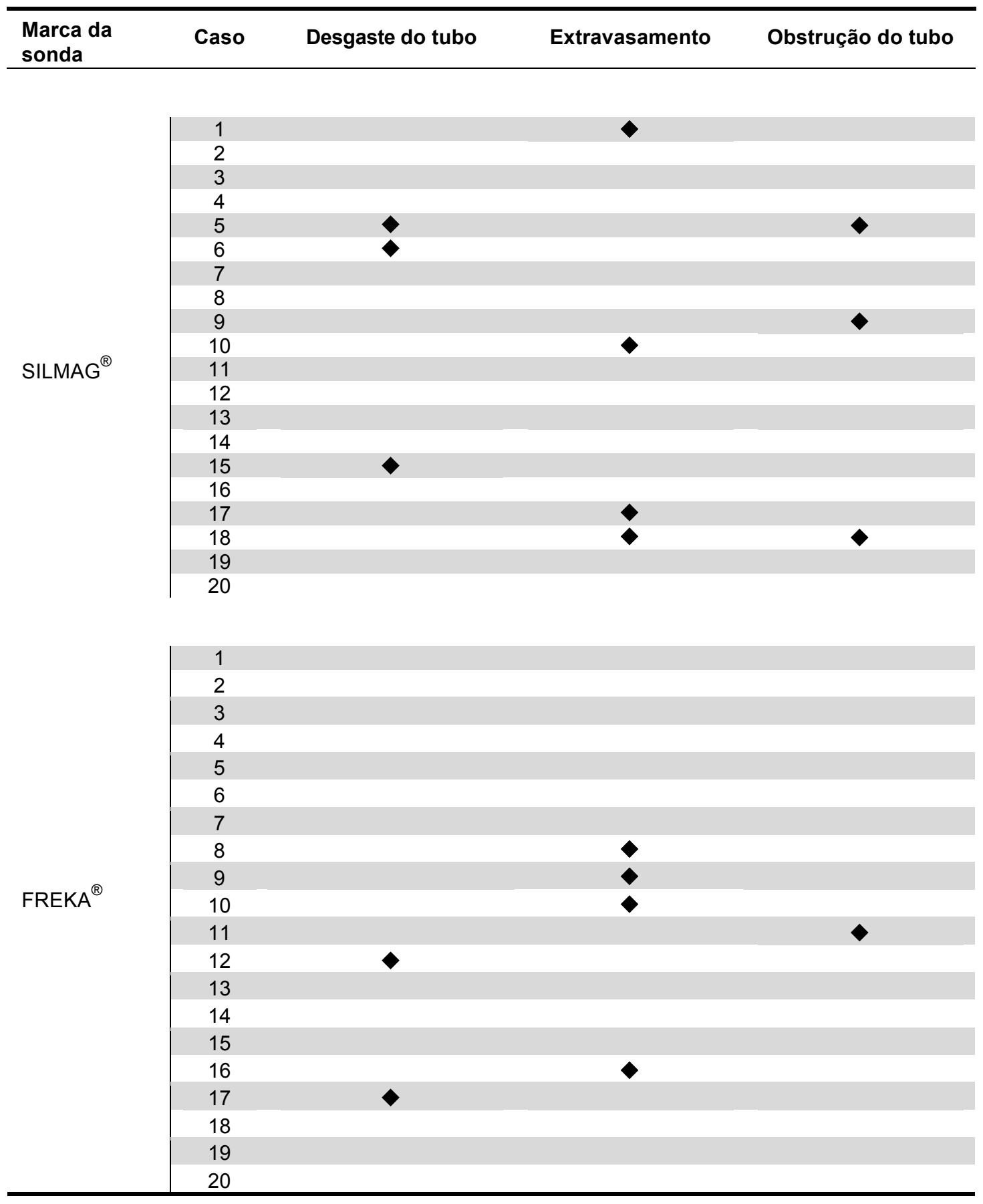




\begin{tabular}{|c|c|c|c|c|}
\hline $\begin{array}{l}\text { Marca da } \\
\text { sonda }\end{array}$ & Caso & Desgaste do tubo & Extravasamento & Obstrução do tubo \\
\hline \multirow{20}{*}{ BARD $^{\circledR}$} & 1 & & & \\
\hline & 2 & & $\diamond$ & \\
\hline & 3 & & & \\
\hline & 4 & & & \\
\hline & 5 & & & \\
\hline & 6 & & & \\
\hline & 7 & & & \\
\hline & 8 & & & \\
\hline & 9 & & & \\
\hline & 10 & $\diamond$ & & \\
\hline & 11 & & $\diamond$ & \\
\hline & 12 & & & \\
\hline & 13 & & $\diamond$ & \\
\hline & 14 & & & $\diamond$ \\
\hline & 15 & & & \\
\hline & 16 & & & \\
\hline & 17 & & & \\
\hline & 18 & & & \\
\hline & 19 & & & \\
\hline & 20 & & & \\
\hline
\end{tabular}




\section{Referências}

Akkersdijk WL, van Bergeijk JD, van Egmond T, Mulder CJ, van Berge HGP, van Erpecum KJ. Percutaneous endoscopic gastrostomy (PEG): comparison of push and pull methods and evaluation of antibiotic prophylaxis. Endoscopy 1995; 27(4):313-6.

August D, Teitelbaum D, Albina J, Bothe A, Guenter P, Heitkemper M, et al. (A.S.P.E.N. Board of Directors and The Clinical Guidelines Task Force). Guidelines for the use of parenteral and enteral nutrition in adult and pediatric patients. J Parent Enteral Nutr 2002; 26(suppl. 1):1SA-138SA.

Blacka J, Donoghue J, Sutherland M, Martincichs I, Mitten-Lewis S, Morris P, et al. Dwell time and functional failure in percutaneous endoscopic gastrostomy tubes: a prospective randomized-controlled comparison between silicon polymer and polyurethane percutaneous endoscopic gastrostomy tubes. Aliment Pharmacol Ther 2004; 20:875-82.

Bleck JS, Reiss B, Gebel M, Wagner S, Strassburg CP, Meier PN et al. Percutaneous sonographic gastrostomy: method, indications and problems. Am J Gastroenterol 1998; 93(6):941-5.

Campoli PMO, Cardoso DMM, Turchi MD, Ejima FH, Mota OM. Assessment of safety and feasibility of a new technical variant of gastropexy for percutaneous endoscopic gastrostomy: an experience with 435 cases. BMC Gastroenterol 2009; 9:48.

Campoli PMO, Cardoso DMM, Turchi MD, Mota OM. Clinical Trial: rendomized study comparing the durability of silicone and latex percutaneous endoscopic gastrostomy tubes. Digest Endosc 2001; 23(2):135-9. 
Cochran W. Sampling techniques. 3. ed. New York: John Wiley \& Sons; 1986.

Deitel M, Bewndango M, Spratt EH, Burul CJ, To TB. Percutaneous endoscopic gastrostomy by the "pull" and "introducer" methods. Can J Surg 1988; 31(2):102-4.

Eisen GM, Baron TH, Dominitz JA, Faigel DO, Goldstein JL, Johanson JF, et al. (ASGE Standards of Practice Committee). Role of endoscopy in enteral feeding. Gastrointest Endosc 2002a; 55(7):794-7.

Eisen GM, Baron TH, Dominitz JA, Faigel DO, Goldstein JL, Johanson JF, et al. (ASGE Standards of Practice Committee). Endoscopic enteral nutrition access devices. Gastrointest Endosc 2002b; 56(6):796-802.

Eisen GM, Baron TH, Dominitz JA, Faigel DO, Goldstein JL, Johanson JF, et al. (ASGE Standards of Practice Committee). Complications of upper GI endoscopy. Gastrointest Endosc 2002c; 55(7):784-93.

Fernandez I, Rodriguez S, Gonzalez A, Castellano G, Montejo JC, Casis B et al. A comparative study of 2 techniques of percutaneous endoscopic gastrostomy. Rev Esp Enferm Dig 1995; 87(5):357-61.

Ferreira AO. Substâncias e protocolos para revestimento entérico de cápsulas em farmácias magistrais. In: Guia prático da farmácia magistral. 2. ed. Juiz de For a: Pharmabooks; 2002. P.130-140.

Foster JM, Filocamo P, Nava H, Schiff M, Hicks W, Rigual N et al. The introducer techniques is the optimal method for placing percutaneous endoscopic gastrostomy tubes in head and neck câncer patients. Surg Endosc 2007; 21(6):897-901.

Fox VL, Abel SD, Malas S, Duggan C, Leichner AM. Complications following percutaneous endoscopic gastrostomy and subsequent catheter replacement in children and young adults. Gastrointest Endosc 1997; 45:64-71. 
Gauderer MWL. Percutaneous endoscopic gastrostomy and the evolution of contemporary long-term enteral access. Clin Nutr 2002; 21:103-10.

Gauderer MW, Ponsky JL, Izant RJ Jr. Gastrostomy without laparotomy: a percutaneous endoscopic technique. J Pediatr Surg 1980; 15:872-5.

Guédon C, Hochain P, Zalar A, Bouteloup C, Lalaude O, Ducrotté P. Evaluation prospectve de trois kits de gastrostomie percutanée endoscopique (GPE). Gastroenterol Clin Biol 1999; 23:581-5.

Guédon C, Touchais JY, Ducrotté P, Colin R, Lerebours E. Evaluation prospective de deux kits de gastrostomie percutanée endoscopique. Gastroenterol Clin Biol 1993; 17:519-20.

Hashiba K. Técnica de abertura de gastrostomia sob controle e manipulação emdoscópica. Rev Paulista Med 1980; 95:38-9.

Hicks ME, Surratt RS, Picus D, Marx MV, Lang EV. Fluoroscopicallu guided percutaneous gastrostomy and gastroenterostomy: analysis of 158 consecutive cases. AJR 1990; 154:725-8.

Hogan RB, De Marco DC, Hamilton JK, Walker CO, Polter DE. Percutaneous endoscopic gastrostomy: to push or pull. A prospective randomized trial. Gastrointest Endosc 1986; 32(4):253-8.

Isaacson M. Myocardial aneurysm causing esophageal obstruction: report of a case presenting a double cardiac aneurysm with severe dysphagia necessitating gastrostomy. N Orleans Med Surg J 1948; 100(12):568-73.

Kozarek RA, Ball TJ, Ryan JA. When push comes to shove: a comparison between two methods of percutaneous endoscopic gastrostomy. Am J Gastroenterol 1989; 81(8):642-6.

Lachter J, Dolinsky R, Peretz D, Reshef R. Long-term use of percutaneous endoscopic gastrostomies: a survey of duration of use and level of maintenance. Internet J Gastroenterol 2006; 4(2). 
Lin HS, Ibrahin HZ, Kheng JW, Fee W, Terris D. Percutaneous endoscopic gastrostomy: strategies for prevention and management of complications. Laryngoscope 2001; 111:1847-52.

Löser C, Aschi G, Hébuterne X, Mathis-Vliegen EMH, Muscaritoli M, Niv H, et al. ESPEN guidelines on artificial enteral nutrition - percutaneous endoscopic gastrostomy (PEG). Clin Nutr 2005; 24:848-61.

Mathus-Vliegen LMH, Koning H. Percutaneous endoscopic gastrostomy and gastrojejunostomy: a critical reappraisal of patient selection, tube function and the feasibility of nutritional support during extended follow-up. Gastrointest Endosc 1999; 50:746-54.

McClave SA, Chang WK. Complications of enteral access. Gastrointest Endosc 2003; 58:739-51.

Mello G. Características Técnicas e descritivas dos materiais. In: Mello G, Mansur G. (eds.). Gastrostomia endoscópica percutânea. Técnicas e aplicações. 1. Ed. Rio de Janeiro: Rubio; 2012. P 27-36.

Perona F, Castellazzi G, De luliis A, Rizzo L. Percutaneous radiologic gastrostomy: a 12-year series. Gut Liver 2010; 4(suppl. 1):544-9.

Ponsky JL, Gauderer MW. Percutaneous endoscopic gastrostomy: a nonoperative technique for feeding gastrostomy. Gastrointest Endosc 1981; 27:911.

Preshaw RM. A percutaneous method for inserting a feeding gastrostomy tube. Surg Gynecol Obstet 1981; 152:658-60.

Rafferty GP, Tham TCK. Endoscopic placement of enteral feeding tubes. World J Gastrointest Endosc 2010; 2(5):155-65.

Rodríguez Ortega P, Calañas Continente A, Molina Puertas MJ, Gutiérrez Alcántara C, Benito López P, Lavado Henández R. Gastrostomía endoscópi- 
ca percutânea: 7 años de experiência em nutrición enteral a largo plazo. Seguimiento clínico. Nutr Hosp 2011; 26:399-401.

Russell TR, Brotman M, Norris F. Percutaneous gastrostomy: a new simplified and cost-effective technique. Am J Surg 1984; 148(1):132-7.

Sachs BA, Vine HS, Palestrant AM, Ellison HP, Shropshire D, Lowe R. A nonoperative technique for establishment of a gastrostomy in the dog. Invest Radiol 1983; 18:485-7.

Sachs G, Shin JM, Hunt R. Novel approaches to inhibition of gastric acid secretion. Curr Gastroenterol Reo 2010; 12:437-47.

Safadi BY, Marks JM, Ponsky JL. Percutaneous endoscopic gastrostomy: an update. Endoscopy 1998; 39(9):781-9.

Sartori S, Trevisani L, Nielsen I, Tassinari D, Ceccotti P, Abbasciano V. Longevity of silicone and polyurethane catheters in long-term enteral feeding via percutaneous endoscopic gastrostomy. Aliment Pharmacol Ther 2003; 17:853-6.

Schapiro GD, Edmundowicz SA. Complications of percutaneous endoscopic gastrostomy. Gastrointest Endosc Clin N Am 1996; 6:409-22.

Schrag SP, Sharma R, Jaik NP, Seamon MJ, Lukaszczyk JJ, Martin ND, et al. Complications related to percutaneous endoscopic gastrostomy (PEG) tubes: a comprehensive clinical review. J Gastrintest Liver Dis 2007; 16:40718.

Shastri YM, Shirodkar M, Mallath MK. Endoscopic feeding tube placement in patients with cancer: a prospective clinical audit of 2055 procedures in 1866 patients. Aliment Pharmacol Ther 2008; 27:649-58.

Stroud M, Duncan H, Nightingale J. Guidelines for enteral feeding in adult hospital patients. Gut 2003; 52(suppl. VII):vii1-12. 
Tokunaga T, Kubo T, Ryan S, Tomizawa M, Yoshida S, Takagi K, et al. Long term outcome after placement of a percutaneous endoscopic gastrostomy tube. Geriatr Gerontol Int 2008; 8:19-23.

Tucker AT, Gourin CG, Ghegan MD, Porubsky ES, Martindale RG, Terris DJ. "Push" versus "pull" percutaneous endoscopic gastrostomy tube placement in patients with advanced head and neck cancer. Laryngoscope 2003; 113(11):1898-902.

Van Dyck E, Macken EJ, Roth B, Pelckmans PA, Moreels TG. Safety of pulltype and introducer percutaneous endoscopic gastrostomy tubes in oncology patients: a retrospective analysis. BMC Gastroenterol 2011; 11:23-8.

Wanden-Berghe C, Muñoz J, Cantó C, Domenech MD, Reyes D, Pérez Moya $C$, et al. Gastrostomía endoscópica percutánea (PEG): diez años de experiencia. Nutr Hosp 2010; 25:949-53. 